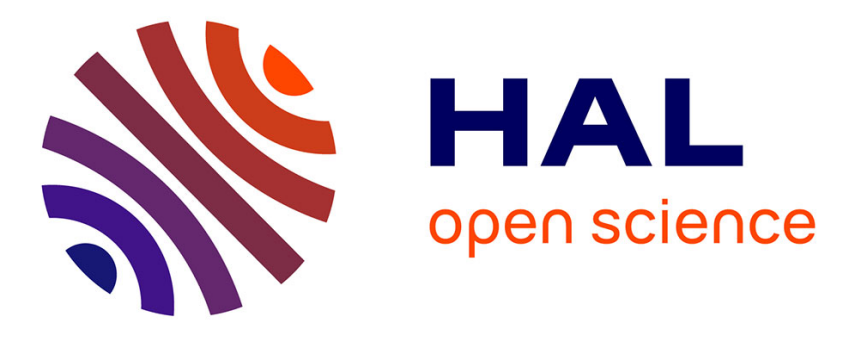

\title{
Plant oils: From chemical composition to encapsulated form use
}

Narimane Lammari, Ouahida Louaer, Meniai Abdeslam-Hassen, Hatem Fessi, Abdelhamid Elaïssari

\section{To cite this version:}

Narimane Lammari, Ouahida Louaer, Meniai Abdeslam-Hassen, Hatem Fessi, Abdelhamid Elaïssari. Plant oils: From chemical composition to encapsulated form use. International Journal of Pharmaceutics, 2021, 601, pp.120538. 10.1016/j.ijpharm.2021.120538 . hal-03200146

\section{HAL Id: hal-03200146 https://hal.science/hal-03200146}

Submitted on 16 Apr 2021

HAL is a multi-disciplinary open access archive for the deposit and dissemination of scientific research documents, whether they are published or not. The documents may come from teaching and research institutions in France or abroad, or from public or private research centers.
L'archive ouverte pluridisciplinaire HAL, est destinée au dépôt et à la diffusion de documents scientifiques de niveau recherche, publiés ou non, émanant des établissements d'enseignement et de recherche français ou étrangers, des laboratoires publics ou privés. 
6 France

$7{ }^{2}$ Environmental Process Engineering Laboratory, University Constantine 3, Salah Boubnider, 8 Constantine, Algeria.

\section{Plant oils: From chemical composition to encapsulated form use}

Narimane Lammari ${ }^{1,2}$, Ouahida Louaer ${ }^{2}$, Abdeslam Hassen Meniai ${ }^{2}$, Hatem Fessi ${ }^{3}$, Abdelhamid Elaissari ${ }^{1 *}$

${ }^{1}$ Univ Lyon, University Claude Bernard Lyon-1, CNRS, ISA-UMR 5280, 69622 Villeurbanne,

${ }^{3}$ Univ Lyon, Université Claude Bernard Lyon-1, CNRS, LAGEP UMR 5007, F-69622 Lyon, France

* Corresponding author : Abdelhamid Elaissari ; abdelhamid.elaissari@univ-lyon1.fr

Abbreviations

EO: Essential oil; VO: Vegetable oil; pNPs: Polymeric nanoparticles; SLN: Solid lipid 21 nanoparticles; EE\%: Encapsulation efficiency; HLB: Hydrophilic lipophilic balance; SUV: 22 Small unilamellar vesicles; LUV: Large unilamellar vesicles; MLV: Multilamellar vesicles; 23 NLC: Nanostructured lipid carriers; MIC: Minimum inhibitory concentration; AUC: Area 24 under the curve. 
Abstract

The last decade has witnessed a burgeoning global movement towards essential and vegetable oils in the food, agriculture, pharmaceutical, cosmetic, and textile industries thanks to their natural and safe status, broad acceptance by consumers, and versatile functional properties. However, efforts to develop new therapy or functional agents based on plant oils have met with challenges of limited stability and/or reduced efficacy. As a result, there has been increased research interest in the encapsulation of plant oils, whereby the nanocarriers serve as barrier between plant oils and the environment and control oil release leading to improved efficacy, reduced toxicity and enhanced patient compliance and convenience. In this review, special concern has been addressed to the encapsulation of essential and vegetable oils in three types of nanocarriers: polymeric nanoparticles, liposomes and solid lipid nanoparticles. First, the chemical composition of essential and vegetable oils was handled. Moreover, we gather together the research findings reported by the literature regarding the different techniques used to generate these nanocarriers with their significant findings. Finally, differences and similarities between these nanocarriers are discussed, along with current and future applications that are warranted by their structures and properties.

Key words: Essential oil, vegetable oil, encapsulation, polymeric nanoparticle, liposome, solid lipid nanoparticle.

\section{Graphical abstract}

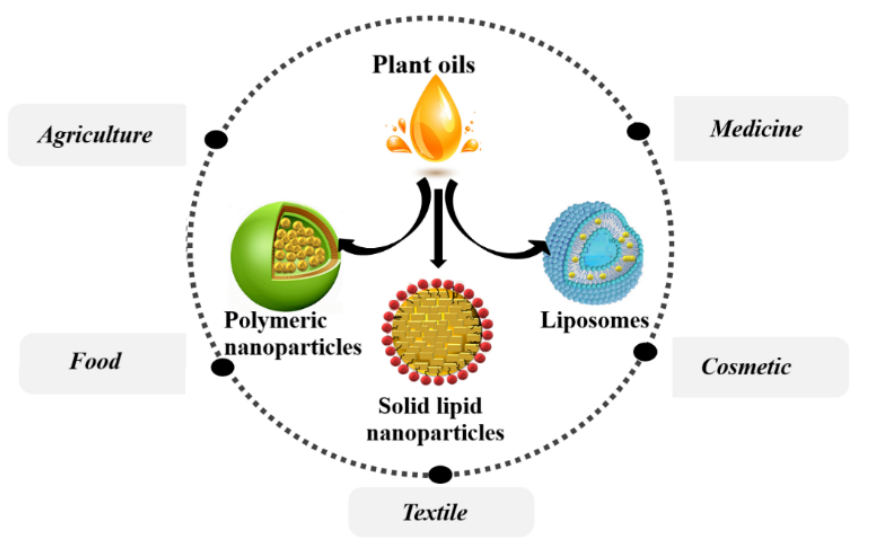




\section{Introduction}

The last decade has evidently witnessed a tremendous surge in the use of herbal medicine as a form of complementary or replacement therapy (Mainardi et al., 2009). The global acceptance and public concern in the use of herbal medicines, phytonutrients or nutraceuticals continue to assume exponential increase. It has been estimated that up to $80 \%$ of people worldwide relying on them as a primary source of healthcare (Ekor, 2013). This concern in drugs of natural origin is related to numerous reasons, namely, the traditional medicine is more affordable, closer to the patient's ideology and receives greater public access than chemical synthesized treatment. Furthermore, abusive and/or incorrect use of conventional medicines results in some cases in harmful side effects (Wachtel-Galor and Benzie, 2011). The use of aromatic and medicinal plants is incessantly expanding due to increasing consumers demand and concern in these plants for several applications. In fact, consumers are becoming more and more aware of the benefits of inherent practice of medicinal and aromatic plants and their metabolites (Chikezie et al., 2015; Rates, 2001). These plants produce a large variety of secondary metabolites; among them, essential and vegetable oils deserve particular attention (Dhifi et al., 2016; Kumar et al., 2016; Pandey et al., 2016; Yara-Varón et al., 2017).

Essential oils (EO) comprised volatile and semi-volatile organic compounds determining the specific aroma, flavor and fragrance of plants. They are volatile and instable at roomtemperature. In the other hand, vegetable oils (VO) consist of esters of glycerol and fatty acids and are nonvolatile and stable at room temperature (Moghaddam and Mehdizadeh, 2017; Sagiri et al., 2016). Besides being edible in their refined or virgin form, VO play a crucial role in therapeutic and prophylactic prevention of diseases such as inflammation, diabetes, cancer and atherosclerosis (Ganesan et al., 2018; Kochikuzhyil et al., 2010; Saha and Ghosh, 2011; Yu et al., 2004). Subsequently, EO received significant attention in food, agricultural and pharmaceutical fields due to their antioxidant, antibacterial, antiviral and antifungal properties. 
The diverse health benefits associated with the consumption of EO constitute an area of intense research (Ali et al., 2015; Dhifi et al., 2016; Elshafie and Ippolito, 2017). Meantime, the benefits linked to these bioactive agents is generally hampered by several obstacles. For instance, the oxidation is the main problem limiting the use of VO in several fields. The unsaturated fatty acids present in VO lead to increase the risk of lipid oxidation which in turn result in producing numerous free radical species, primary oxidation products such as lipid hydroperoxides and secondary oxidation products such as hydrocarbons, epoxides, ketones and aldehydes that negatively impact aroma. Moreover, VO oxidation can generate toxic products that can largely affect biological tissues (Chen et al., 2011; Matthäus, 2010). At the same time, numerous studies have evidenced that EO are unstable and degraded easily if they are not protected from external factors like oxidation, volatilization, heat and light (Turek and Stintzing, 2013). Besides all these, the low water solubility, low permeation and low bioavailability of plant oils in biological fluids and tissues constitute other factors that limit their rational use (Dima et al., 2020; Rein et al., 2013). Therefore, designing suitable carriers by using nanoencapsulation approach is crucial to overcome restrictions outlined (El-Asbahani et al., 2015; Sagiri et al., 2016). Hoyos-leyva et al. (2019) revealed that the encapsulation of almond oil in starch microcapsules conferred more protection against oxidation when compared to unencapsulated oil. Similar results were already reported when investigating the stability of linseed, jasmine and holy basil oils-loaded nanoparticles against heat, oxidation and volatilization as compared to the free oils (Lv et al., 2014; Rubilar et al., 2012; Sutaphanit and Chitprasert, 2014). Moreover, several studies have evidenced the amelioration of plant oils biological performance after being incorporated in nanosystems. Alaarg et al. (2016) depicted that the encapsulation of docosahexaenoic acid in liposomes improve its anticancer activity. Zhaveh et al. (2015) related the superior performance of Cuminum cyminum EO nanogels against Aspergillus flavus as compared to the free oil to the increased surface area of the nanoparticles. 

main groups: polymer-based nanocarriers and lipid-based nanocarriers. Among the several colloidal systems investigated in drug delivery, polymeric nanoparticles (pNPs), liposomes and solid lipid nanoparticles (SLN) gained more interest (Allen and Cullis, 2013; El-say and Elsawy, 2017; Geszke-Moritz and Moritz, 2016; Immordino et al., 2006; Mehnert and Mäder, 2012; Rani et al., 2017). In this context, the present review covers literature data summarizing the current development of nanocarrier systems for plant oils delivery with a focus on the main properties and preparation technique of pNPs, liposomes and SLN. In addition, the chemical composition of both essential and vegetable oils along with the emerging and potential applications of plant oils loaded nanocarriers in several fields were explored.

\section{Chemical composition of vegetable oils}

Vegetable oils, also named non-essential or fixed oils, are fats usually extracted from plant seeds (e.g., soybean oil, rapeseed oil, sesame oil etc.), or less often from other parts of fruits (e.g., olive oil, palm oil etc.), by simple pressing and/or solvent extraction process (YaraVarón et al., 2017). Depending on the origin, the crop, the season, and the producing methods, their composition is highly variable and complex (Lligadas et al., 2010).

\subsection{Triglycerides}

The main components of $\mathrm{VO}$ are triglycerides; they represent 95 to $98 \%$ of the global constituents depending on the source of oil (Yara-Varón et al., 2017). The word 'oil' hereby refers to triglycerides that are liquid at room temperature (Guner et al., 2006). Triglycerides are composed of three fatty acid molecules esterified to one glycerol molecule, as demonstrated in Fig. 1 (Miao et al., 2014). Depending on the saturation degree of fatty acids, triglycerides are classified into saturated, mono- and poly-unsaturated fatty acids. The characteristics of VO depend on several parameters including; i) fatty acid chain length, ii) the degree of unsaturation, and iii) the stereochemistry of the double bonds (Meier et al., 2007). Additionally, varieties in 

triglycerides (Yara-Varón et al., 2017).

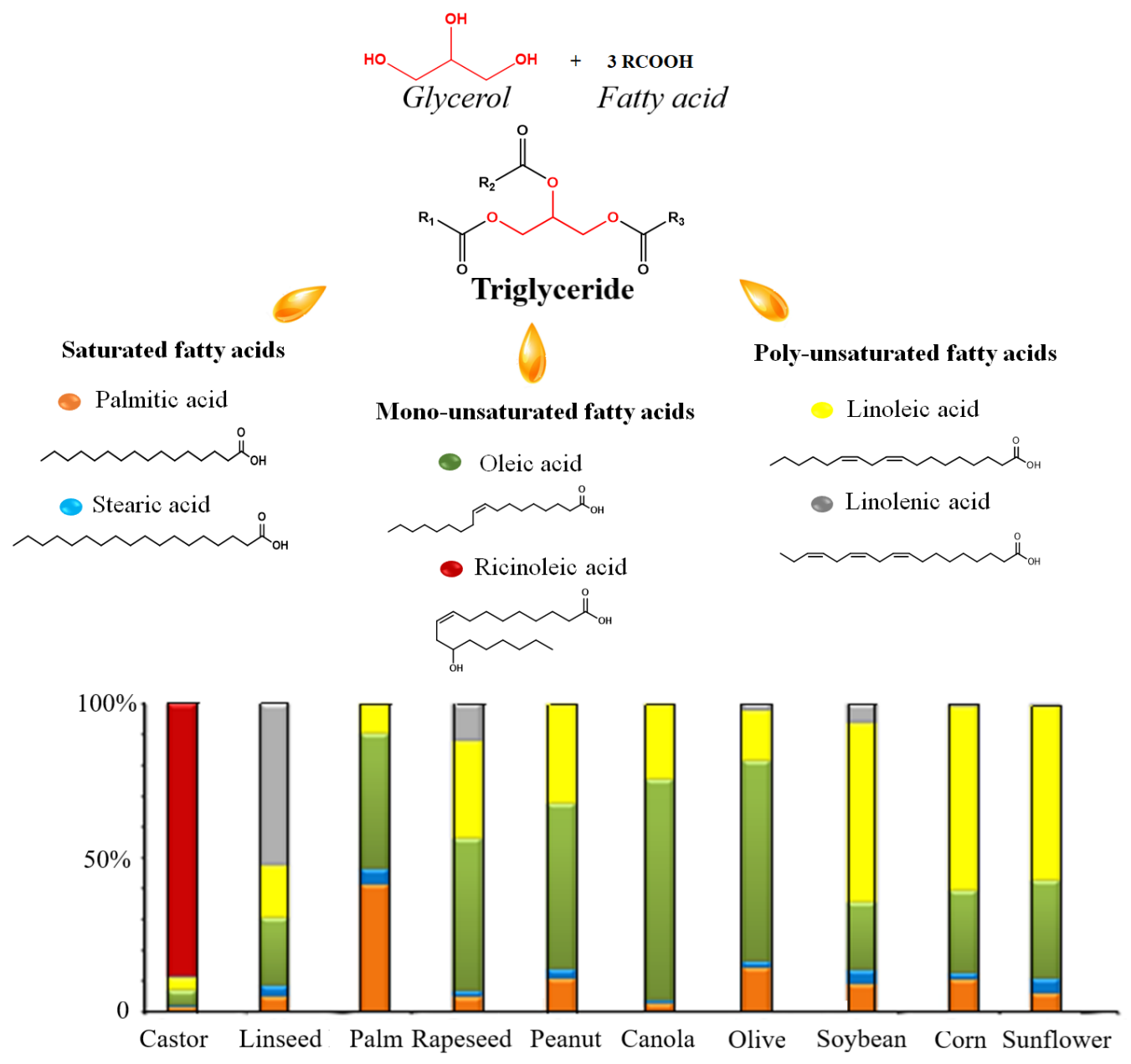

Fig. 1. Triglycerides composition of different vegetable oils.

\subsection{Minor Components}

Apart of triglycerides, VO contain also a diversity of non-triglyceride minor compounds (less than 5\%) which present crucial biological properties and nutritional values for nutraceutical and pharmaceutical industries (Fig. 2) (Yara-Varón et al., 2017). They comprised two types: glycerolipids including monoglycerides, diglycerides and phospholipids; and nonglycerolipids such as tocopherols/tocotrienols, sterols, free fatty acids, pigments, vitamins, phenolic compounds, proteins and water (Xenakis et al., 2010). 


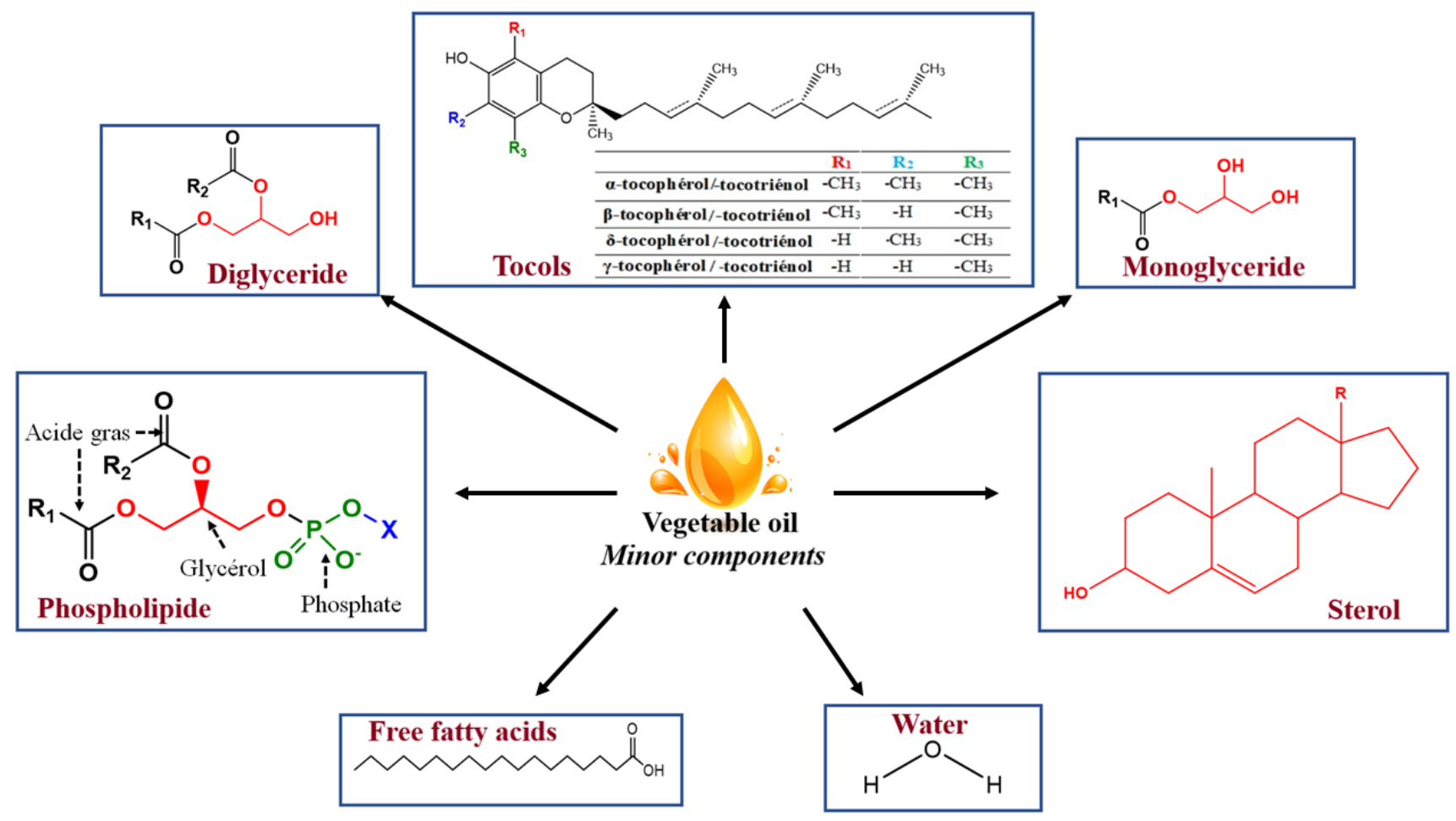

Fig. 2. Minor components of vegetable oils.

\section{Chemical composition of essential oils}

Essential oils are oily aromatic liquids extracted from different plant organs as secondary metabolites like, leaves (eucalyptus, thym, salvia), zest (citrus), flowers (lavender, rose, jasmine), fruits (citrus), seeds (sesame), roots (ginger) and wood (sandal) (El-Asbahani et al., 2015). The EO are generally complex mixtures of individual aroma compounds. Even they are not strictly oils, they are poorly soluble in water (Calo et al., 2015). In last decades, innovative methods have been emerged to extract EO from plant raw materials (Boukroufa et al., 2015; Gavahian et al., 2015; Sodeifian et al., 2016; Zermane et al., 2016). The constituents of plant EO comprise mainly four main groups: terpenes, phenylpropanoids, straight-chain compounds and miscellaneous groups.

\subsection{Terpenes}

Terpenes are the most abundant compounds found in plant EO (Chizzola, 2013). They are synthesized via the mevalonic acid pathway in the cytoplasm of plant cells (Morsy, 2017). 
146 Terpene compounds can be divided into two main categories: terpene hydrocarbons and 147 oxygenated compounds (Moghaddam and Mehdizadeh, 2017).

\subsubsection{Terpenes hydrocarbon}

The essential building block of terpenes is the isoprene unit joined in a head-to-tail manner. Basing on the number of isoprene units, different terpenes can be found in EO, as demonstrated in Fig. 3 (El-Asbahani et al., 2015; Morsy, 2017). Terpenes hydrocarbons are the first main group of components composed completely of carbon and hydrogen atoms and varied significantly in size and complexity (Moghaddam and Mehdizadeh, 2017). Monoterpenes and sesquiterpenes are the dominant terpenes found in plant EO. They are built up by two and three isoprene units, respectively. These terpenes could present acyclic, cyclic or aromatic structures. Cyclic terpenes can be classified depending on their ring size into monocyclic, bicyclic or tricyclic terpenes (Table 1). These compounds oxidize rapidly due to their fast reaction to heat and air sources (George et al., 2015). Diterpenes result by the combination of four isoprene units in a head-to-tail manner; they are essential constituents of plant resins (Langenheim, 2003). Commonly, diterpenes, triterpenes and tetraterpenes are present in EOs at a very low concentration. Their content may vary with the extraction method (Morsy, 2017).

\subsubsection{Terpenoids}

Terpene can be changed by adding functional groups and become terpenoid. When a monoterpene or a sesquiterpene has a functional group added to it, it is known as a monoterpenoid or sesquiterpenoid; respectively. The suffix "oid" means "derived from" or "like" therefore "terpenoid" can refer to all molecules with a terpene-like structure (Moghaddam and Mehdizadeh, 2017). They are classified into carboxylic acids, alcohols, aldehydes, esters, ethers, ketones, phenols, lactones, oxides, etc. 


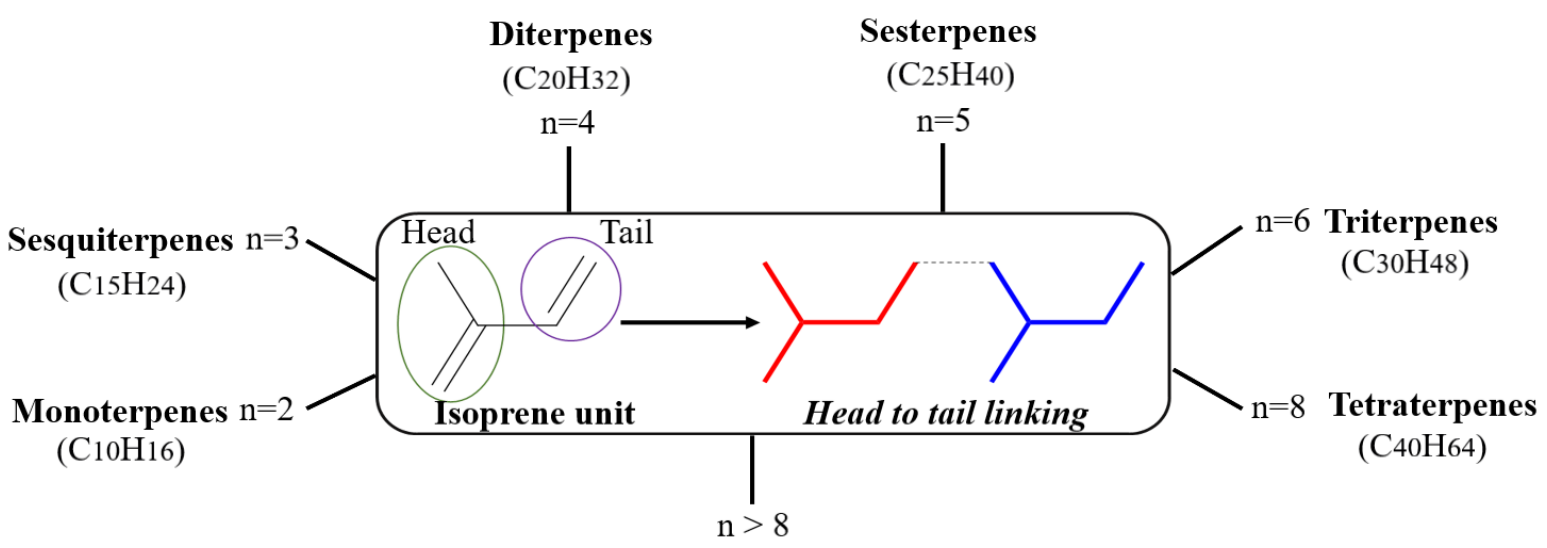

Fig. 3. Composition of terpenes.

\subsection{Phenylpropanoid}

This class of compounds, derived from phenylpropene, is synthesized from the amino acid phenylalanine and 1-tyrosine via the shikimic acid pathway. Their name is derived from the aromatic phenyl group and the propene tail. The propyl side chain may contain hydroxyl or carboxyl group; while the aromatic ring may carry methoxy, hydroxyl and methylene dioxy groups (Morsy, 2017). Phenylpropanoids give a specific flavor and odor to the plant when they are present (Moghaddam and Mehdizadeh, 2017). Eugenol and cinnamaldehyde are example of this group of constituents (Fig. 4).

\subsection{Straight-chain compounds}

This group contains only straight-chain compounds, not containing any side branches. They range from n-heptane, to compounds with 35 carbon atoms. The leaf alcohol (3(Z)-hexen1-ol) (Fig. 4) represents an example of this class; it gives an intense grassy-green odor upon cutting green grass and leaves (Morsy, 2017).

\subsection{Miscellaneous group}

They issue from the degradation of unsaturated fatty acids, lactones, terpenes, glycosides and represent sulfur- and nitrogen-containing compounds. Diallyl disulfide and indole are example of this class of compounds (Fig. 4) (Morsy, 2017). 

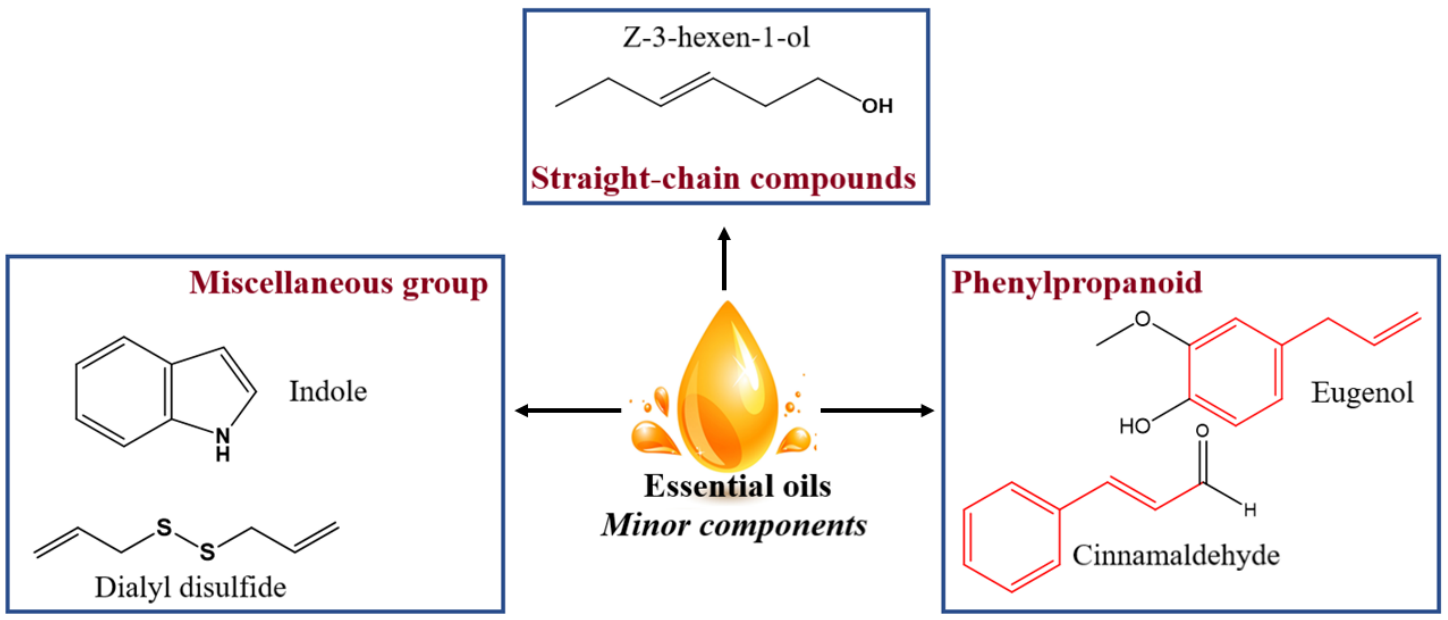

Fig. 4. Examples of phenylpropanoids, straight chain compounds and miscellaneous groups.

\section{Limitation in clinical use of plant oils}

Since ancient times, EO have been recommended all over the world for a variety of health problems and diseases (Moghaddam and Mehdizadeh, 2017). Enormous studies have investigated the biological properties of EO, including antimicrobial, antifungal (Ceole et al., 2017; Garcia-Rellán et al., 2016), antiviral (Zeghib et al., 2017), insecticidal (Chen et al., 2016; Jassbi et al., 2017), antioxidant (Hassanen et al., 2015; Limaverde et al., 2017), anticancer (Carneiro et al., 2017; Thakre et al., 2016), antidiabetic (Tahir et al., 2016), anti-inflammatory (Chansang et al., 2018; Nonato et al., 2012), antihypertensive (Cherkaoui-Tangi et al., 2016) and immunomodulatory (Orhan et al., 2016; Ozek et al., 2017). In medical field, EO have been used against nosocomial infections, as a cleaning liquid for disinfection of medical equipment and surfaces (Warnke et al., 2009) or as an aerosol in operating blocks and waiting rooms for air cleaning to limit contaminations (De Billerbeck, 2007). The application of EO has emerged to food and agriculture fields. They are used as antioxidants and preservatives in food (Khosravi, 2013; Pandey et al., 2016), as plant and crop protectants (Abdullah et al., 2018) and incorporated into foodstuff packaging (Ribeiro-Santos et al., 2017). 
In the other side, $\mathrm{VO}$ is a source of everlasting components which are responsible of

207

pertinent biological properties. Many of the fatty acids and other compounds present in VO have long been known to benefit our health. Numerous experimental studies approved that a dietary intake of omega-3 polyunsaturated fatty acids can reduce inflammation and may prevent the risk of chronic diseases like heart disease, cancer, and arthritis (Gammone et al., 2019; Hardman and Fakas, 2016; Kris-Etherton et al., 2003). In addition, polyphenols, medium chain fatty acids and tocopherol present in some $\mathrm{VO}$ were the reason of their antioxidant and antistress activities (Duthie et al., 2016; Yaep et al., 2015). Current animal studies have indicated that palmitic acid had a potent antiviral property against HIV-1 and HIV-2 (Özçelik et al., 2005). Linoleic and oleic acids were considered as effective antibacterial agents (Dilika et al., 2000). Further experimental studies highlighted other biological benefits of VO such as antiinflammatory (Hsu and Parthasarathy, 2017), analgesic and antipyretic (Intahphuak et al., 2010), hypolipidemic (Ali and El-Anany, 2017), antibacterial (Tabassum and Vidyasagar, 2014), antiviral (Orhan et al., 2011), hepatoprotective and gastroprotective properties (Cheng et al., 2015).

In the pharmaceutical field, plant oils entered in the composition of many dosage forms through several pathways, including the cutaneous route (creams, ointments, massage oils, gels), the oral route (tablets, syrup, capsules), the rectal route (suppositories) and the pulmonary route (aerosols, nasal drops, sprays) (El-Asbahani et al., 2015). Despite that, the preparations based on plant oil have some important constraints. The VO oral delivery is always confronted to their low solubility in biological fluids, low permeation and poor bioavailability because of their possible oxidation in the gastrointestinal tract (Márquez-Ruiz et al., 2008). For instance, Kanner and Lapidot (2001) suggested that the adsorbed oxygen and low pH of the human gastric fluid may enhance the oxidation of VO in the presence of catalysts found in foods. Moreover, it was reported that hydroperoxide resulted from the hydrolysis of triacylglycerol 
contained in VO by pancreatic lipase are not likely to be absorbed in their intact form (Suomela et al., 2004).

Additionally, the toxicity and irritation effects of EO on the oesophageal and gastro intestinal mucosa limit also their uses. EO could be the reason of potential allergic reactions of the skin if they are undiluted or insufficiently diluted (Pedro et al., 2013; Warshaw et al., 2015). For instance, applying excessive amounts of cinnamaldehyde rich-EO to a large surface of the skin can result in significant allergic reaction and anaphylactic shock, which in turn may be fatal (Diba and Statham, 2003). Some oils like those extracted from cumin, bergamot, verbena and lemon can cause photosensitization and induce malignant skin changes like redness, itching, burns, hyperpigmentation, pigmentary changes or berloque dermatitis (Zammit, 2010). Moreover, the high volatility and the high risk of deterioration of EO upon their direct exposure to heat, humidity, light, or oxygen discourages their free use, i.e. without a pharmaceutical vehicle (Turek and Stintzing, 2013). Therefore, the nanoncapsulation has been considered as a key to overcome the mentioned limitations (El-Asbahani et al., 2015; Sagiri et al., 2016).

Encapsulation strategies help in converting oils into several dosage forms including, liquid, solid or semi-solid dosage forms and thus enables retention of their activity for longer periods of time (Sagiri et al., 2016). Nanocarriers protect plant oils from environmental factors such as $\mathrm{pH}$, oxygen, light etc., serving as barrier between the molecule and the environment. They also shield the oils from oxidative degradation, evaporation and photo-degradation (Bilia et al., 2014). Their ability to control oil release confers improved efficacy, reduced toxicity, improved patient compliance and convenience (El-Asbahani et al., 2015; Zhao et al., 2017).

\section{Plant oils-loaded nanodelivery systems}

Nanodelivery systems is an area of intense research as they provide a number of benefits for therapy, such as (i) high drug efficacy, specificity and tolerability, (ii) sustained and controlled release of drugs (iii) less risk of toxicity (iv) deep tissue diffusion due to the 
nanometric size, and (iv) protection of drugs at both extracellular and intracellular levels (Bilia

et al., 2014; Kumari et al., 2010). In this paper, we highlighted the different experimental strategies designed to encapsulate plants oils into two main groups of organic nanocarriers; polymer based-nanocarriers (including polymeric nanoparticles) and lipid based-nanocarriers (including liposomes and solid lipid nanoparticles).

\subsection{Encapsulation in polymer-based nanocarriers}

Polymeric nanoparticles (pNP) are submicronic core-shell spherical systems prepared from natural or synthetic polymers (Mattheolabakis et al., 2012). Depending on the nanoparticle preparation process, nanocapsule or nanosphere can be obtained. Nanospheres have a matrixlike form in which the drug is evenly distributed. Nanocapsules are, however, vesicular structures in which the drug is confined in an inner core surrounded by a polymeric membrane (Crucho and Barros, 2017) (Fig. 5). Many polymers were used for this purpose, notably, biodegradable polyesters like poly(lactide-co-glycolide), polylactide and poly ( $\varepsilon$-caprolactone) were widely used (Froiio et al., 2020). Recently, pNP are extensively studied for plant oil delivery in view of their ability to entrap and protect oils, biodegradability, bioavailability and their high stability. The plant oil may be conjugated with the polymer (matrix or wall) or entrapped in the oily core (Bilia et al., 2014). Several methods have been reported for developing pNP while the nanoprecipitation, the ionic gelation, the emulsification/solvent evaporation and spray drying methods, are extensively used and Fig. 5 demonstrates the principle of each technique. 


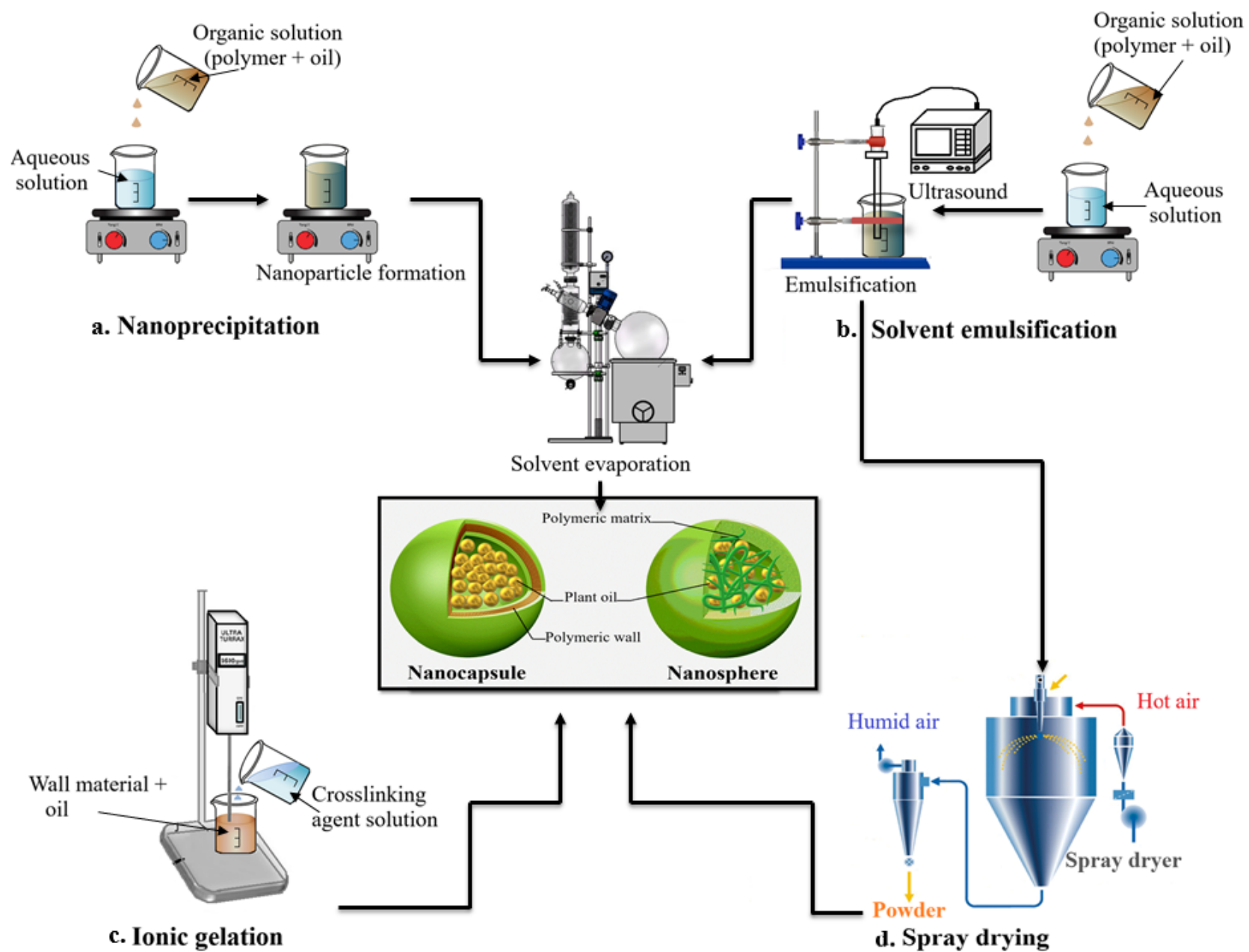

Fig. 5. Schematic illustration of the techniques used to produce polymeric nanoparticles.

\subsubsection{Spray drying}

Spray-drying technique has been used for decades to encapsulate plant oils in microand nano polymeric particles. It is based on the conversion of an infeed (solution, emulsion or suspension) into a dry powder in a single and continuous step. With respect to the encapsulation of plant oil, oil in water emulsion was atomized into fine drops in a drying chamber where hot air is passed $\left(150-250^{\circ} \mathrm{C}\right)$. A fast evaporation of water occurred leading to the instantaneous formation of powder (Fig.5.d) (Encina et al., 2016; Matos et al., 2019). Spray drying technique is extensively used to encapsulate both essential and vegetable oils in micro and nanoparticles, as illustrated in Table 1. 

produced by spray drying technique, high average diameter with moderate oil entrapment amount have been reported by numerous work studies, as depicted in Table 1. Hoyos-leyva et al. (2019) reported that almond oil loaded taro starch particles had an average size ranging from 1.4 to $31.1 \mu \mathrm{m}$ with an EE\% of 37.5\%. In addition, De-Oliveira et al. (2014) found that Lippia sidoides EO loaded alginate : cashew gum nanoparticles exhibited a spherical shape with size ranging from 223 to $399 \mathrm{~nm}$, zeta potential values in range of -30 to $-36 \mathrm{mV}$ and $\mathrm{EE} \%$ of about $50 \%$. In another work, the same EO was encapsulated in chitosan : cashew gum based nanoparticles owning an EE\% of 70\% with an average particle sizes in the range 335-558 nm (Abreu et al., 2012). Furthermore, the mixture maltodextrin : soy protein was used to encapsulate walnut oil and the resultant particles showed an average diameter of 4 to $10 \mu \mathrm{m}$ with an EE\% equal to 60\% (González et al., 2016).

The main feature of spray drying method is the formation of special particles. Indeed, the scanning electron microscopy carried by Tonon et al. (2011) on flaxseed oil loaded microparticles revealed the formation of hollow particles, i.e. particles with concave and shriveled surfaces. Same images were found by Gallardo et al. when visualizing linseed oilloaded gum arabic microcapsules. They ascribed this form to vacuoles formation inside the particles after the crust development. The magnitude of this process is inversely related to solid concentration in the emulsion (Gallardo et al., 2013). Moreover, Wang et al. (2018) carrying or cracks.

In vitro release profile of plant oils from particles prepared by spray drying technique generally exhibit a controlled manner. In a study carried out by De-Oliveira et al. (2014) the nanoparticles have reached a level of maximal release around 30-50 h. In that time, the content 
of Lippia sidoides EO from alginate : cashew gum particles varied from 45 and 95\% depending on the ratio of used polymers. Higher and faster release rate was achieved with high amount of cashew gum due to its greater hydrophilic character which allows greater diffusion of EO through the polymeric wall. Conversely, a smaller and more controlled release was assessed when increasing alginate content; after $50 \mathrm{~h}$, only $45 \%$ of oil was released. This was related to medium (De-Oliveira et al., 2014).

Particles produced by spray drying process provides a high stability for encapsulated oils. In this context, Hoyos-leyva et al. (2019) investigated the oxidative stability of almond oil before and after encapsulation into taro starch microcapsules. They found that these systems conferred more protection against oxidation when compared to unencapsulated almond oil due to the relatively reduced porosity of the material, which in turn limits the exposure of the oil to stress conditions during storage.

Several parameters have to be taken into consideration to efficiently entrap plant oils in studied in the literature (Bae and Lee, 2008; Chin et al., 2018; Gallardo et al., 2013; Laohasongkram et al., 2011; Lozano et al., 2012; Rodea-gonzález et al., 2012; Rubilar et al., 2012; Shamaei et al., 2017). Carneiro et al. (2013) investigated the microencapsulation of presented by maltodextrin : arabic gum emulsion implies a higher resistance to droplets movement, thus preventing coalescence and leading to smaller droplets size. Shamaei et al. 
material to the surface activity and molecular weight of wall material constituents. They found that as the ratio of tween 80 to skim milk powder increases, the mean droplet size decreases. This in turn was attributed to the fact that tween 80 mitigated droplet coalescence and Ostwald ripening phenomena in the emulsion by reducing the surface tension and interfacial free energy of the emulsion. In another study, emulsion droplet size was found to decrease as the ratio of wall to core material increases due to the fact that at low ratio, there may not be enough coating materials to cover the whole surface of the droplets in order to prevent them from coalescence which in turn increases the droplet size (Rodea-gonzález et al., 2012). Same result was also reported for chia seed oil-loaded microcapsules prepared by spray drying process (Laohasongkram et al., 2011). Moreover, Chew et al. (2018) spotlighted that adding $\beta-$ cyclodextrin to the wall matrix increases the $\mathrm{EE} \%$ of refined kenaf seed oil due to its host-guest character. In fact, its interior cavity acts as a host which can fix the guest (hydrophobic oil), while the exterior surface can bind with water or hydrophilic head of other wall materials. Furthermore, Us-medina and coworkers (2018) stated that adding chia mucilage to sodium caseinate : maltodextrin wall matrix increases the EE\% of chia seed oil from 71.26 to $86.65 \%$. They attributed this result to the fact that chia mucilage, used as thickener agent, increases the viscosity of the system which in turn promotes a greater physical stability of the emulsion during the spray drying process.

With respect to the oil content, Rubilar et al. (2012) revealed that increasing the oil concentration provokes a significant increase in droplet emulsion size and viscosity, which in turn reduces the $\mathrm{EE} \%$ and increases the surface oil content of the powder leading to potential lipid oxidation. Similar result was already published (Tonon et al., 2012).

Air inlet temperature is another factor to take into account for the development of plant oil-loaded particles; and it was widely investigated in the literature (Frascareli et al., 2011; Laohasongkram et al., 2011; Roccia et al., 2014; Shamaei et al., 2017). Frascareli et al. ( 2011) 
studied the encapsulation of coffee oil and observed that as the air flow temperature increases the $\mathrm{EE} \%$ decreases due to the fact that higher temperature leads to faster drying of the external phase which creates cracks in the particle wall, resulting in oil loss. Moisture content is an important variable for the shelf life of powders. It was reported that increasing the inlet temperature reduced the moisture content (Mohammed et al., 2017). However, higher values (more than $175^{\circ} \mathrm{C}$ ) resulted in an increase in moisture content due to the formation of rapid crust which hampered the water evaporation leading to particles with more moisture content. The particle size is another parameter which vary when modifying the air inlet temperature. In 2017, Mohammed and coworkers pointed out that an increased inlet air temperature produced larger-sized Nigella sativa EO particles and ascribed this result to the microcapsule structure. Indeed, high temperature enable the particles to form early which in turn prevents the shrinkage of particles during drying (Mohammed et al., 2017). used to encapsulate either essential or vegetable oils. This was related to the fact that short time inlet temperature of drying gas (Fang and Bhandari, 2012). According to Table 1, natural polymers like maltodextrin, gums and chitosan are the mostly used wall materials. Currently, this technique is widely used in nutraceutical and food industry due to its benefits including i) ease of scaling up, ii) simplicity, iii) low production costs, and iv) ability to produce microparticles facile to the transport and storage. Many drawbacks are associated to the use of this process including the lack of uniformity; high particle size, low oil loading and possibility of oil loss. Moreover, the wall material used must have good water solubility as most formulations used by the food industry are aqueous-based and simultaneously impart a suitable viscosity in order to enable the drying process (Corrêa-Filho et al., 2019). 


\subsubsection{Emulsion evaporation}

Emulsion evaporation method has been proposed by Vanderhoff and Asser (1979) to develop pNPs. In this process, an organic solution consisting of polymer and oil is emulsified with a non-solvent mixture under a high shear stress (e.g. by high-shear homogenization or ultrasonication). After that, the organic solvent is evaporated either by continuous magnetic stirring at room temperature or under reduced pressure leading to nanoparticles formation (Fig.5.b) (Rao and Geckeler, 2011; Rodríguez et al., 2016). This technique has been used to encapsulate both essential and vegetable oils in pNPs, as depicted in Table 1.

The emulsion evaporation technique produces nanoparticles with higher EE\% and smaller average diameter, as compared to the spray drying technique. In this context, Gomes et al. (2011a) reported a particle size of 179.3 and $173.8 \mathrm{~nm}$ with an EE\% of 98 and $92 \%$ for eugenol- and trans-cinnamaldehyde loaded poly (lactide-co-glycolide) nanoparticles, respectively. Similarly, chia seed oil loaded nanoparticles using chia mucilage as wall material exhibited a small particle size $(205 \mathrm{~nm})$ with negative zeta potential $(-11.58 \mathrm{mv})$ and high EE\% (82.8\%) (Campo et al., 2017). Moreover, poly (lactide-co-glycolide) nanoparticles were prepared to encapsulate clove EO, rich in eugenol which has potent antimicrobial activities (Priyadarshini et al., 2018). The average size of the resultant nanoparticles was about $237 \mathrm{~nm}$ with negative zeta potential of $-40 \mathrm{mv}$ and an $\mathrm{EE} \%$ equal to $93 \%$.

The nanoparticles prepared by emulsion evaporation process exhibited in vitro release pattern similar to that of particles produced by spray drying. In 2018, Priyadarshini et al. pointed out that in vitro cumulative clove EO release form poly (lactide-co-glycolide) nanoparticles followed a biphasic profile with an initial burst release at the first $4 \mathrm{~h}$ due to the release of clove EO found near the nanoparticles surface (Priyadarshini et al., 2018). A cumulative amount of $75 \%$ was progressively released up to $\sim 15$ days. Similar in vitro release kinetics were governed by eugenol and trans-cinnamaldehyde from poly (lactide-co-glycolide) nanoparticles where 64 
and $87 \%$ of the initial load was released in the medium within $72 \mathrm{~h}$, respectively (Gomes et al., 2011a).

The stability of the pNPs formulated by this technique was investigated in the literature.

In 2017, Campo et al. studied the oxidation of chia seed oil by gas chromatography with flame ionization detector in both emulsions and chia seed mucilage based-nanoparticles at accelerated conditions $\left(40 \pm 1^{\circ} \mathrm{C}\right)$ during 28 days of storage (Campo et al., 2017). No significant change was shown in term of particle size, zeta potential or polydispersity index. However, the fatty acid methyl esters content reduction in pNPs was smaller than in emulsions; therefore, the chia seed mucilage provided a high protection against oil oxidation (Campo et al., 2017).

With respect to the emulsification evaporation process, several parameters may affect the nanoparticles properties. Freiberger et al. (2015) investigated the effect of polymer type (poly(3-hydroxybutyrate-co-3-hydroxyvalerate)/polylactide); dispersion mechanism (ultrasonication / high shear homogenization) and polymer : oil ratio on the average size and oil recovery of biocompatible nanoparticles containing coffee oil. The statistical analysis showed non-significant effect of the experimental factors on the nanoparticle size within the experimental range. While for the coffee oil recovery, regression analysis produced a significant model. Less oil was lost by volatilization when sonication was used, because the required dispersion time (3min) was smaller when compared to the ultraturrax time (10min). Results showed also that less coffee oil loss was pronounced when using poly(3-hydroxybutyrate-co3-hydroxyvalerate) combined to the high shear homogenization as well as using polylactide combined with sonication. This was explained by the high viscosity of poly(3hydroxybutyrate-co-3-hydroxyvalerate)-dichloromethane solution which could avoid oil volatilization even with high shear homogenization (Freiberger et al., 2015). Regarding the polymer:oil ratio, an increase in polymer amount lead to increase the viscosity of the solution resulting in efficient oil protection from the heat generated by the homogenizer. 

essential and vegetable oils. Although it provides high EE\%, this method is less used to encapsulate plant oils, as compared to the spray drying technique. The possible reason behind this is the possible coalescence of droplets during evaporation which may lead to polydisperse particles and the need for a high shear process.

\subsubsection{Nanoprecipitation}

Nanoprecipitation is a simple, fast and increasingly trending technique for nanoparticles preparation (Almoustafa et al., 2017). It was firstly reported by Fessi et al. (1989) and it is based on the interfacial deposition of polymers as a result of the displacement of a water miscible solvent from a lipophilic solution (Fig.5.a) (Miladi et al., 2016). This method has been widely used to encapsulate plants oils in pNPs and Table 1 summarizes some work studies using the nanoprecipitation process to encapsulate either essential or vegetable oils during the last decade.

According to Table 1, the nanoparticles produced by nanoprecipitation process owned small particle size, narrow distribution with high EE\%. Ianniteli et al. (2011) developed carvacrol loaded poly (lactide-co-glycolide) based-nanocapsules with a spherical shape, small particle size $(209.8 \mathrm{~nm})$ and regular distribution (poly dispersibility index $=0.26)$. Similarly, Cymbopogon martini EO was efficiently entrapped in poly (e-caprolactone) basednanoparticles with an average size of $282.1 \mathrm{~nm}$, zeta potential equal to $-27.2 \mathrm{mV}$ and $\mathrm{EE} \%$ of about $99.54 \%$ (Khoobdel et al., 2017). Furthermore, Babassu tree nut oil loaded- poly (lactideco-glycolide) nanoparticles exhibited an average diameter about $209.2 \mathrm{~nm}$ with a negative zeta potential of $-15.8 \mathrm{mV}$ (Sousa et al., 2013).

In term of particle size, Esfandyari-Manesh and coworkers (2013) compared the nanoprecipitation to the emulsification solvent evaporation method to design carvone/anethole loaded poly (lactide-co-glycolide) nanoparticles and found that the particles produced by 
nanoprecipitation had smaller average diameter (158 and $126 \mathrm{~nm}$ for anethole and carvone, respectively) and narrower size distribution (0.08). Additionally, the amount of carvone and anethole were determined respectively by HPLC and UV analysis and results showed higher oil loading for the particles produced by nanoprecipitation (14.73 and $12.32 \%$ for anethole and carvone, respectively). The authors related the low EO loading for the emulsification method to its loss during the evaporation step which has taken a long time (about $3 \mathrm{~h}$ ). In addition, the high particle diameter of the nanoparticles prepared by this method was attributed to the difficulty for the mutual dispersion of the phase which is viscous due to the presence of high amount of oil and polymer.

According to the literature, to develop pNPs with suitable physicochemical properties, numerous factors had to be taken into consideration. The polymer type and amount have a critical effect on nanoparticles average size. In 2017, Khoobdel et al. (2017) developing poly ( $\varepsilon$-caprolactone) -based nanoparticles loaded with rosemary EO reported that increasing polymer quantity, leads in increasing the thickness of the particles shell and thus increasing their mean diameter, instead of increasing their number. Moreover, low values of EE\% were observed when using Eudragit L100 as polymer for the encapsulation of Siberian cedar seed oil or free fatty acids due to its porous structure which enabled oil leakage (Averina and Allémann, 2013). Regarding the type of the EO, Liakos et al. (2018) studied the influence of EO chemical composition on the particle size of three types of pNPs: Peppermint, cinnamon and lemongrass EOs loaded-cellulose acetate nanocapsules. The average size was increasing as follow: Cinnamon-pNPs $<$ Peppermint-pNPs $<$ Lemongrass pNPs. The larger pNPs were those containing lemongrass EO, due to the presence of high percentage of geranial and neral which have long carbon chains $(\approx 10 \mathrm{C}$ atoms) leading to larger pNPs when attached to cellulose acetate. While, peppermint contains mainly $35 \%$ menthol and $27 \%$ menthone leading to the creation of less uniform, complex and large nanoparticles. In the other hand, cinnamon EO 
consists essentially of cinnamaldehyde which reacts with hydroxyl group of cellulose acetate

489

490

491

492

493

494

495

496

497

498

499

500

501

502

503

504

505

506

507

508

509

510

511 giving hemiacetal bound and hence combats the nanocapsules. Liakos and his coworkers assessed also in their study higher zeta-potential upon increasing lemongrass EO concentration, suggesting that some EO molecules are present onto the outer surface of the particles (Liakos et al., 2018). Similarly, it was reported that the presence of lime EO decreased the zeta potential and the values were 61.1 and $57.0 \mathrm{mV}$ for free- and loaded- chitosan nanocapsules, respectively. They attributed this result to the diminution of free $\mathrm{NH}_{3}{ }^{+}$groups of chitosan following their interaction with lime EO (Sotelo-Boyás et al., 2017b). However, in another work study, the presence of rosemary EO did not affect the zeta potential of poly ( $\varepsilon$-caprolactone) nanoparticles which confirm its presence in the core of the nanoparticles instead of being adsorbed on their surface (Khoobdel et al., 2017).

In term of surfactant type and amount, Badri et al. (2015) pointed out that the amount of polyvinyl alcohol used as surfactant had no significant effect on the average diameter of poly ( $\varepsilon$-caprolactone) nanoparticles but at higher concentration (more than $0.1 \mathrm{mg} / \mathrm{mL}$ ), a significant increase was assessed due to the deposition of extra polyvinyl alcohol on the nanoparticle surface. Furthermore, it was reported that the use of span 20 instead of tween 20 gave smaller rosemary EO-loaded nanocapsules, lower polydispersity index and limited loss of the oil during the solvent evaporation step. In the presence of span 20, the hydrophilic lipophilic balance (HLB) was between 12 and 15 (14.3), which was in the range of HLB necessary for rosemary EO nanoemulsion stability (Ephrem et al., 2014). Furthermore, the effect of the ratio between organic and aqueous phase may affect the particle size. Indeed, an increase in argan oil loaded nanoparticles was assessed when increasing the organic to aqueous phase ratio due to the slow diffusion of the organic solvent (acetone) to water resulting slow polymer precipitation and thus, larger pNPs were obtained (Badri et al., 2015). 
Results revealed a decrease in particle size by increasing the stirring speed. While, it increases when decreasing the organic phase addition speed due to the difficulty to get a homogenous mixture of phases. Furthermore, Ephrem et al. (2014) studied the influence of the evaporation method on the pNPs properties and rosemary EO loss and found that the evaporation of acetone under normal pressure at room temperature was the best since it avoided heat and low pressure, giving negligible loss of the encapsulated EO.

Recently, a novel form of pNPs was developed called lipid-core nanocapsules which is composed of a mixture of oil and solid lipid surrounded by a polymeric wall (Ourique et al., 2010). For instance, the oily core of pNP may consist of a liquid lipid, a mixture of liquid lipids, or a mixture of liquid lipid and solid lipid. The latter concerns a specific form of nanocapsules called lipid-core nanocapsules (Frank et al., 2015). Several research works have been already published investigated the feasibility to entrap VO into lipid core NPs (Almeida et al., 2009; Drozdek and Bazyli, 2016; Friedrich et al., 2008; Marchiori et al., 2017; Rigo et al., 2013; Weber et al., 2016). In this context, nanoprecipitation technique was efficiently carried out to develop borage oil : betamethasone co-loaded lipid-core nanocapsules with a mean size around $210 \mathrm{~nm}$, negative zeta potential $(-16.6 \mathrm{mv})$, low polydispersity index $(<0.05)$ and high EE\% (up to $100 \%$ ) (Weber et al., 2016). Furthermore, Rigo et al. (2013) studied the influence of the type of $\mathrm{VO}$ on the release kinetic of clobetasol propionate, selected as model drug, from the lipid core nanoparticles. Results revealed a biphasic drug release profiles for all the formulations. After $168 \mathrm{~h}$, the concentration of clobetasol propionate released from the formulation was in the following order: Sunflower oil-pNPs $<$ Soybean oil-pNPs $<$ Rice ban-pNPs. The authors related these results to the consistency indices of the mixture oil : sorbitan monostearate, used 
as solid lipid; and a greater control of the drug release was observed with higher consistency index of the VO-sorbitan monostearate.

Regarding the nanoparticles stability, Badri et al. (2018) investigated the stability of poly (ع-caprolactone) based nanoparticles containing Nigella sativa EO coupled with indomethacin during one month under three different conditions $\left(4^{\circ} \mathrm{C}, 25^{\circ} \mathrm{C}\right.$ and $\left.40^{\circ} \mathrm{C}\right)$. The samples were analyzed at predefined times and results demonstrated no significant change in either size or zeta potential for all the tested particles. Similarly, the photodegradation study of the lipid-core nanocapsules containing borage oil and betamethasone was carried out to demonstrate the ability of nanocapsules in the photoprotection of the drug. In brief, nanoparticles suspensions were placed in transparent quartz cell and exposed to UVC radiation and the total concentration of drug was quantified. Results revealed a degradation of $61 \%$ from the nanocapsules suspension at the end of the experiment $(10 \mathrm{~h})$, while $58 \%$ of drug was degraded in $2 \mathrm{~h}$ from drug solution. This confirmed the property of polymeric wall to protect the bioactive molecules (Weber et al., 2016).

Regarding the scalability and reproducibility of the nanoprecipitation process, it was noticed no significant difference between rosemary EO loaded poly ( $\varepsilon$-caprolactone) nanocapsules prepared at small and large scales in term of shape, particle size, polydispersity index zeta potential and EE\% (Ephrem et al., 2014).

Overall, the nanoprecipitation or solvent displacement method is widely used to develop pNPs for plants oils encapsulation. According to the Table 1, the polymers commonly used to design the polymeric matrix are synthetic polyesters like poly (lactide-co-glycolide) (Esfandyari-Manesh et al., 2013; Iannitelli et al., 2011; Sousa et al., 2013), poly ( $\varepsilon$ caprolactone) (Badri et al., 2018; Christofoli et al., 2015; Ephrem et al., 2014; Jummes et al., 2020; Khoobdel et al., 2017), polylactide (Liakos et al., 2016), Eudragit ${ }^{\circledR}$ L100 (Averina and Allémann, 2013), S100 (Averina and Allémann, 2013), L100-55 (Pina-Barrera et al., 2019) and 
RS100 (El-Asbahani et al., 2015; Froiio et al., 2019). Synthetic polymers are more used than

563

564

565

566

567

568

569

570

571

572

573

574

575

576

577

578

579

580

581

582

583

584

585

586

natural ones like chitosan (Luque-Alcaraz et al., 2016; Sotelo-Boyás et al., 2015, 2017a, 2017b)

and cellulose derivatives (Liakos et al., 2018; Marchiori et al., 2017) because they have higher purity and better reproducibility. The benefits associated to this encapsulation method are rapidity, simplicity, reproducibility, and scalability. Moreover, NPs with narrow size distribution, high EE\% and high stability could be obtained. In addition, the use of surfactant or high production energy is avoided. The main drawback of this method in encapsulating plant oils is the use of organic solvents which may be toxic for health.

\subsubsection{Ionic gelation}

In order to avoid the use of toxic organic solvent or high shear forces, Calco et al. (1997) proposed a novel approach called ionic gelation or coacervation. Alginate, an anionic polysaccharide, and chitosan, a cationic polyelectrolyte, are extensively used for ionic gelation purpose. These polyelectrolytes can interact with crosslinking agents like tripolyphosphate having an opposite charge via electrostatic interaction and aggregate into nanoparticles (J. Yang et al., 2015). The coacervation consists on the transition from liquid to gel state upon complexation between the oppositely charged molecules at determined $\mathrm{pH}$ values leading to the formation of nano-sized particles (Nagavarma et al., 2012) (Fig.5.c). A number of studies have been carried out using this technique to encapsulate plant oils, as displayed in Table $\mathbf{1}$.

Recently, cinnamon EO-loaded chitosan nanoparticles crosslinked with tripolyphosphate were prepared by using coacervation method and the obtained particles owned small average diameter $(80-100 \mathrm{~nm})$ with good zeta potential values $(-11.2$ to $-22.4 \mathrm{mV})$ (Liu et al., 2017). In addition, cardamom EO was successfully entrapped into chitosan based nanoparticles with an average particle size ranging between 50 and $100 \mathrm{~nm}$, zeta potential more than $+50 \mathrm{mV}$ and a high EE\% which was more than 90\% (Jamil et al., 2016). Furthermore, Woranuch and his coworker (2013) reported that the thermal stability of eugenol was enhanced 
by encapsulation in chitosan: tripolyphosphate- nanoparticles. According to some research works depicted in Table 2, the ionic gelation technique may produce microparticles with moderate EE\% as compared to the nanoprecipitation process (Feyzioglu and Tornuk, 2016; López-meneses et al., 2018; Sutaphanit and Chitprasert, 2014; Yang et al., 2014; K. Zhang et al., 2012).

Currently, several research works have been reported to investigate the effect of pNPs composition and operating conditions on physicochemical properties of particles prepared by ionic gelation method. The optimization of the type and amount of polymer and crosslinking agent is crucial to develop pNPs with suitable characteristics. In this approach, Carum copticum EO-loaded chitosan nanoparticles were prepared by ionic gelation method using two types of crosslinking agents: tripolyphosphate and hexametaphosphate (Esmaeili and Asgari, 2015). The efficacy of crosslinking agent type and tripolyphosphate concentration on the EE\% were evaluated. The particles prepared using hexametaphosphate $(0.5 \%(\mathrm{w} / \mathrm{v}))$ had significantly lower loading capacity and EE\% than those prepared using tripolyphosphate $(0.5 \%(\mathrm{w} / \mathrm{v}))$. This was attributed to the ring structure and bigger size of hexametaphosphate which in turn lead to decrease the crosslinking phenomenon. In the same work, different nanoparticles were prepared using different tripolyphosphate concentrations $(0.25,0.5,0.75$ and $1 \%(\mathrm{w} / \mathrm{v}))$ and results indicated that maximum EE\% was obtained with the concentration of $0.5 \%(\mathrm{w} / \mathrm{v})$. The low value of EE\% obtained with the concentration of $0.25 \%(\mathrm{w} / \mathrm{v})$ was explained by the shortage of tripolyphosphate concentration to crosslink the nanoparticles; while the low values shown with 0.75 and $1 \%(\mathrm{w} / \mathrm{v})$ tripolyphosphate concentrations were related to the particle shrinkage (Esmaeili and Asgari, 2015).

With respect to the polymer effect, the viscosity of chitosan was optimized for fabrication of vanilla oil loaded microcapsules using the coacervation method (Yang et al., 2014). Results showed that at low chitosan viscosity, no microcapsules were formed because 
chitosan at low viscosity could not form hard membrane wall. On the other hand, when using high viscosity chitosan, aggregation problem was observed (Yang et al., 2014).

Regarding the EO concentration, Hasheminejad et al. (2019) stated that both particle size and zeta potential decreased significantly when increasing clove EO concentration. The reduction in particle size was explained by the great packing of polymer chains, due to the high number of amino groups in chitosan responsible for the interaction with the oil. Additionally, the thermogravimetric analysis performed by Hosseini et al. (2013) on oregano EO loadedchitosan nanoparticles demonstrated that as the initial EO content increases from 0.1 to $0.8 \mathrm{~g} / \mathrm{g}$ chitosan, loading capacity increases too from 3 to $8 \%$, but the EE\% decreases from 47 to $21 \%$. This was explained by the saturation of oregano EO loaded into chitosan nanoparticles. The EO concentration was found to affect also the in vitro release profile. Indeed, Hosseini and his coworkers reported that low concentration of oregano EO $(0.1 \mathrm{~g} / \mathrm{g}$ chitosan) leads to burst release ( $82 \%$ of encapsulated EO was released from the nanoparticles within $3 \mathrm{~h}$ ). While, as oregano EO amount increased, the burst effect was dramatically alleviated and the cumulative release was reduced from 82 to $12 \%$ after $3 \mathrm{~h}$. This phenomenon was attributed to the fact that chitosan nanoparticles with smaller particle size would have bigger surface-to-volume ratio which may result in fast release of oregano EO adsorbed on their surfaces (Hosseini et al., 2013). Another factor affecting the release profile was found to be the composition of the encapsulated material. In 2014, Dima et al. investigating the release of Pimenta dioica EO found that chitosan microspheres covered with k-carrageenan are more fragile and exhibit higher swelling degree with zero order release kinetics, as compared to the chitosan : kcarrageenan microspheres hardened by glutaraldehyde crosslinking which show non-Fickian release mechanism (Dima et al., 2014).

Numerous research works noticed the stability of pNPs produced by ionic gelation method. In 2014, Sutaphanit et al. reported that the encapsulation of holy basil EO into gelatin 
637 by simple coacervation method could prevent its volatility and oxidation (Sutaphanit and 638 Chitprasert, 2014). Indeed, the particles stored under accelerated conditions at $60{ }^{\circ} \mathrm{C}$ for 49 days

639

640

641

642

643

644

645

646

647

648

649

650

651

652

653

654

655

656

657 exhibited small decreases in the holy basil EO retention rate and antioxidant activity (Sutaphanit and Chitprasert, 2014). Moreover, the stability studies performed on peppermint oil loaded capsules showed that only $7 \%$ of the oil was released during the storage of 40 days in cold water (Dong et al., 2011). In another work study, jasmine EO nanoparticles exhibited high heatstability against humid heat $\left(80^{\circ} \mathrm{C}\right.$ for $\left.7 \mathrm{~h}\right)(\mathrm{Lv}$ et al., 2014).

On the whole, ionic gelation method is broadly used to encapsulate plants oils when compared to simple emulsion evaporation method. Gelatin (Devi et al., 2012; Dong et al., 2011; Sutaphanit and Chitprasert, 2014; K. Zhang et al., 2012), arabic gum (Dong et al., 2011; Lv et al., 2014; X. Yang et al., 2015; K. Zhang et al., 2012), alginate (Devi et al., 2012; Natrajan et al., 2015) and chitosan (Feyzioglu and Tornuk, 2016; Hosseini et al., 2013; Jamil et al., 2016; Liu et al., 2017; López-meneses et al., 2018) are the most commonly used wall materials. In addition, tripolyphosphate (Hasheminejad et al., 2019; Hosseini et al., 2013; Hu et al., 2015; Liu et al., 2017; Woranuch and Yoksan, 2013) and glutaraldehyde (Devi et al., 2012; Dima et al., 2014; Natrajan et al., 2015; Sutaphanit and Chitprasert, 2014) are widely used as crosslinking agents. The main advantages of ionic gelation method are, in particular; the avoidance of high shear forces and the use of aqueous solvents instead of organic ones. Moreover, ionic gelation is simple, economic and reproducible. However, moderate EE\% and larger particle size were assessed using this method as compared to the nanoprecipitation technique. 
658 Table 1. Preparation methods for plant oils encapsulation in polymeric nanoparticles and fine applications.

\begin{tabular}{|c|c|c|c|c|c|c|c|c|}
\hline \multirow{2}{*}{$\begin{array}{l}\text { Encapsulated } \\
\text { oil }\end{array}$} & \multirow[t]{2}{*}{ Plant (origin) } & \multirow[t]{2}{*}{ Wall material } & \multicolumn{3}{|c|}{ Physicochemical properties } & \multirow[t]{2}{*}{ Biological properties } & \multirow[t]{2}{*}{ Application } & \multirow[t]{2}{*}{ Ref. } \\
\hline & & & $\begin{array}{c}\text { Size } \\
(\mathbf{n m})\end{array}$ & $\begin{array}{l}\text { Z.pot } \\
\text { (mv) }\end{array}$ & $\begin{array}{l}\mathbf{E E} \\
(\%)\end{array}$ & & & \\
\hline \multicolumn{9}{|c|}{ Nanoprecipitation method } \\
\hline $\begin{array}{l}\text { Baccharis } \\
\text { dracunculifolia }\end{array}$ & Baccharis dracunculifolia DC & Eudragit RS 100 & 151.6 & +51.7 & 99.4 & Antibacterial & Food & (Timbe et al., 2020) \\
\hline Oregano & Origanum vulgare L. & PCL & $158-300$ & -13.8 to -28.5 & & Antibacterial & Food & (Souza et al., 2020) \\
\hline Geraniol & 1 & PCL & 289.3 & -26.6 & 99.88 & Antioxidant, antimicrobial & Cosmetics & (Jummes et al., 2020) \\
\hline Zataria & Zataria multiflora Boiss. & PCL & $192-398$ & +13.9 to +29.2 & $75-79$ & Insecticide & Agriculture & (Ahsaei et al., 2020) \\
\hline \multirow[t]{4}{*}{ Thyme } & Thymus vulgaris L. & Eudragit L 100-55 & 153.9 & -4.11 & 52.81 & Antioxidant & Food & $\begin{array}{lll}\text { (Pina-Barrera et al., } \\
\text { 2019) }\end{array}$ \\
\hline & Thymus leptobotrys L. & Eudragit RS 100 & 144 & +80.9 & 1 & Bacteriostatic, fungistatic & Medicine & (El-Asbahani et al., 2015) \\
\hline & Thymus satureoides L. & Eudragit RS 100 & 132 & 81.6 & 1 & Bacteriostatic, fungistatic & Medicine & (El-Asbahani et al., 2015) \\
\hline & Thymus serpyllum L. & Chitosan & $117-226$ & +27 & / & Antimicrobial & Agriculture & $\begin{array}{l}\text { (Sotelo-Boyás et al., } \\
2015)\end{array}$ \\
\hline Sweet orange & Citrus sinensis L. & Eudragit RS100 & $57-208$ & +39 to +74 & $56-96$ & Antimicrobial & Food & (Froiio et al., 2019) \\
\hline Bergamot & Citrus bergamia Risso. & Eudragit RS100 & $57-208$ & +39 to +74 & $28-84$ & Antimicrobial & Food & (Froiio et al., 2019) \\
\hline \multirow[t]{4}{*}{ Rosemary } & Rosmarinus officinalis L. & PCL & $181-407$ & +11.6 to +28.3 & $82.9-84.3$ & Insecticide & Agriculture & (Ahsaei et al., 2020) \\
\hline & & Eudragit EPO & 200 & 1 & 59 & Antioxidant & Cosmetics & (Silva-Flores et al., 2019) \\
\hline & & PCL & 145 & -11.0 & 78.2 & Insecticide & Agriculture & (Khoobdel et al., 2017) \\
\hline & & PCL & 220 & -19.9 & 99 & Antioxidant, antimicrobial & Medicine & (Ephrem et al., 2014) \\
\hline \multirow[t]{2}{*}{ Lavender } & Lavandula dentate $\mathrm{L}$. & Eudragit EPO & 200 & 1 & 41 & Antioxidant & Cosmetics & (Silva-Flores et al., 2019) \\
\hline & & PEO-b-PLA & $10-75$ & 1 & $70-75$ & Antimicrobial & Textile & (Popiolski et al., 2016) \\
\hline Peppermint & Mentha piperita L. & Cellulose acetate & 180 & -38 & 1 & Antimicrobial & Medicine & (Liakos et al., 2018) \\
\hline Cinnamon & Cinnamomum cassia persl. & Cellulose acetate & 150 & -40 & 1 & Antimicrobial & Medicine & (Liakos et al., 2018) \\
\hline \multirow[t]{3}{*}{ Lemongrass } & Cymbopogon citratus DC. & PLA & 96.4 & 1 & 99 & Antifungal & Medicine & (Antonioli et al., 2020) \\
\hline & & Cellulose acetate & 200 & -36 & 1 & Antimicrobial & Medicine & (Liakos et al., 2018) \\
\hline & & PLA & 300 & -6 & 1 & Antimicrobial & Medicine & (Liakos et al., 2016) \\
\hline $\begin{array}{l}\text { Black seed oil } \\
+ \\
\text { Indometacin } \\
\end{array}$ & Nigella sativa $\mathrm{L}$. & PCL & $230-260$ & -20 to -30 & $\begin{array}{l}\text { Oil }=84 \\
\text { Drug }=70\end{array}$ & Anti-inflammatory & Cosmetics & (Badri et al., 2018) \\
\hline
\end{tabular}




\begin{tabular}{|c|c|c|c|c|c|c|c|c|}
\hline \multirow[t]{2}{*}{ Lime } & \multirow[t]{2}{*}{ Citrus aurantiifolia Christm. } & Chitosan & $100-300$ & +57 & / & Antimicrobial & Food & $\begin{array}{l}\text { (Sotelo-Boyás et al., } \\
\text { 2017b) }\end{array}$ \\
\hline & & Chitosan & $250-1000$ & +20.2 & / & Antimicrobial & Agriculture & $\begin{array}{l}\text { (Sotelo-Boyás et al., } \\
\text { 2015) }\end{array}$ \\
\hline Pepper tree & Schinus molle L. & Chitosan & 754 & +9.1 & 1 & Antifungal & Food & $\begin{array}{l}\text { (Luque-Alcaraz et al., } \\
\text { 2016) }\end{array}$ \\
\hline $\begin{array}{l}\text { Zanthoxylum } \\
\text { rhoifolium }\end{array}$ & Zanthoxylum rhoifolium L. & PCL & 500 & -20 & 96 & Insecticide & Agriculture & (Christofoli et al., 2015) \\
\hline $\begin{array}{l}\text { Argan oil } \\
+ \text { Indometacin }\end{array}$ & Argania spinosa L. & PCL & $290-350$ & -40 to -50 & $65-75$ & Anti-inflammatory & Cosmetics & (Badri et al., 2015) \\
\hline $\begin{array}{l}\text { Pelargonium } \\
\text { graveolens }\end{array}$ & Pelargonium graveolens L. & Eudragit RS 100 & 113 & +80.6 & / & Bacteriostatic, fungistatic & Medicine & (El-Asbahani et al., 2015) \\
\hline $\begin{array}{l}\text { Eugenia } \\
\text { caryophyllata }\end{array}$ & Eugenia caryophyllata $\mathrm{C}$. & Eudragit RS 100 & 131 & +80.7 & 1 & Bacteriostatic, fungistatic & Medicine & (El-Asbahani et al., 2015) \\
\hline \multirow[t]{3}{*}{ Carvacrol } & 1 & PLA & 114.7 & +54.7 & 53.9 & Antimicrobial & Food & (Niza et al., 2020) \\
\hline & 1 & PHB & 146 & -26 & 21 & Antimicrobial & 1 & (Shakeri et al., 2014) \\
\hline & 1 & PLGA & 209.8 & 1 & 26 & Antimicrobial & Medicine & (Iannitelli et al., 2011) \\
\hline Carvone & / & PLGA & 126 & I & 1 & Antimicrobial & Food & $\begin{array}{l}\text { (Esfandyari-Manesh et } \\
\text { al., 2013) }\end{array}$ \\
\hline Anethole & I & PLGA & 158 & 1 & / & Antimicrobial & Food & $\begin{array}{l}\text { (Esfandyari-Manesh et } \\
\text { al., 2013) }\end{array}$ \\
\hline Date seed & Phoenix dactylifera L. & Eudragit RS 100 & 207 & +59 & 97 & Antidiabetic & Medicine & (Lammari et al., 2020) \\
\hline $\begin{array}{l}\text { Pomegranate } \\
\text { oil+ Silibinin }\end{array}$ & Punica granatum L. & Ethylcellulose & 1 & / & / & $\begin{array}{l}\text { Anti-inflammatory for skin } \\
\text { damage UVB }\end{array}$ & Cosmetics & (Marchiori et al., 2017) \\
\hline Rosehip & Rosa rugosa Thunb. & Eudragit RS100 & 158 & +9.8 & / & $\begin{array}{l}\text { Accelerate the skin } \\
\text { regenerating process }\end{array}$ & Cosmetics & (Contri et al., 2016) \\
\hline Castor & Ricin commun L. & TAD & $260-150$ & 1 & 1 & Source of PUFA & 1 & $\begin{array}{l}\text { (Chattopadhyay and Prez, } \\
\text { 2016) }\end{array}$ \\
\hline Olive & Olea europaea L. & TAD & 185 & -30 & 1 & Source of PUFA & I & $\begin{array}{l}\text { (Chattopadhyay and Prez, } \\
\text { 2016) }\end{array}$ \\
\hline Pumpkin & Cucurbita pepo L. & TAD & 172 & -35 & / & Source of PUFA & / & $\begin{array}{l}\text { (Chattopadhyay and Prez, } \\
\text { 2016) }\end{array}$ \\
\hline Sunflower & Helianthus annuus L. & TAD & 178 & -33 & 1 & Source of PUFA & I & $\begin{array}{l}\text { (Chattopadhyay and Prez, } \\
\text { 2016) }\end{array}$ \\
\hline Hazelnut & Corylus avellana L. & TAD & 175 & -35 & 1 & Source of PUFA & 1 & $\begin{array}{l}\text { (Chattopadhyay and Prez, } \\
\text { 2016) }\end{array}$ \\
\hline
\end{tabular}




\begin{tabular}{|c|c|c|c|c|c|c|c|c|}
\hline $\begin{array}{l}\text { Borage oil+ } \\
\text { Betamethason } \\
\text { e dipropionate }\end{array}$ & Borago officinalis L. & PCL & 210 & -16.6 & 100 & $\begin{array}{l}\text { Treatment of atoptic } \\
\text { dermatitis }\end{array}$ & Cosmetics & (Weber et al., 2016) \\
\hline Rice bran & Oryza sativa $\mathrm{L}$. & PCL & 200 & -9 & / & $\begin{array}{l}\text { Sunscreen (treatment of } \\
\text { inflammatory disorders of } \\
\text { skin) }\end{array}$ & Cosmetics & (Rigo et al., 2015) \\
\hline Pine seed & Pinus pinea $\mathrm{L}$. & \multirow{2}{*}{$\begin{array}{l}\text { Eudragit L 100-55 } \\
\text { / Eudragit L100/ } \\
\text { Eudragit S100 }\end{array}$} & $236-296$ & 1 & $85-91$ & \multirow[t]{2}{*}{ Source of PUFA } & \multirow[t]{2}{*}{ Medicine } & \multirow{2}{*}{$\begin{array}{l}\text { (Averina and Allémann, } \\
\text { 2013) }\end{array}$} \\
\hline Free fatty acid & 1 & & $260-319$ & / & $83-99$ & & & \\
\hline Babassu & Attalea speciosa Mart. & PLGA & 209.2 & -15.8 & 1 & $\begin{array}{l}\text { Treatment of benign } \\
\text { prostatic hyperplasia }\end{array}$ & Medicine & (Sousa et al., 2013) \\
\hline \multicolumn{9}{|c|}{ Emulsion evaporation method } \\
\hline $\begin{array}{l}\text { Mastic tree of } \\
\text { Chios }\end{array}$ & $\begin{array}{l}\text { Pistacia lentiscus L. var. } \\
\text { chia }\end{array}$ & PLA & $239-286$ & $\begin{array}{l}-29.1 \text { to } \\
-34.5\end{array}$ & $9-37$ & Antimicrobial & Cosmetic & (Vrouvaki et al., 2020) \\
\hline Clove & Syzygium aromaticum $\mathrm{L}$. & PLGA & 237.6 & -40 & 93.95 & Antimicrobial & Medicine & $\begin{array}{lll}\text { (Priyadarshini et al., } \\
2018)\end{array}$ \\
\hline Eugenol & 1 & PLGA & 179.3 & 1 & 98 & Antimicrobial & Food & (Gomes et al., 2011a) \\
\hline $\begin{array}{l}\text { Trans- } \\
\text { cinnamaldehy } \\
\text { de }\end{array}$ & I & PLGA & 173.8 & 1 & 92 & Antimicrobial & Food & (Gomes et al., 2011a) \\
\hline Chia seed & Salvia hispanica L. & $\begin{array}{l}\text { Chia seed } \\
\text { mucilage }\end{array}$ & 205 & -11.58 & 82.8 & Source of PUFA & 1 & (Campo et al., 2017) \\
\hline \multirow[t]{2}{*}{ Coffee } & \multirow{2}{*}{ Coffea arabica $\mathrm{L}$. } & PLA & 263 & 1 & 112.7 & Flavoring agent & Food & (Freiberger et al., 2015) \\
\hline & & PHBV & 271 & & 94.5 & Flavoring agent & Food & (Freiberger et al., 2015) \\
\hline \multicolumn{9}{|c|}{ Ionic gelation method } \\
\hline $\begin{array}{l}\text { Homalomena } \\
\text { pineodora }\end{array}$ & Homalomena pineodora L. & Chitosan & 70 & +24.1 & & Wound healing & Medicine & (Rozman et al., 2020) \\
\hline Piper nigrum & Piper nigrum L. & Chitosan & 527.5 & -5.3 & $35-40$ & Pesticide & Agriculture & (Rajkumar et al., 2020) \\
\hline Nettle & Urtica dioica $\mathrm{L}$. & Chitosan & $\begin{array}{c}208.3- \\
369.4 \\
\end{array}$ & 1 & $59.5-68.2$ & Antimicrobial & $\begin{array}{l}\text { Food; } \\
\text { Medicine }\end{array}$ & (Bagheri et al., 2020) \\
\hline Tarragon & Artemisia dracunculus L. & Gelatin+Chitosan & $246-505$ & $27.1-37.1$ & $9.8-35.6$ & Preservative & Food & (Zhang et al., 2020) \\
\hline Camelthorn & Alhagi maurorum L. & Chitosan & 172 & +28.6 & 1 & Antimicrobial & Medicine & $\begin{array}{l}\text { (Hassanshahian et al., } \\
2020)\end{array}$ \\
\hline Great morinda & Morinda citrifolia $\mathrm{L}$. & Chitosan & 1006 & +43.5 & 1 & Anticancer & Medicine & (Rajivgandhi et al., 2020) \\
\hline Clove & Syzygium aromaticum $\mathrm{L}$. & Chitosan & 268.5 & +22.4 & I & Antifungal & $\begin{array}{l}\text { Agriculture; } \\
\text { Food }\end{array}$ & $\begin{array}{l}\text { (Hasheminejad et al., } \\
\text { 2019) }\end{array}$ \\
\hline Pepper tree & Schinus molle L. & Chitosan & 516.9 & +40.2 & 26.6 & $\begin{array}{l}\text { Antifungal, anti- } \\
\text { aflatoxigenic }\end{array}$ & Medicine & $\begin{array}{ll}\text { (López-meneses et al., } \\
\text { 2018) }\end{array}$ \\
\hline
\end{tabular}




\begin{tabular}{|c|c|c|c|c|c|c|c|c|}
\hline \multirow[t]{2}{*}{ Cinnamon } & \multirow[t]{2}{*}{ Cinnamomum cassia persl. } & Chitosan & $80-100$ & $\begin{array}{l}-11.2 \text { to }- \\
22.4\end{array}$ & $\begin{array}{c}47.67- \\
55.64\end{array}$ & Antimicrobial & Food & (Liu et al., 2017) \\
\hline & & Chitosan & 215 & 1 & 1 & Antimicrobial & Food & (Hu et al., 2015) \\
\hline \multirow[t]{3}{*}{ Cardamon } & Elettaria cardamomum L. & Chitosan & $50-100$ & $>+50$ & $>90$ & Antimicrobial & Medicine & (Jamil et al., 2016) \\
\hline & Summer savory & Chitosan & $135.5-237.4$ & -9.68 to -21.12 & $35.1-40.7$ & Antioxidant, antimicrobial & Food & $\begin{array}{l}\text { (Feyzioglu and Tornuk, } \\
\text { 2016) }\end{array}$ \\
\hline & Carum copticum & Chitosan & l & 1 & 36.2 & Antioxidant, antimicrobial & $\begin{array}{l}\text { Cosmetics; } \\
\text { Medicine }\end{array}$ & $\begin{array}{l}\text { (Esmaeili and Asgari, } \\
\text { 2015) }\end{array}$ \\
\hline Tumeric & Curcuma longa $\mathrm{L}$. & Alginate + Chitosan & $<300$ & 1 & 71 & Anticancer & Medicine & (Natrajan et al., 2015) \\
\hline Lemongrass & & Alginate+Chitosan & $<300$ & 1 & 86.9 & Anticancer & Medicine & (Natrajan et al., 2015) \\
\hline Jasmine & Jasminum polyanthum L. & Gelatin+Gum arabic & & 1 & 1 & Flavor agent & Food; Textile & (Lv et al., 2014) \\
\hline Holy basil & Ocimum tenuiflorum $\mathrm{L}$. & Gelatin & $392.30 .10^{3}$ & 1 & 95.41 & Antioxidant & Medicine & $\begin{array}{ll}\text { Sutaphanit } & \text { and } \\
\text { Chitprasert, 2014) } & \\
\end{array}$ \\
\hline Pimenta & Pimenta dioica $\mathrm{L}$. & $\begin{array}{l}\text { Chitosan }+ \\
\text { k-carrageenan }\end{array}$ & I & 1 & / & Antioxidant, antifungal & Food & (Dima et al., 2014) \\
\hline Eugenol & / & Chitosan & $80-100$ & +16.2 to +33.5 & $1.1-20.2$ & Antioxidant & Food & $\begin{array}{l}\text { (Woranuch and Yoksan, } \\
\text { 2013) }\end{array}$ \\
\hline Poppy seed & Papaver somniferum L. & $\begin{array}{l}\text { Gelatin+arabic } \\
\text { gum }\end{array}$ & $<5000$ & 1 & 76.8 & $\begin{array}{l}\text { Anti-cancer, anti-tumor, } \\
\text { anti-diabetic }\end{array}$ & Medicine & (X. Yang et al., 2015) \\
\hline Vanilla & Vanilla planifolia L. & $\begin{array}{l}\text { Chitosan+arabic } \\
\text { gum }\end{array}$ & 7500 & 1 & 94.2 & Flavor agent & Food & (Yang et al., 2014) \\
\hline Olive & Olea europaea L. & $\begin{array}{l}\text { Gelatin }+ \\
\text { Sodium alginate }\end{array}$ & 1 & 1 & / & $\begin{array}{l}\text { Source of vitamins and fatty } \\
\text { acids }\end{array}$ & Medicine & (Devi et al., 2012) \\
\hline Peppermint & Mentha piperita L. & Gelatin+Arabic gum & 1 & 1 & 1 & 1 & 1 & (Dong et al., 2011) \\
\hline \multicolumn{9}{|c|}{ Spray drying method } \\
\hline Carvacrol & / & $\begin{array}{l}\text { Pectin+sodium } \\
\text { alginate }\end{array}$ & $2580-5300$ & / & / & Antioxidant, antimicrobial & / & (Sun et al., 2020) \\
\hline Black seed & Nigella sativa L. & $\begin{array}{l}\text { Sodium caseinate }+ \\
\text { maltodextrin DE10 }\end{array}$ & 18500 & 1 & 95.4 & Antioxidant & Medicine & (Mohammed et al., 2017) \\
\hline Eucalyptus & Eucalyptus staigeriana L. & Cashew gum & $27.7-432.6$ & +24.5 to +10.4 & $\begin{array}{c}24.89- \\
26.80\end{array}$ & Antimicrobial & Food & (Herculano et al., 2015) \\
\hline \multirow[t]{2}{*}{$\begin{array}{l}\text { Lippia } \\
\text { sidoides }\end{array}$} & Lippia sidoides L. & $\begin{array}{l}\text { Alginate:cashew } \\
\text { gum }\end{array}$ & 223- 399 & -30 to -36 & 50 & Larvicide & Agriculture & (De-Oliveira et al., 2014) \\
\hline & & $\begin{array}{l}\text { Chitosan+cashew } \\
\text { gum }\end{array}$ & $335-558$ & 1 & 70 & Larvicide & Agriculture & (Abreu et al., 2012) \\
\hline
\end{tabular}




\begin{tabular}{|c|c|c|c|c|c|c|c|c|}
\hline \multirow[t]{3}{*}{ Oregano } & \multirow[t]{3}{*}{ Origanum vulgare L. } & Inulin & $3000-4500$ & l & / & Antioxidant & Food & $\begin{array}{l}\text { (Beirão da costa et al., } \\
\text { 2013) }\end{array}$ \\
\hline & & Rice starch & $3000-4500$ & l & l & Antioxidant, antimicrobial & Food & $\begin{array}{l}\text { (Beirão da costa et al., } \\
\text { 2012) }\end{array}$ \\
\hline & & Gelatine/sucrose & $3000-4500$ & l & l & Antioxidant, antimicrobial & Food & $\begin{array}{l}\text { (Beirão da costa et al., } \\
\text { 2012) }\end{array}$ \\
\hline Soybean & Glycine $\max \mathrm{L}$. & $\begin{array}{l}\text { Kafirin + sodium } \\
\text { caseinate }\end{array}$ & 10450 & l & l & Source of PUFA & Food & (X. Bai et al., 2019) \\
\hline Almond & Prunus dulcis L. & Taro starch & $\begin{array}{c}1600- \\
31.1 .10^{3} \\
\end{array}$ & I & 37.5 & $\begin{array}{l}\text { Prevention of colon cancer } \\
\text { and cardiovascular diseases }\end{array}$ & Medicine & $\begin{array}{l}\text { (Hoyos-leyva et al., } \\
2019 \text { ) }\end{array}$ \\
\hline Peony & Paeonia lactiflora L. & $\begin{array}{l}\text { Whey } \\
\text { protein+Corn syrup } \\
+ \text { Lecithin }\end{array}$ & l & l & 93.6 & Source of PUFA & Food & (Wang et al., 2018) \\
\hline \multirow[t]{2}{*}{$\begin{array}{l}\text { Refined kenaf } \\
\text { seed }\end{array}$} & \multirow[t]{2}{*}{ Hibiscus cannabinus L. } & $\begin{array}{l}\beta \text {-cyclodextrin }+ \\
\text { gum arabic }+ \\
\text { sodium caseinate }\end{array}$ & l & l & / & Source of MUFA and PUFA & l & (Chew et al., 2020) \\
\hline & & $\begin{array}{l}\beta \text {-cyclodextrin }+ \\
\text { Arabic gum }\end{array}$ & $\begin{array}{l}(25.4-37.3) \\
10^{3}\end{array}$ & l & $90.0-95.3$ & Source of MUFA and PUFA & / & (Chew et al., 2018) \\
\hline \multirow[t]{2}{*}{ Chia seed } & \multirow[t]{2}{*}{ Salvia hispanica L. } & $\begin{array}{l}\text { Sodium caseinate } \\
+ \text { maltodextrin }+ \\
\text { chia protein rich } \\
\text { fraction }+ \text { chia } \\
\text { mucilage }\end{array}$ & / & l & $53.4-96.2$ & Source of omega 3 & Food & (Us-medina et al., 2018) \\
\hline & & $\begin{array}{l}\text { Maltodextrin }+ \\
\text { soy protein }\end{array}$ & $\begin{array}{l}4000- \\
10000\end{array}$ & I & $\approx 60$ & Source of omega 3 & Food & (González et al., 2016) \\
\hline Walnut & Juglans cinerea L. & $\begin{array}{l}\text { Skim milk } \\
\text { powder }+ \text { Tween } \\
80\end{array}$ & 1 & l & 1 & $\begin{array}{l}\text { Source of PUFA, } \\
\text { tocopherols and } \\
\text { phytosterols. }\end{array}$ & $\begin{array}{l}\text { Food; } \\
\text { Medicine }\end{array}$ & (Shamaei et al., 2017) \\
\hline Sunflower & Helianthus annuus L. & $\begin{array}{l}\text { Maltodextrin }+ \\
\text { HPMC }\end{array}$ & l & l & 79.43 & Source of PUFA & / & (Roccia et al., 2014) \\
\hline Linseed & Linum usitatissimum L. & $\begin{array}{l}\text { Alginate+ whey } \\
\text { protein }\end{array}$ & l & -44 & 84 & Source of omega 3 & Food & (Fioramonti et al., 2019) \\
\hline
\end{tabular}




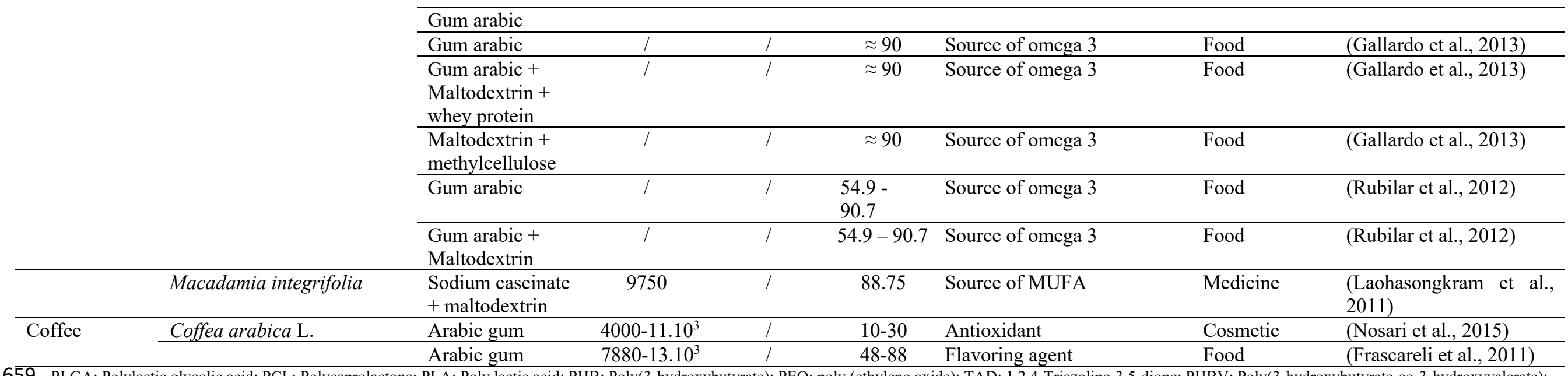

659 PLGA: Polylactic glycolic acid; PCL: Polycaprolactone; PLA: Poly lactic acid; PHB: Poly(3-hydroxybutyrate); PEO: poly (ethylene oxide); TAD: 1,2,4-Triazoline-3,5-dione; PHBV: Poly(3-hydroxybutyrate-co-3-hydroxyvalerate);

660 HPC: Hydroxypropylcelullose; HPMC: Hydroxypropylmethylcellulose; PVA: Poly vinyl alcohol; PUFA: Poly unsaturated fatty acids; MUFA: Mono unsaturated fatty acids. 


\subsection{Encapsulation in lipid based nanocarriers}

663

664

665

666

667

668

669

670

671

672

673

674

675

676

677

678

679

\subsubsection{Liposomes}

Liposomes were first developed for drug delivery purposes by Bangham et al. in 1965 (1965). Liposomes are vesicles formed by one or more lipid bilayers defining one or several aqueous compartments. They can be classified depending on their size and lamellarity to: i) small unilamellar vesicles (SUV) with a size between $20 \mathrm{~nm}$ and $100 \mathrm{~nm}$, ii) large unilamellar vesicles (LUV) with a size greater than $100 \mathrm{~nm}$ and iii) multilamellar vesicles (MLV) with a size greater than $0.5 \mu \mathrm{m}$, as demonstrated in Fig. 6 (El-Asbahani et al., 2015). Generally, the liposome bilayer consists of natural and/or synthetic phospholipids like phosphatidylcholline, phosphatidylethanolamine, phosphatidylserine, phosphatidylglycerol and phosphatidylinositol. Cholesterol may also be incorporated to the lipidic bilayer to reduce the permeability of watersoluble molecules through the membrane and improve its fluidity, and stability (Laouini et al., 2012). Due to the lipophilic character of the liposome bilayer, plant oils like essential or vegetable oils are highly entrapped to enhance their bioavailability and hurdle their physicochemical instability upon exposure to light, oxygen and temperature (El-Asbahani et al., 2015). Several methods have been used to develop liposomes containing plants oils, while the thin film hydration, solvent injection and heating methods were widely used in the last decade. 


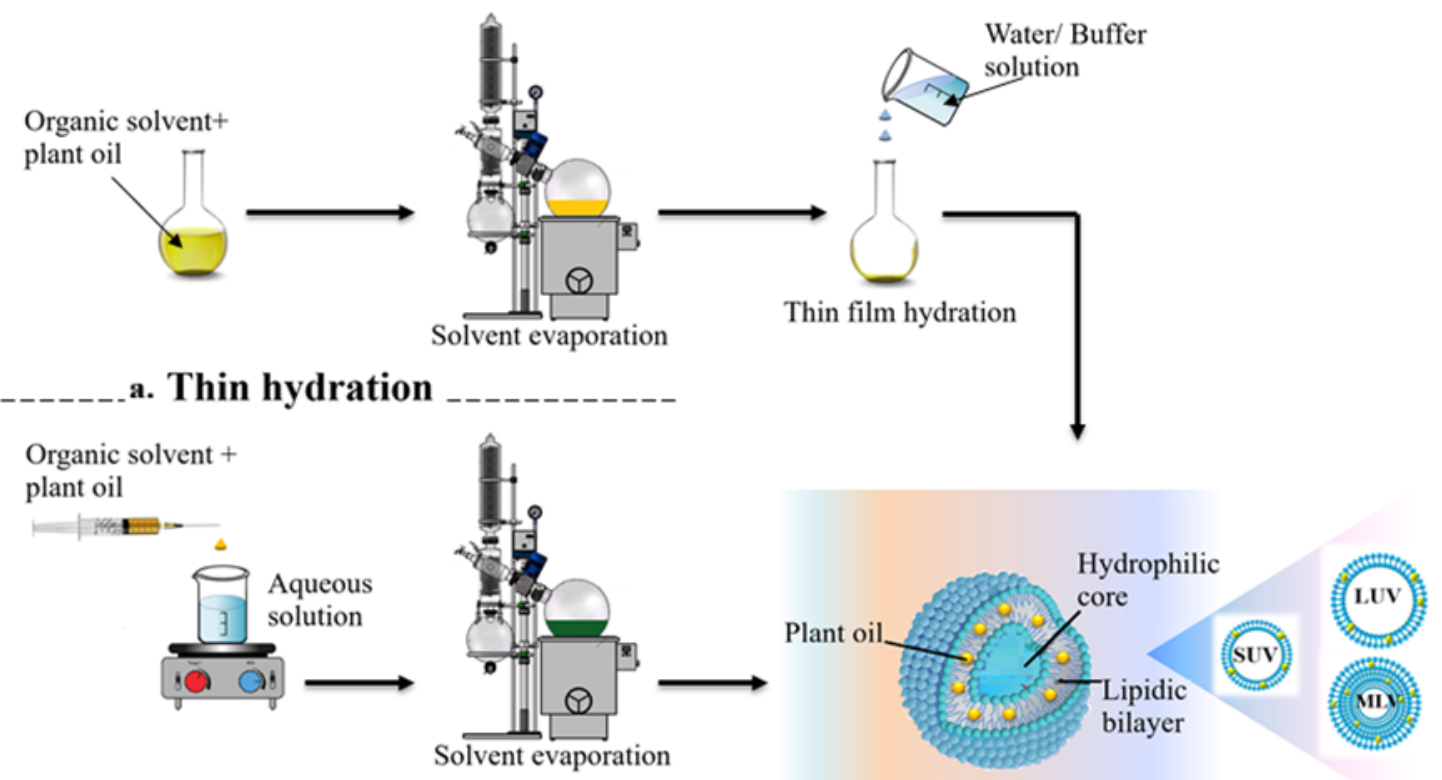

b. Solvent injection

Liposome

680

681

682

683

684

685

686

687

688

689

690

691

\subsubsection{Thin lipid film hydration}

Thin lipid film hydration or thin membrane hydration is the first process which was initially used for liposomes production (Bangham et al., 1965). A mixture of lipid ingredients was dispersed in organic solvent in a round-bottom flask. Subsequent evaporation of the organic solvent was performed using a rotary evaporator at reduced pressure. Finally, the hydration of the formed lipid film by water or buffer solution under agitation at temperature above the lipid transition temperature allows the formation of MLVs dispersion (Fig.6.a) (Laouini et al., 2012). Liposome size reduction techniques, such as sonication or extrusion were applied to ensure size reduction and particles uniformity (Patil and Jadhav, 2014). Thin hydration method was extensively used to develop plant oils-loaded liposomes, as illustrated in Table 2. 

a small average diameter with a spherical shape. Cui et al. (2015) revealed that clove EO loaded-

694

695

696

697

698

699

700

701

702

703

704

705

706

707

708

709

710

711

712

713

714

715

716 liposomes had small size of $149.2 \mathrm{~nm}$, a high zeta potential $(-24.5 \mathrm{mV})$ with an entrapment efficiency of $20.41 \%$, for $5.0 \mathrm{mg} / \mathrm{mL}$ clove oil concentration. Accordingly, Cui et al. (2016) used the same method to limit the volatility of salvia EO by encapsulation in soy lecithin/cholesterol based liposomes. Atomic force microscopy images showed that the obtained liposomes were spherical in shape, uniformly dispersed without any aggregation with an average size ranging from 100 to $700 \mathrm{~nm}$. Furthermore, bergamot EO and its fraction (bergapten) were entrapped in phospholipids based-liposomes using thin lipid hydration process (Celia et al., 2013). The prepared liposomes had an average size of 188.25 and 185.14 $\mathrm{nm}$, a zeta potential of -2.95 and $-2.57 \mathrm{mV}$ and a high EE\% of 75.0 and $77.0 \%$ for bergamot EO and its fraction, respectively (Celia et al., 2013).

Several authors have compared the size of empty liposomes to EO-loaded liposomes prepared by thin hydration method. Ge and his coworker (2016) revealed a significant difference in the average size between empty- and Melaleuca alternifolia EO loaded-liposomes. Empty liposomes had an average size of $142 \mathrm{~nm}$, while loaded liposomes were smaller with size around $75 \mathrm{~nm}$. Similar results were found byYoshida et al. (Yoshida et al., 2010). Risaliti et al. (2019) attributed this to the high cohesion package of oil components to the bilayer constituents. On the other hand, Detoni et al. (2012) reported no difference in liposomes size between empty and Zanthoxylum tingoassuiba EO-loading MLVs and SUVs, respectively. Moreover, nerolidol- and cyclodextrin/nerolidol-loaded liposomes prepared by thin lipid hydration method showed larger mean particle size than blank liposomes (Azzi et al., 2018). Cui et al. studying the encapsulation of curry EO in liposomes, revealed that the oil concentration had a positive effect on vesicles size (Cui et al., 2017a). For instance, the vesicles size was increased from 103.86 to $257.36 \mathrm{~nm}$ as a consequence of an increase in the oil 
concentration from 2.0 to $6.0 \mathrm{mg} / \mathrm{ml}$. Similar behavior was pointed for the encapsulation of cinnamon EO in soy lecithin/cholesterol based liposomes prepared by thin hydration method (Cui et al., 2016a). Accompanying the increase of cinnamon oil concentration from 3.0 to 6.0 $\mathrm{mg} / \mathrm{mL}$, the vesicles size was progressively increased from 133 to $157 \mathrm{~nm}$. Similar results were also reported when increasing cardamom EO (Nahr et al., 2019), thyme EO (Cui et al., 2017b) and chrysanthemum EO (Lin et al., 2019b).

The liposome size was not only affected by the EO concentration. In fact, Nazari et al., (2019) developing garlic EO nanophytosomes by thin hydration method, investigated the effect of the preparation method. For instance, nanophytosomes were a novel lipid based vesicular delivery systems where stable hydrogen bonds are formed between the phosphatidylcholine molecules and nutraceuticals leading to the formation of stable complex (Ghanbarzadeh et al., 2016). In this study, MLVs reduction size was performed using three different types of methods: sonication, homogenization and the combination of sonication and homogenization. Results showed that the combination of two methods produced the smallest liposomes $(115 \mathrm{~nm})$ with transparent suspension view. Homogenization produced larger particles than probe sonication method and the average size was around 161 and $135 \mathrm{~nm}$, respectively. Considering the zeta potential, all the prepared phytosomes had lower values $(-12.36$ to $-3.86 \mathrm{mV})$ than the expected and reported values for soy bean phosphatidylcholine made nanovesicular systems (around -26 $\mathrm{mV}$ ). This was linked to the interaction between the positively charged allicin (the main component of garlic EO) and the negatively charged phosphate group of phosphatidylcholine (Nazari et al., 2019). In another work study, Salari and his colleague (2019) developing rosemary EO loaded- L- $\alpha$-phosphatidylethanolamine dioleoyl : cholesteryl hemisuccinate liposomes found that sonication method produced smaller liposome than filtration method. The average sizes were 142.5 and $437.2 \mathrm{~nm}$, respectively. Results showed also that increasing the 
lipid ratio of L- $\alpha$-phosphatidylethanolamine dioleoyl to cholesteryl hemisuccinate from 3:2 to 7:3 resulted in much larger liposomes with more negative zeta potential.

As there are several types of phospholipids, it is reliable to alter the size, charge and $\mathrm{EE} \%$, upon variation of type or addition of new ingredients to the lipid mixture. In this approach, the effect of lipid composition on the EE\% of Anethum graveolens EO-loaded liposomes was investigated by Ortan et. al (2009). Liposomes with different lipids; fresh egg yolk, dimiristroylphosphatidyl choline, dipalmitoylphosphatidyl choline, dimiristroylphosphatidyl glycerol and dioleoylphosphatidyl choline, were prepared by thin hydration method. Results showed that oil entrapment varied in this way: dimiristroylphosphatidyl glycerol $(55.2 \%)<$ dimiristroylphosphatidyl choline $(58.9 \%)<$ dioleoylphosphatidyl choline $(77 \%)<$ dipalmitoylphosphatidyl choline $(97 \%)<$ fresh egg yolk (98\%). Although dipalmitoylphosphatidyl choline showed good entrapment efficiency, its use was difficult as it required high temperature due to its high transition temperature. The authors related the low values of $\mathrm{EE} \%$ of dioleoylphosphatidyl choline, dimiristroylphosphatidyl glycerol and dimiristroylphosphatidyl choline to their unsaturation.

In addition to the factors mentioned above, other parameters may affect the physicochemical properties of liposomes prepared by thin hydration process. In this context, Plackett-Burman design was applied in order to investigate the effect of the mass ratio of phosphatidylcholine and cholesterol, tree tea EO concentration, tween 80 concentration, hydration medium $\mathrm{pH}$, temperature, sonication time and power on physicochemical properties of tree tea EO-loaded liposomes (Ge \& Ge, 2015). Results revealed that only three factors (the ratio of phosphatidylcholine and cholesterol, EO concentration and tween 80) exhibited a significant impact on the entrapment efficiency of tree tea EO. Increasing the lipid ratio with EO amount and decreasing tween 80 had a positive effect on EO encapsulation efficiency. Good $\mathrm{EE} \%(97.18 \%)$ was obtained with the following parameters: the mass ratio of fresh egg yolk 
and cholesterol (5:51); EO concentration (1.21\%); tween 80 concentration $(0.79 \%)$; $\mathrm{pH} 7.4$; temperature $\left(55^{\circ} \mathrm{C}\right)$; sonication time $(15 \mathrm{~min})$ and sonication power $(300 \mathrm{w})(\mathrm{Ge} \& \mathrm{Ge}, 2015)$.

Regarding the stability of EO loaded in liposomes, Liolios et al. (2009) investigated the oxidative stability of carvacrol and thymol isolated from Origanum dictamnus L. EO and their mixtures, before and after their encapsulation in egg L- $\alpha$ phosphatidylcholine/cholesterol-based liposomes by differential scanning calorimetry analysis. Results showed the appearance of exothermic peaks related to the auto-oxidation process of the samples. The onset temperatures at which the auto-oxidation process starts were in the following order: Carvacrol $\left(258^{\circ} \mathrm{C}\right)<$ Thymol $\left(273^{\circ} \mathrm{C}\right)<$ Carvacrol : Thymol $\left(302^{\circ} \mathrm{C}\right)<$ Empty liposomes $\left(362^{\circ} \mathrm{C}\right)<$ Liposomes +Carvacrol : Thymol $\left(392^{\circ} \mathrm{C}\right)$. One can conclude that carvacrol and thymol presented better antioxidant action when encapsulated than when in pure form. The antioxidant activity of empty liposomes is lower than that of oil loaded- liposome, suggesting that the liposome membranes were stabilized by the link of the lipophilic compounds with lipid bilayers (Liolios et al., 2009).

Beyond EO, liposomes can potentially enable the encapsulation of $\mathrm{VO}$ and their derivatives, as illustrated in Table 3. Recently, numerous studies have been investigated to encapsulate fatty acids in liposomes. Among the several polyunsaturated fatty acids (PUFAs), dietary $\omega 3$ like eicosapentaenoic and docosahexaenoic acids have been extensively investigated for their beneficial effects (Hadian, 2016). Alaarg et al. (2016) developed docosahexaenoic acid- loaded liposomes by thin hydration method. The obtained liposomes exhibited small average diameter around $100 \mathrm{~nm}$, narrow size distributions, negative zeta potential $(15.7 \pm$ $2.5 \mathrm{mv}$ ) and high EE\% of $81.35 \%$. Moreover, eicosapentaenoic and docosahexaenoic acids were entrapped in nanoliposomes (i.e. nanoscale lipid vesicles) developed by thin hydration followed by either extrusion ultrasonic irradiation; bath sonication; probe sonication; or combined probe and bath sonication (Hadian et al., 2014). Results showed that probe sonication 
produced liposomes with higher EE\% for both investigated fatty acids. Results displayed also that $\mathrm{EE} \%$ differs form a $\mathrm{VO}$ to another for liposomes prepared in the same experimental conditions. Indeed, the EE\% value was higher for docosahexaenoic acid than for eicosapentaenoic acid. This was ascribed to the fact that docosahexaenoic acid may change the physical properties of 1,2-dipalmitoyl-sn-glycero-3-phosphocholine bilayer, as it would provide a tightly pack conformation because of the coiled configuration (Hadian et al., 2014).

In overall, thin hydration method is widely employed to develop plant oils loaded liposomes due to its simplicity. Several phospholipids are used in the literature including soybean phosphatidylcholine (Ge \& Ge, 2016; Ge \& Ge, 2015; Khatibi et al., 2017; Nazari et al., 2019; Rasti et al., 2012; Q. Wang et al., 2015), dipalmitoyl phosphatidylcholine (Detoni et al., 2012), egg phosphatidylcholine (Saffari et al., 2016), phospholipon ${ }^{\circledR} 90 \mathrm{G}$ (Risaliti et al., 2019). Cholesterol is the most used fluidifying agent (Alikhani-Koupaei, 2015; H. Cui, Yuan, et al., 2017; Y. Cui et al., 2010; Y. Ge \& Ge, 2016; Ge \& Ge, 2015; Khatibi et al., 2017; Lin et al., 2018; Lin, Chen, et al., 2019; Q. Wang et al., 2015); in other cases, tween 80 (Y. Ge et al., 2019; Y. Ge \& Ge, 2016; Ge \& Ge, 2015; Lin, Chen, et al., 2019) and poly vinyl pyrrolidone (Cui et al., 2017a, 2017b, 2016a, 2016b, 2015; Lin et al., 2019b, 2018) were incorporated as surfactants.

Using this method, heterogeneous vesicles of large sizes may be produced which requires additional steps like sonication and extrusion to reduce and homogenize the vesicle size and thus, the process consumes more time. Besides, thin hydration method is difficult to scale up and requires organic solvents which in turn represent the major drawback. In fact, their residues may remain in the final liposome preparation resulting in potential toxicity and reduced stability of the lipid vesicles (Cortesi et al., 1999; Vemuri and Rhodes, 1995).

\subsubsection{Solvent injection}



the dissolution of the lipid into an organic phase such as ethanol or ether, followed by the injection of the lipid solution into aqueous solution resulting in liposomes dispersion (Laouini et al., 2012). After that, the organic solvent was evaporated under reduced pressure (Fig. 6.b). This technique is widely used for plant oil encapsulation, as demonstrated in Table 2. The solvent injection' main feature is that narrow size distribution of submicron liposomes (under $100 \mathrm{~nm}$ ) could be produced without extrusion or sonication (Stano et al., 2004). Moreover, compared with thin hydration method, the ethanol injection technique was found to be scalable. In fact, clove EO-liposomes were successfully scaled-up using a membrane contactor $(600 \mathrm{ml})$ and a pilot plant (3L) (Sebaaly et al., 2015a). Furthermore, various eugenol- and clove EOliposomes were prepared at laboratory (ethanol injection) and large scale (membrane contactor): free hydroxypropyl- $\beta$-cyclodextrin loaded liposomes; drug in hydroxypropyl- $\beta$ cyclodextrin in liposomes (DCL) and $\mathrm{DCL}_{2}$ obtained by double loading technique, where the drug is added in the organic phase and the inclusion complex in the aqueous phase (Sebaaly et al., 2016a). Results showed that eugenol and clove EO loaded DCL and DCL2 developed at large scale had a mean size similar to those obtained by laboratory scale. Besides, Eugenol and clove EO loaded DCL and $\mathrm{DCL}_{2}$ had a mean particle size significantly smaller than that of free hydroxypropyl- $\beta$-cyclodextrin liposomes containing either eugenol or clove EO at both laboratory and large scales. This was explained by the complete incorporation of the aromatic cycle of eugenol inside the hydrophobic cavity of hydroxypropyl- $\beta$-cyclodextrin, resulting in limit interaction between eugenol and lipidic bilayers. Regarding the polydispersity index and zeta potential, no difference was assessed between all the tested liposomes. composition and operating conditions on physicochemical properties of liposomes prepared by 
The effect of oil concentration, injection rate, stirring speed on the average diameter of black seed oil-liposomes was studied (Rushmi et al., 2017). Results showed that liposomes decrease in size from 520.70 to $51.48 \mathrm{~nm}$ after oil incorporation. As the concentration of oil increases

843 from 0.17 to $0.67 \% \mathrm{v} / \mathrm{v}$, liposomes size reduced significantly due to the antioxidant activity of the oil which could decrease phospholipid bilayer oxidation, preventing liposomes growth; while, no change in average size of liposomes was noticed upon further increase in oil $(0.67 \%$ $\mathrm{v} / \mathrm{v}$ ). Thus, the oil concentration of $0.67 \% \mathrm{v} / \mathrm{v}$ was found to be optimum for its antioxidant activity. Results showed also that small sized liposomes were formed under $1 \mathrm{~mL} / \mathrm{min}$ injection rate and $2200 \mathrm{rpm}$ stirring speed. Low injection rates result in faster lipids oxidation while high rates may cause a variable distribution of particle size. Similar results were already reported (Sebaaly et al., 2016b). In regards of the phospholipid:cholesterol ratio effect, the EE\% was improved from 39.8 to $49.9 \%$ after increasing the ratio of egg extract to cholesterol from 3:1 to 3:2 (Rushmi et al., 2017). This was related to the fact that cholesterol may reduce the flexibility and mobility of lipidic layer which in turn lead to enhance liposomes stability. Moreover, another study performed by Hammoud et al. (2019) spotlighted that the type of encapsulated EO affects significantly the phospholipid and cholesterol incorporation rates into the lipid layer. Lower phospholipids incorporation rates were observed when encapsulating isoeugenol, pulegone or thymol. While, high cholesterol incorporation rates were measured in presence of estragole or terpineole. Additionally, the oil entrapment efficiency was found to be affected by the chemical structure of encapsulated EO. In fact, EO bearing hydroxyl groups in their structure are more greatly to fluidize the lipid layer than those without a hydroxyl group leading to higher EE\%. The authors concluded that EO bearing hydroxyl groups had low aqueous solubility with low Henry constant value and higher liposomal EE\% (Hammoud et al., 2019). 

(2016) investigated the stability of galanga EO-loaded liposomes at low temperature $\left(4^{\circ} \mathrm{C}\right)$ and dark conditions and results revealed minor change in mean particle size and polydispersity index. Furthermore, the photostability of eugenol in aqueous solution and in liposome formulations (Phospholipon 80H, Phospholipon 90H and Lipoid S100) was investigated under UV light irradiation for 96hours (Sebaaly et al., 2015b). Results revealed that liposomes formulations protect eugenol more than aqueous solutions. The percentages of remaining eugenol were 58, 82, 91 and 95\% for aqueous solution, Phospholipon $80 \mathrm{H}-$, , 90H- and S100liposomes, respectively. The highest value of remaining eugenol for lipoid S100 was related to the flexibility of the membrane resulting in a deep insertion of eugenol into the lipid bilayer leading to better protection from any UV light effect (Sebaaly et al., 2015b). been published during the last decade regarding the encapsulation of VO. Recently, Huang et al. (2020) developed co-loaded linseed oil with quercetin in liposomes with the aim of enhancing their solubility and stability. The produced liposomes owned a spherical shape with a small average size $(262.2 \mathrm{~nm})$. In 2019, Bai and his coworkers investigated the effect of different coix seed oil: $\beta$-carotene ratios on the physiochemical properties, stability and antioxidant activity of coix seed oil : $\beta$-carotene co-loaded-liposomes (C. Bai et al., 2019). Results showed that by increasing coix seed oil, the EE\% of $\beta$-carotene in the liposomes decreased. The values of EE\% for 1:1, 1:5, and 1:10, $\beta$-carotene:coix seed oil liposomes were $83.8,81.3$, and $80.8 \%$, respectively, which were slightly lower than that of liposomes containing $\beta$-carotene alone $(86.0 \%)$. This was ascribed to the ability of coix seed oil to compete for the available hydrophobic domains within the phospholipid bilayers. 
reduction. According to the previous work studies, phospholipon ${ }^{\circledR} 90 \mathrm{H}$ (Sebaaly et al., 2016a, 2016b), phospholipon ${ }^{\circledR} 80 \mathrm{H}$ (Sebaaly et al., 2016b), lipoid ${ }^{\circledR} \mathrm{S} 100$ (Hammoud et al., 2019; Sebaaly et al., 2016b) and egg phospholipids (C. Bai et al., 2019; Rushmi et al., 2017) are widely used as bilayer forming lipids. Ethanol injection method suffers from several drawbacks including continuous exposure of plant oils to high temperature and organic solvents which may affect both the safety and stability of the liposomes (Nkanga et al., 2019).

\subsubsection{Heating method}

The heating method, called also Mozafari method, was first developed in 2005. It is known to be the most attractive method for liposomes preparation due to its organic solvent/detergents free characteristics (Mozafari \& Mortazavi, 2005). In this technique, lipids are hydrated in the presence of hydrating agent (glycerin or propylene glycol) and heated at 40 $120^{\circ} \mathrm{C}$ (at the temperature which is above the transition temperature of the phospholipids) depending on the properties of the ingredients, the presence or absence of cholesterol, and the type of material to be entrapped (Fig.6.c) (Mozafari et al., 2008).

Currently, Mozafari method is widely used to encapsulate VO and polyunsaturated fatty acids (Table 2). When compared to thin hydration process, Mozafari method produce liposomes with higher stability. Rsati et al. (2012) investigated the difference between the oxidative stability of liposomes (before sonication) and nanoliposomes (after sonication) produced by Mozafari and conventional thin hydration techniques. For both methods, polyunsaturated fatty acids entrapment efficiency values of nanoliposomes were higher than those of liposomes. Authors related this result to the fact that size reduction increases the surface area of the liposomes resulting in increasing the contact and bond between the fatty acids and phospholipids in the bilayers. Moreover, liposomes prepared by Mozafari process showed higher physical stability than those prepared by conventional method (Rasti et al., 2012). In 
another work study, the effect of formulation strategies on phytosterol, extracted from canola oil, loaded-liposomes was investigated (Poudel et al., 2019). The results showed that Mozafari method produce liposomes with high average size $(260 \mathrm{~nm})$ as compared to those obtained by thin film hydration homogenization $(186 \mathrm{~nm})$ and thin film hydration ultrasonication $(196 \mathrm{~nm})$.

This result was attributed to the high shear force and cavitation involved in size reduction during the ultrasonication and homogenization process; while in Mozafari method, less intense magnetic stirring will probably yield to larger particles. In term of polydispersity index and zeta potential, no difference was found for all the formulations (Poudel et al., 2019).

Like the methods discussed above, Mozafari method was affected by several operating conditions. In 2013, Rasti et al. investigated the effect of shear rate, mixing and sonication times on colloidal properties of polyunsaturated fatty acids (docosahexaenoic acid and eicosapentaenoic acid) nanoliposomes (Rasti et al., 2013). In their study, response surface methodology was applied to predict the optimum levels of liposome preparation condition producing maximum EE\% and minimum average size. According to ANOVA analysis, all the independent variables and their interactions were found significant; while, the main significant effect on liposome size and $\mathrm{EE} \%$ was found to be the shear rate. After optimizing the operating 2013).

Besides using heating method to encapsulate VO in liposomes, no report was found regarding the encapsulation of EO maybe due to their high sensitivity and volatility upon exposure at high temperature. Thus, this technique is not suitable for thermosensitive bioactive agents. In closing, Mozafari method showed to be a fast, simple, scalable, and non-toxic technique for liposome preparation with high EE\%. In addition, the obtained liposomes can be 937 freely used without any further sterilization treatments as they were prepared under heating 
938 conditions which in turn could minimize both formulation timing and complexity (Nkanga et 939 al., 2019). 
940 Table 2. Preparation methods for plant oils encapsulation in liposomes with their fine applications.

\begin{tabular}{|c|c|c|c|c|c|c|c|c|}
\hline \multirow{2}{*}{$\begin{array}{l}\text { Encapsulated } \\
\text { oil }\end{array}$} & \multirow[t]{2}{*}{ Plant (origin) } & \multirow{2}{*}{$\begin{array}{l}\text { Phospholipid } \\
\text { used }\end{array}$} & \multicolumn{3}{|c|}{ Physicochemical properties } & \multirow[t]{2}{*}{ Biological properties } & \multirow[t]{2}{*}{ Application } & \multirow[t]{2}{*}{ Ref. } \\
\hline & & & Size (nm) & Z.pot (mV) & EE (\%) & & & \\
\hline \multicolumn{9}{|c|}{ Thin hydration method } \\
\hline Myristica & $\begin{array}{l}\text { Myristica fragrans } \\
\text { Houtt. }\end{array}$ & $\begin{array}{l}\text { Soybean } \\
\text { phospholipid }\end{array}$ & / & 1 & 1 & Antimicrobial, antioxidant & Food & (Zhu et al., 2020) \\
\hline $\begin{array}{l}\text { Ferula } \\
\text { gummosa }\end{array}$ & $\begin{array}{l}\text { Ferula gummosa } \\
\text { Boiss. }\end{array}$ & Phospholipid & $74.3-99.9$ & l & l & Antibacterial & & (Najafi et al., 2020) \\
\hline Laurel & $\begin{array}{l}\text { Laurelia } \\
\text { sempervirens Tul. }\end{array}$ & $\mathrm{L}-\alpha-\mathrm{PCH}$ & 200 & / & / & Antibacterial, antioxidant & Food & (Wu et al., 2020) \\
\hline Cardamon & $\begin{array}{l}\text { Elettaria } \\
\text { cardamomum } \mathrm{L} .\end{array}$ & Phospholipid & $71.8-147.9$ & $\begin{array}{l}-17.4 \text { to }- \\
10.7\end{array}$ & $<60$ & Antimicrobial, antioxidant & Food & (Nahr et al., 2019) \\
\hline Chrysanthemum & $\begin{array}{l}\text { Chrysanthemum } \\
\text { pacificum } \mathrm{L} .\end{array}$ & $\begin{array}{l}\text { Soybean } \\
\text { phospholipid }\end{array}$ & 132.4 & -37.6 & 42.7 & Antibacterial & Food & (Lin et al., 2019b) \\
\hline \multirow[t]{2}{*}{ Sage } & Salvia triloba $\mathrm{L}$. & $\begin{array}{l}\text { Phospholipon } \\
90 \mathrm{G}\end{array}$ & $\approx 200$ & -20 to -35 & 57 & $\begin{array}{l}\text { Antioxidant, antibacterial } \\
\text { Anti-inflammatory }\end{array}$ & Medicine & (Risaliti et al., 2019) \\
\hline & & $\begin{array}{l}\text { Soybean } \\
\text { phospholipid }\end{array}$ & 188.5 & -48.38 & 46.5 & Antibacterial & Food & (Cui et al., 2016b) \\
\hline \multirow[t]{3}{*}{ Rosemary } & $\begin{array}{l}\text { Rosmarinus } \\
\text { officinalis L. }\end{array}$ & $\begin{array}{l}\text { L- } \alpha \text {-PEA } \\
\text { dioleoyl }\end{array}$ & 79 & -2.77 & 45 & Anticancer & Medicine & (Salari and Salari, 2019) \\
\hline & & $\begin{array}{l}\text { Phospholipon } \\
90 \mathrm{G}\end{array}$ & $\approx 200$ & -20 to -35 & 65 & $\begin{array}{l}\text { Antioxidant; antibacterial } \\
\text { Anti-inflammatory }\end{array}$ & Medicine & (Risaliti et al., 2019) \\
\hline & & $\mathrm{PCH}$ & / & 1 & I & Preservative & Food & (Alikhani-Koupaei, 2015) \\
\hline Garlic & Allium sativum L. & Soybean PCH & 115 & -12.36 & 86.00 & Antibacterial, antioxidant & Food & (Nazari et al., 2019) \\
\hline \multirow[t]{3}{*}{ Tea tree } & Melaleuca & Soybean PCH & $50-100$ & 1 & 98.49 & Antimicrobial & / & (Ge et al., 2019) \\
\hline & alternifolia Cheel. & Soybean PCH & 58 & 1 & 97.18 & Antimicrobial & / & (Ge \& Ge, 2015) \\
\hline & & Soybean $\mathrm{PCH}$ & 75 & -7.45 & 96.08 & Antimicrobial & 1 & (Ge and $\mathrm{Ge}, 2016)$ \\
\hline Ajwain & $\begin{array}{l}\text { Trachyspermum } \\
\text { copticum L. }\end{array}$ & Soybean $\mathrm{PCH}$ & 170.8 & 1 & 85.9 & Antimicrobial & Cosmetics & (Tabatabai et al., 2018) \\
\hline \multirow[t]{2}{*}{ Thyme } & Thymus vulgaris L. & $\begin{array}{l}\text { Soybean } \\
\text { phospholipid }\end{array}$ & 182.60 & -40.90 & 35.35 & Antibacterial & Food & (Lin et al., 2018) \\
\hline & & $\begin{array}{l}\text { Soybean } \\
\text { phospholipid }\end{array}$ & 208.1 & -52.2 & 38.16 & Antibacterial & Food & (Cui et al., 2017b) \\
\hline \multirow[t]{2}{*}{ Eucalyptus } & $\begin{array}{l}\text { Eucalyptus globulus } \\
\text { L'Hér. }\end{array}$ & $\begin{array}{l}\text { Soybean } \\
\text { phospholipid }\end{array}$ & / & / & 97.35 & Antimicrobial & Medicine & (Tang and Ge, 2017) \\
\hline & $\begin{array}{l}\text { Eucalyptus } \\
\text { citriodora } \mathrm{L} .\end{array}$ & $\begin{array}{l}\text { Soybean } \\
\text { phospholipid }\end{array}$ & 266.56 & -33.73 & 22.47 & Antimicrobial & / & (Lin et al., 2019a) \\
\hline
\end{tabular}




\begin{tabular}{|c|c|c|c|c|c|c|c|c|}
\hline Cineole & / & Egg yolk PCH & 128 & 6.8 & 67.7 & Permeation enhancers & Medicine & (Saffari et al., 2016) \\
\hline Thymol & l & Soybean PCH & 270.20 & +39.99 & / & Antibacterial & Food & (Engel et al., 2017) \\
\hline Carvacrol & & $\mathrm{L}-\alpha-\mathrm{PCH}$ & 1 & 1 & 1 & Antimicrobial & Food & (Liolios et al., 2009) \\
\hline $\begin{array}{l}\text { Zataria } \\
\text { multiflora }\end{array}$ & $\begin{array}{l}\text { Zataria } \\
\text { Boiss. }\end{array}$ & Soybean PCH & 99.9 & l & 18.4 & Antimicrobial & $\begin{array}{l}\text { Food } \\
\text { Cosmetics }\end{array}$ & (Khatibi et al., 2017) \\
\hline Curry & $\begin{array}{l}\text { Helichrysum } \\
\text { italicum } \mathrm{G} .\end{array}$ & $\begin{array}{l}\text { Soybean } \\
\text { phospholipid }\end{array}$ & 196.6 & -31.1 & 56.3 & Antibacterial & Food & (Cui et al., 2017a) \\
\hline Limonene & / & Egg yolk PCH & 102 & 6.1 & 71.0 & Permeation enhancers & Medicine & (Saffari et al., 2016) \\
\hline Cinnamon & $\begin{array}{l}\text { Cinnamomum } \\
\text { cassia persl. }\end{array}$ & $\begin{array}{l}\text { Soybean } \\
\text { phospholipid }\end{array}$ & 144.3 & -54.7 & 29.2 & Antibacterial & Medicine & (Cui et al., 2016a) \\
\hline Clove & $\begin{array}{l}\text { Syzygium } \\
\text { aromaticum } \mathrm{L} .\end{array}$ & $\begin{array}{l}\text { Soybean } \\
\text { phospholipid }\end{array}$ & 149 & -24.5 & 20.4 & Antibacterial & Food & (Cui et al., 2015) \\
\hline Bergamot & Monarda didyma $\mathrm{L}$. & Phospholipid & 185.1 & -2.95 & 75.0 & Anticancer & Medicine & (Celia et al., 2013) \\
\hline Bergapten & 1 & Phospholipid & 185.1 & -2.95 & 75.0 & Anticancer & Medicine & (Celia et al., 2013) \\
\hline $\begin{array}{l}\text { Macassar } \\
\text { kernels }\end{array}$ & Brucea javanica L. & Phospholipid & 108.2 & -57.0 & 92.4 & Anticancer & Medicine & (Cui et al., 2010) \\
\hline Dill & $\begin{array}{l}\text { Anethum graveolens } \\
\text { L. }\end{array}$ & $\mathrm{PCH}$ & / & / & 98 & Antimicrobial & / & (Ortan et al., 2009) \\
\hline $\begin{array}{l}\text { Zanthoxylum } \\
\text { tingoassuiba }\end{array}$ & $\begin{array}{l}\text { Zanthoxylum } \\
\text { tingoassuiba } \mathrm{L} .\end{array}$ & $\begin{array}{l}\text { 1,2-Dipalmitoyl } \\
\text { PCH }\end{array}$ & $210-3630$ & / & $68.5-79.2$ & Anticancer & Medicine & (Detoni et al., 2012) \\
\hline Sterol & / & $\mathrm{PCH}$ & $<200$ & -9 to -14 & $>89$ & Antioxidant & Food & (Poudel et al., 2019) \\
\hline DHA & l & 1,2-Dipalmitoyl & 99 & -15.7 & 81.4 & Anticancer; anti-inflammatory & Medicine & (Alaarg et al., 2016) \\
\hline & & $\mathrm{PCH}$ & 1 & l & 38.6 & Anticancer; anti-inflammatory & Medicine & (Hadian et al., 2014) \\
\hline EPA & l & $\begin{array}{l}\text { 1,2-Dipalmitoyl } \\
\text { PCH }\end{array}$ & / & / & 56.9 & Anticancer; anti-inflammatory & Medicine & (Hadian et al., 2014) \\
\hline $\mathrm{EPA}+\mathrm{DHA}$ & / & $\begin{array}{l}\text { Soybean } \\
\text { phospholipid }\end{array}$ & $<100$ & -48.4 & / & Anticancer; anti-inflammatory & Medicine & (Rasti et al., 2012) \\
\hline \multicolumn{9}{|c|}{ Solvent injection method } \\
\hline Anethole & 1 & Lipoid S100 & 1 & / & / & Antibacterial & / & (Auezova et al., 2020) \\
\hline Cinnamaldehyde & l & $\begin{array}{l}\text { Egg yolk } \\
\text { phospholipid }\end{array}$ & $1000-2500$ & / & / & Antimicrobial & / & (Wang et al., 2019) \\
\hline Isoeugenol & / & Lipoid S100 & / & / & 96.4 & / & / & (Hammoud et al., 2019) \\
\hline Pulegone & l & Lipoid S100 & / & / & 90.5 & / & / & (Hammoud et al., 2019) \\
\hline Terpineol & l & Lipoid S100 & l & l & 73.7 & / & / & (Hammoud et al., 2019) \\
\hline Thymol & / & Lipoid S100 & / & / & 79.1 & / & / & (Hammoud et al., 2019) \\
\hline Estragole & l & Lipoid S100 & / & / & 90.9 & / & l & (Hammoud et al., 2019) \\
\hline Eucalyptol & 1 & Lipoid S100 & 1 & l & 61.9 & / & 1 & (Hammoud et al., 2019) \\
\hline Black seed & Nigella sativa L. & Egg yolk PCH & $50-900$ & l & $34-87$ & Analgesic & Medicine & (Rushmi et al., 2017) \\
\hline
\end{tabular}




\begin{tabular}{|c|c|c|c|c|c|c|c|c|}
\hline Garlic & Allium sativum L. & Phospholipid & 131.7 & / & 64.3 & Antimicrobial & Food & (Zabihi et al., 2017) \\
\hline \multirow[t]{2}{*}{ Galangal } & Alpinia officinarum & Phospholipid & 61.9 & -16 & 1 & Antimicrobial; antioxidant & Medicine & (Liu et al., 2016) \\
\hline & & Phospholipid & 125.6 & -35.5 & 35.6 & Antimicrobial; antioxidant & Medicine & (Cao et al., 2016) \\
\hline \multirow[t]{2}{*}{ Clove } & $\begin{array}{l}\text { Syzygium } \\
\text { aromaticum L. }\end{array}$ & $\begin{array}{l}\text { Phospholipon } \\
90 \mathrm{H}\end{array}$ & / & 1 & $54.2-59.7$ & Anti-inflammatory & Medicine & (Sebaaly et al., 2016a) \\
\hline & & Phospholipid & / & l & / & Anti-inflammatory & Medicine & (Sebaaly et al., 2015b) \\
\hline \multirow[t]{4}{*}{ Eugenol } & / & Lipoid S100 & 74.6 & l & 24.2 & Anti-cancer & Medicine & (Mishra et al., 2019) \\
\hline & & $\begin{array}{l}\text { Phospholipon } \\
90 \mathrm{H}\end{array}$ & / & 1 & $63.1-63.5$ & Anti-inflammatory & Medicine & (Sebaaly et al., 2016a) \\
\hline & & $\begin{array}{l}\text { Phospholipid } \\
\text { S75 }\end{array}$ & 58.6 & l & 59.2 & Antibacterial & Food & (Peng et al., 2015) \\
\hline & & Phospholipid & / & l & / & Anti-inflammatory & Medicine & (Sebaaly et al., 2015b) \\
\hline $\begin{array}{l}\text { Linseed oil + } \\
\text { quercetin }\end{array}$ & $\begin{array}{l}\text { Linum } \\
\text { usitatissimum L. }\end{array}$ & $\begin{array}{l}\text { Soybean } \\
\text { phospholipid }\end{array}$ & 262.2 & l & l & Source of PUFA & Food & (Huang et al., 2020) \\
\hline $\begin{array}{l}\text { Coix seed oil }+ \\
\text { B-carotene }\end{array}$ & $\begin{array}{l}\text { Coix lacryma-jobi } \\
\text { L. }\end{array}$ & Egg yolk PCH & $156.7-193.1$ & -47.8 to -32.4 & $80.8-83.8$ & Anticancer & Medicine & (C. Bai et al., 2019) \\
\hline Linoleic acid & 1 & Soybean $\mathrm{PCH}$ & 266 & 1 & 83.3 & 1 & Food & (Vélez et al., 2019) \\
\hline \multicolumn{9}{|c|}{ Heating method } \\
\hline Sterol & 1 & $\begin{array}{l}\text { Soybean } \\
\text { phospholipid }\end{array}$ & $>200$ & -9 to -14 & $>89$ & Antioxidant & Food & (Poudel et al., 2019) \\
\hline $\mathrm{EPA}+\mathrm{DHA}$ & / & $\begin{array}{l}\text { Soybean } \\
\text { phospholipid }\end{array}$ & $<200$ & -48.3 & / & l & l & (Rasti et al., 2012) \\
\hline
\end{tabular}

941 EPA: Eicosapentaenoic acid; DHA: Docosahexaenoic acid; PUFA: Polyunsaturated fatty acids; PCH: phosphatidylcholine; PEA: phosphatidylethanolamine. 


\subsubsection{Solid lipid nanoparticles and nanostructured lipid carriers}

Solid lipid nanoparticles (SLN) are other lipid-based carriers that have emerged as they combine the benefits of liposomes and polymeric nanoparticles (Sarangi and Padhi, 2016). Solid lipid nanoparticles, developed since 1990, are suspensions of nanosized solid lipid particles dispersed in an aqueous media (Patel, 2013). There are composed of surfactants and a lipid matrix that acquires a solid-state lipid at ambient temperature (Bayón-Cordero et al., 2019). The commonly used materials to structure the lipid core are fatty acids (stearic acid, palmitic acid, decanoic acid and benzoic acid), triacylglycerols (trimyristin, trilaurin, tristearin and tripalmitin) and acyl glycerols (glycerol monostearate, glycerol palmitostearate and glycerol benzoate). These lipids are characterized by their purity, low price, safety and biodegradability. In the other hand, phospholipids (phosphatidylcholine, soy and egg lecithins), poloxamer, pluronic ${ }^{\circledR} \mathrm{F} 127$, bile salts, tween 80 and polyvinyl alcohol are example of commonly used surfactants (Kaliamurthi and Selvaraj, 2016).

In the aim of enhancing the loading capacity of SLN, a second generation of lipid nanoparticles was developed in 1999; so called nanostructured lipid carriers (NLC) in which the matrix is composed not only of a solid lipid, but of a blend of a solid and a liquid lipid oil, as illustrated in Fig. 7. These carriers may provide an additional space for the loading of bioactive agents, improving in this way the amount of the active compounds entrapped and minimizing the probability of expulsion from the lipid phase (Patel, 2013).

Considering the delivery of plant oil, the main reason to use SLN or NLC as nanocarriers is the improvement of entrapment efficiency. Since the oils are mostly lipophilic, they present a good miscibility with the lipid matrix, resulting high amount of oil could be entrapped (Falcao et al., 2015). In addition, these lipid-based carriers protect the labile and sensitive oil components from chemical, photochemical or oxidative degradation, due to the immobilization by solid 967 lipids. Different methods are employed to produce SLN, however, high pressure 
968 homogenization and high-speed homogenization (ultrasonication) are commonly used due to

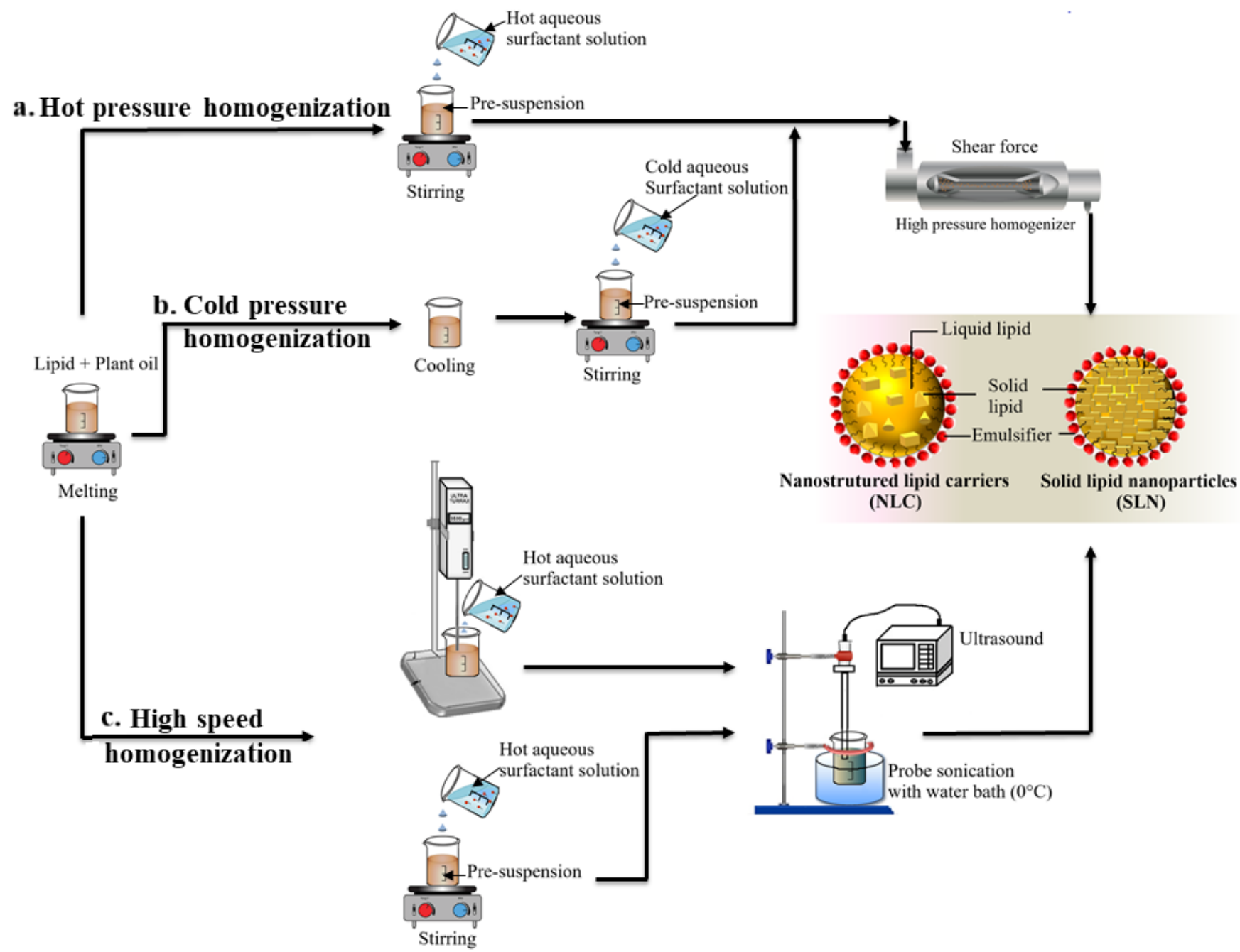

971 Fig. 7. Schematic illustration of solid lipid nanoparticles and nanostructured lipid carriers'

972 preparation methods.

\subsubsection{High pressure homogenization}

The high-pressure homogenization method was extensively used to encapsulate plant

975 oils in SLN since it produces particles with small size and higher homogeneity. Using a high-

976 pressure homogenizer, liquids were pushed with high pressure (100-2000 bar) through a narrow gap (micron size) creating fluid acceleration over a very short distance at very high viscosity of 
over $1000 \mathrm{~km} / \mathrm{h}$ which in turn result in disrupting the particles down to submicron range (Garud et al., 2012).

Using the high-pressure homogenization to encapsulate plants oils, the lipid is heated at 5 to $10^{\circ} \mathrm{C}$ above its melting point, and the oil is dissolved within (Fig.7.a). After that two approaches are involved: hot or cold homogenization. In hot homogenization, hot aqueous surfactant solution is dispersed with the plant oil-lipid melt under stirring at the same temperature creating the pre-emulsion. The resultant pre-emulsion was pushed through a piston-gap homogenizer creating a hot oil-in-water $(\mathrm{O} / \mathrm{W})$ nanoemulsion which is cooled after at room temperature allowing the crystallization of the lipid and the formation of SLN.

Using the cold homogenization approach the oil-lipid melt was cooled down creating solid lipid microparticles that are dispersed after in a cold aqueous surfactant solution forming a pre-suspension. The subsequent homogenization of this pre-suspension creates SLN (Fig.7.b). Several studies have been already published investigating the use of high-pressure homogenization process to encapsulate plant oils (see Table 3).

Regarding the size of SLN prepared by this technique, numerous research works reported a small average diameter with good stability and high EE\%. For example, SLN containing frankincense and myhrr EO in a ratio 1:1 were developed using hot homogenization process by Wang et al. (Wang, 2012). An average mean size of $113.3 \mathrm{~nm}$, a zeta potential of $16.8 \mathrm{mV}$ and an $\mathrm{EE} \%$ of $80.60 \%$ were assessed for the obtained SLN. The same process was used to prepare SLN encapsulating the VO: copaiba oil with and without allantoin which is widely used in cosmetology for its keratolytic, moisturizing, soothing and wound healing properties (Svetlichny et al., 2015). The dynamic light scattering analysis revealed an average particle size of $126.06 \mathrm{~nm}$ and $118.63 \mathrm{~nm}$ for the copaiba oil-loaded SLN and copaiba oil: allantoin-co-loaded SLN, respectively. 

preserving the quality of encapsulated oil during long-term storage as compared to un-

1004

1005

1006

1007

1008

1009

1010

1011

1012

1013

1014

1015

1016

1017

1018

1019

1020

1021

1022

1023

1024

1025

1026 encapsulated-form (Tian et al., 2018; Zielinska et al., 2019). Tian et al. (2018) reported that SLN can enhance the stability of citral in acidic surroundings. Gas-chromatography analysis showed that after 12 days storage, $67 \%$ of citral remained in the citral loaded-SLN formulations, while only $8 \%$ remained in the control. In addition, the overall flavour of the degradation products generated from citral-SLN were assessed and results demonstrated that the offflavours had little effect on the whole flavour of citral-SLN in the system sample as compared with the control (Tian et al., 2018).

Several factors such as the kind of lipid, surfactant and the operating process conditions could influence the physicochemical properties of the particles obtained by high-pressure homogenization. In this context, Mai et al. (2018) investigated the influence of homogenization conditions on gac fruit EO-loaded SLN prepared by hot and cold homogenization. Results showed that increasing hot homogenization speed from 5000 to $10000 \mathrm{rpm}$ was accompanied with a decrease in particle size from 3297 to $201 \mathrm{~nm}$. However, further increase in speed leads to increase the particle size due to the fact that the oil particles are more likely to collide and aggregate with others. Concerning hot homogenization time, short time was found not enough for active ingredient encapsulation while more homogenization time result in small particles which in turn lead to reduce the volume containing active ingredients (Mai et al., 2018).

In another work study, the impact of the surfactant content, the ratio of citral to lipid, and their total content on the physicochemical characteristics of citral-loaded SLN has been explored (Tian et al., 2018). As the surfactant amount increases the EE\% decreases due to the fact that the surface of the formed SLN was not large enough to absorb the excess of surfactant which in turn form micelles, resulting a partitioning phenomenon of citral between micelles and SLN; therefore, a decrease in entrapment efficiency was noticed. Results revealed also an 
increase in particle size and a decrease in $\mathrm{EE} \%$ when increasing the content of the mixture citral

1028

1029

1030

1031

1032

1033

1034

1035

1036

1037

1038

1039

1040

1041

1042

1043

1044

1045

1046

1047

1048

1049

1050

1051

: glyceryl monostearate, used as lipid matrix, from 1 to $5 \%$. The increase in the content of citral

: lipid leads to increase the viscosity of the system which in turn reduce the efficiency of the high-pressure homogenization process to decrease the particle size. Additionally, too much citral and lipid cannot be emulsified when the surfactant content is kept constant this is why the $\mathrm{EE} \%$ decreased. The same behavior of $\mathrm{EE} \%$ was observed when increasing the ratio of citral to glycerol monostearate. In fact, the excess of citral cannot be entrapped when the content of the mixture citral : lipid was kept constant (Tian et al., 2018).

In recent years, NLC were introduced to bypass the potential problems associated with the use of SLN. They were widely used for plant oils encapsulation, as depicted in Table 3. The main feature of these nanocarriers is to enhance the drug loading and prevent drug expulsion during long term storage (Sailaja et al., 2011) and this was confirmed by several research works. In 2019, using the high-pressure homogenization technique, Miranda and his colleagues developed Ridolfia segetum EO loaded-NLC with a small particle size $(148.1 \mathrm{~nm})$, a high zeta potential $(16.3 \mathrm{mV})$ with excellent loading capacity $(\mathrm{EE} \%=100 \%)$ (Miranda et al., 2019). In another research work, NLC containing sucupira EO produced by hot homogenization process owning an average diameter of $143 \mathrm{~nm}$ with an EE\% of 99.98\% (Vieira et al., 2020).

Another characteristic intended by using either SLN or NLC as plant oils carrier is providing a controlled released pattern. For this context, in vitro release profile of sucupira oil from NLC was assessed by means of Franz glass diffusion cells and the recorded release profile was fitted into four mathematical models i.e., zero order, first order, Higuchi and KorsmeyerPeppas (Vieira et al., 2020). Results showed that the release profile of sucupira oil followed a sustained manner over the course of $8 \mathrm{~h}$. About $17.5 \%$ was released within the first hour, while the cumulative amount reached $30 \%$ at the end of the $8 \mathrm{~h}$ (Vieira et al., 2020). Results showed also that the best model describing the release of sucupira oil from NLC was the first order with 
a regression coefficient close to 1 . In contrary to SLN, the release profile of plant oils from NLC does not follow Higuchi or Korsmeyers-Peppas model. Indeed, the release was governed by sucupira oil concentration inside the particles rather than the physicochemical properties of the carriers and this was expected as NLC are made of blend of solid and liquid lipids. Higuchi and Korsmeyers-Peppas are typically followed in the case of SLN formulations as these have a higher degree of crystallinity which controls better the release profile.

With respect to vegetable oils, NLC were employed for co-delivery of VO with another bioactive molecule (Badea et al., 2015; Lacatusu et al., 2015; Rahman et al., 2013, 2014; Sidding et al., 2013). The benefit of these nanocarriers is that the VO can complement or even enhance the biological activity of the synthetic drug (Lacatusu et al., 2015). For this context, diethylamino hydroxybenzoyl hexyl benzoate used as UVA filter was co-encapsulated with various vegetable oils and their combinations (pomegranate seed oil, wheat germ oil, blackcurrant seed oil, sesame seed oil, carrot root oil, raspberry seed oil and rice bran oil) in NLC by high pressure homogenization method in order to enhance its antioxidant activity and UV protection performance (Badea et al., 2015). All the prepared NLC owned a mean particle size in the range of 108 to $145 \mathrm{~nm}$ with narrow size distribution, high zeta potential ranging from -34.4 to $-44.3 \mathrm{mV}$ and an entrapment efficiency between 51 and $70 \%$ (Badea et al., 2015). In another work study, in the aim of enhancing the anti-inflammatory properties, olive oil was co entrapped with thymoquinone in NLC and the resultant particles owned an average diameter around $75 \mathrm{~nm}$ with negative zeta potential of $-31 \mathrm{mV}$ (Sidding et al., 2013). Olive oil was further encapsulated in hydrogenated palm oil-NLC for co-delivery with synthetic drug purpose. The resultant particles had a mean diameter, polydispersity index, zeta potential, specific surface area, and crystallinity index of $61.14 \mathrm{~nm}, 0.461,-25.4 \mathrm{mV}, 49.07 \mathrm{~m}^{2}$ and $27.12 \%$ respectively (How et al., 2013). 

instance, Lacatusu et al. (2015) highlighted the possible blend of plant and animal oils - grape seed oil or fish oil with laurel leaf EO in NLC. The mean average diameter of obtained NLC reduces after increase of grape seed oil or fish oil content. This was ascribed to the role of the long fatty chains of these oils which lead to a more confined lipid core. to its benefits including low cost, good scalability and high stability of particles. While, with

1083

1084

1085

1086

1087

1088

1089

1090

1091

1092

1093

1094

1095

1096

1097

1098

1099

1100

respect to the encapsulation of plant oils hot homogenization is more used as compared to the cold homogenization method. Lipids like tristearin (Salminen et al., 2017), n-hexadecyl

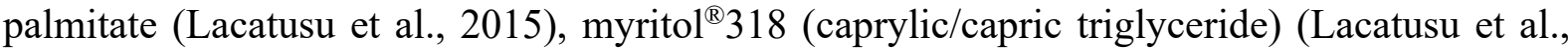
2015), compritol ${ }^{\circledR} 888$ ATO (Wang, 2012), glyceryl monolinoleate (Shi et al., 2013; Tian et al., 2018), oleoyl macrogolglycerides (Shi et al., 2013), lipoid ${ }^{\circledR}$ S100 (Sidding et al., 2013), cetyl palmitate (Svetlichny et al., 2015) and glycerol monostearate (Shi et al., 2013) are usually used to structure either SLN or NLC. Soybean lecithin (Salminen et al., 2017; Wang, 2012), tween 80 (Shi et al., 2013; Sidding et al., 2013; Svetlichny et al., 2015; Wang, 2012), tween 20 (Badea et al., 2015; Lacatusu et al., 2015), span 80 (Mai et al., 2018; Tian et al., 2018) poloxamer (Badea et al., 2015) and sodium taurodeoxycholate hydrate (Salminen et al., 2017) are example of used emulsifiers.

The use of high-speed homogenization process is often limited by the need of high energy input and the high temperature which cause oil loss.

\subsubsection{Ultrasonication / high speed homogenization}

Solid lipid nanoparticles may also be prepared by ultrasonication or high-speed homogenization technique. In brief, the heated aqueous phase was added to the melted lipid phase and emulsified by high speed stirrer, probe sonication or by adding the aqueous phase drop by drop to the lipid phase under magnetic stirring. The obtained pre-emulsion was 
ultrasonicated using probe sonicator with water bath (Fig.7.c). In order to prevent recrystallization during the process, the production temperature was kept at least $5^{\circ} \mathrm{C}$ above the lipid melting point (Ramteke et al., 2012; Yadav et al., 2013).

With respect to the encapsulation of plant oils, the ultrasonication technique is widely used, as described in Table 3. Zataria multiflora EO-loaded SLN were developed using Precirol ${ }^{\circledR}$ ATO 5 (Glyceryl monostearate) as lipidic matrix and tween 80 with poloxamer 188 as surfactants (Nasseri et al., 2016). The obtained SLN owned a particle size around $255.5 \mathrm{~nm}$ with zeta potential of $-37.8 \mathrm{mV}$ and high $\mathrm{EE} \%$ of $84 \%$. The same technique was used to develop cardamom EO loaded-NLC using cocoa butter (as solid lipid), olive oil (as liquid lipid) and tween 80 (as surfactant); and the resultant particles had round shape, smooth surface with particle size less than $100 \mathrm{~nm}$ (Nahr et al., 2018). Similarly, NLC were developed using palm stearin as solid lipid and lecithin as emulsifier and the resultant particles were physically and chemically stable during 70 -day storage at room temperature and $4^{\circ} \mathrm{C}$ (Zhu et al., 2015). Furthermore, Noor et al. (2013) successfully loaded coconut VO into SLN by the same process and reported high EE\% (99.97\%).

Like all the colloidal formulations discussed above, both SLN and NLC prepared by high-speed homogenization provide a controlled release profile of plant oils (Pivetta et al., 2018; Zhao et al., 2017). The release profile of EO from these nanocarriers may be affected by several factors such as the particle size and the composition of lipidic matrix. In 2011, Garg and his coworkers compared the release profile of eugenol from SLN and NLC formulations made from stearic acid and the mixture stearic acid: caprylic triglyceride, respectively (Garg and Singh, 2011). Results revealed a biphasic release pattern from both nanocarriers. After initial burst release, the cumulative amounts of eugenol released within $12 \mathrm{~h}$ were 65 and $78 \%$ from SLN and NLC, respectively. This was related to the structure of the nanocarrier's matrix. The addition of liquid lipid in the case of NLC provides fewer barriers to partitioning of eugenol to 
the dissolution media. The authors ascribed also this result to the small particle size of NLC $(87.7 \mathrm{~nm})$ as compared to that of SLN (332 nm). Indeed, the addition of liquid lipid decreases the viscosity of the organic phase (lipid solution) to be dispersed in the aqueous one resulting in smaller particles. Moreover, liquid lipid may inhibit the crystallization of solid lipid leading to smaller particle size (Garg and Singh, 2011). One may conclude that the incorporation of liquid lipid improves the EE\% but decreases the barrier provided by lipid matrix for the diffusion of bioactive molecule in the dissolution medium.

The particle size and zeta potential of NLC were influenced by several parameters including solid lipid composition, oil and surfactant (type and concentration), lipid:surfactant ratio, etc. The impact of these factors was extensively studied in the literature (Krasodomska et al., 2016; Lacatusu et al., 2013; Soleimanian et al., 2018). It was found that increasing stearic acid concentration results in increasing the size of Eugenia caryophyllata EO-loaded SLN prepared by ultrasonication method (Bazzaz et al., 2018). Moreover, Soleimanian et al. (2018) developing pomegranate seed oil-loaded NLC using two types of natural waxes: beeswax and propolis wax, investigated the influence of solid lipid composition, surfactant blend concentration and oil content on NLC physicochemical properties. Results demonstrated that increasing oil amount resulted in a decrease in particle size of beeswax NLC. This was related to the reduction of core viscosity and enhancement of fluidity which results in a decrease in particle size. The opposite behavior was observed in the case of propolis wax NLC. The particle size increases by increasing the oil content. The authors ascribed that to enhanced interfacial tension or swelling rate of the core as result of greater oil concentration. Concerning the impact of solid lipid type, Soleimanian et al. (2018) reported that small differences in the lipid composition (particularly, the melting point) might have considerable impact on size and quality of nano lipid carriers. Beeswax consisting of a longer series of carboxylic acid homologues, alcohols and hydrocarbons exhibits higher melting point, leading to higher 
viscosity of the dispersed phase which in turn results in increasing particle size $(203 \mathrm{~nm})$. On the other hand, propolis wax having lower proportion of components produced smaller NLC (143 nm). Regarding the zeta potential, the same authors reported that increasing the concentration of surfactant mixture (Lecithin:Tween 80) results in decreasing the zeta potential of NLC. They related this result to the differences in mobility and redistribution of used surfactants. In fact, high amounts of surfactant decrease the surface tension and enhance the particle partition during homogenization, resulting to a decrease in particle size and thus new NLC appear. The time required for the redistribution of surfactant molecules to cover the new surfaces differ. Indeed, low molecular weight surfactants such as tween 80 adsorb rapidly at the interface, while lecithin, as high molecular weight surfactant, needs more time to be adsorbed. Therefore, tween 80, external hydrophilic non-ionic surfactant, will cover the internal lipophilic surfactant (i.e. lecithin), and thus the zeta potential decreases (Soleimanian et al., 2018).

In summary, the ultrasonication is chosen by scientists to design both SLN and NLC systems to entrap plant oils. The commonly used lipid are glyceryl behenate (Zhao et al., 2017), stearic acid (Bazzaz et al., 2018; Garg and Singh, 2013, 2011), carnauba wax (Lacatusu et al., 2013), whey protein isolate (Azizi et al., 2019), glycerol stearate (Lacatusu et al., 2013), palmitic acid (Azizi et al., 2019), propolis (Soleimanian et al., 2018), palm stearin (Zhu et al., 2015), beeswax (Shakeri et al., 2019; Soleimanian et al., 2018), illipe butter (Pivetta et al., 2018), cocoa butter (Nahr et al., 2018), Precirol ${ }^{\circledR}$ ATO 5 (glyceryl palmitostearate) (Ghodrati et al., 2019), miglyol $8^{812}$ (caprylic/caprictriglycerides) (Ghodrati et al., 2019) and myverol ${ }^{\circledR}$ RX GMS 95P (mixture of glycerol palmitic (57,8\%) stearic (37.3\%) and myristic (1.3\%) acid) (Krasodomska et al., 2016). Lecithin (Soleimanian et al., 2018; Zhu et al., 2015), poly vinyl alcohol (Zhao et al., 2017), tween 80 (Lacatusu et al., 2013; Nahr et al., 2018; Noor et al., 2013), poloxamer (Ghodrati et al., 2019; Lacatusu et al., 2013) and pluronic ${ }^{\circledR}$ F68 (Pivetta et al., 2018) are example of used emulsifiers. The main features of the ultrasonication process including 
1176 facility, simplicity and reduced high shear. However, it is limited by the high metal 1177 contamination potential, unproven scalability and high energy requirement. 
1178 Table 3. Preparation methods for plant oils encapsulation in solid lipid nanoparticles and nanostructured lipid carriers with their fine applications.

\begin{tabular}{|c|c|c|c|c|c|c|c|c|}
\hline \multirow[t]{2}{*}{ Encapsulated oil } & \multirow[t]{2}{*}{ Plant (origin) } & \multirow[t]{2}{*}{ Lipid used } & \multicolumn{3}{|c|}{ Physicochemical properties } & \multirow[t]{2}{*}{ Biological properties } & \multirow[t]{2}{*}{ Application } & \multirow[t]{2}{*}{ Ref. } \\
\hline & & & Size $(n m)$ & Z.pot (mV) & EE (\%) & & & \\
\hline \multicolumn{9}{|c|}{ Solid lipid nanoparticles } \\
\hline \multicolumn{9}{|c|}{ High pressure homogenization } \\
\hline Carvacrol & 1 & Cocoa butter & 1 & 1 & 1 & Antioxidant & Medicine & (Carvalho et al., 2020) \\
\hline Geranial & / & $\begin{array}{l}\text { Monoterpene } \\
\text { Imwitor } ₫ 900 \mathrm{~K}\end{array}$ & 120.1 & 0 & / & 1 & l & (Zielińska et al., 2020) \\
\hline Ziziphora & $\begin{array}{l}\text { Ziziphora } \\
\text { clinopodioides }\end{array}$ & $\begin{array}{l}\text { Percirol ATO5 } \\
\text { Campritol } 888\end{array}$ & 241.1 & -22.6 & 93 & Insecticide & Agriculture & (Jajarm et al., 2020) \\
\hline \multirow[t]{2}{*}{ Eugenol } & 1 & $\begin{array}{l}\text { Caprylic } \\
\text { triglyceride } \\
\text { Stearic acid }\end{array}$ & 332 & -18.7 & 91.8 & Anticancer & Medicine & (Garg and Singh, 2011) \\
\hline & l & $\begin{array}{l}\text { Hydrogenated } \\
\text { palm oil } \\
\text { Coconut oil }\end{array}$ & $164.5-172.9$ & l & l & Antifungal & Food & (McDaniel et al., 2019) \\
\hline Thymol & l & Hydrogenated & $166.4-170.5$ & 1 & 1 & Antifungal & Food & (McDaniel et al., 2019) \\
\hline Cinnamaldehyde & l & $\begin{array}{l}\text { palm oil } \\
\text { Coconut oil }\end{array}$ & $198.0-202.1$ & & & & & \\
\hline Sclareol & I & Compritol & 128 & -29.3 & I & $\begin{array}{l}\text { Treatment of metabolic } \\
\text { disorder }\end{array}$ & Medicine & (Cerri et al., 2019) \\
\hline Chamomile & $\begin{array}{l}\text { Matricaria } \\
\text { chamomilla } \mathrm{L} .\end{array}$ & Stearic acid & 542 & -35.9 & l & Wound healing & Cosmetics & (Gad et al., 2019) \\
\hline \multirow[t]{2}{*}{$\alpha$-pinene } & 1 & Imwitor ${ }^{2} 900 \mathrm{~K}$ & 136.7 & l & 1 & Antimicrobial, antioxidant & 1 & (Zielinska et al., 2019) \\
\hline & & $\begin{array}{l}\text { Monoterpene } \\
\text { Imwitor }{ }^{\circledR} 900 \mathrm{~K}\end{array}$ & 89.7 & 0 & l & 1 & l & (Zielińska et al., 2020) \\
\hline \multirow[t]{2}{*}{ Citral } & / & $\begin{array}{l}\text { Glyceryl } \\
\text { monostearate }\end{array}$ & 215.4 & l & l & Flavoring agent & Food & (Tian et al., 2018) \\
\hline & & $\begin{array}{l}\text { Monoterpene } \\
\text { Imwitor } \AA 900 \mathrm{~K}\end{array}$ & 125.4 & 0 & & 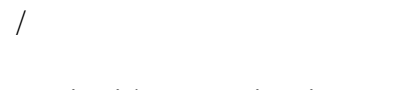 & / & (Zielińska et al., 2020) \\
\hline Gac fruit EO & $\begin{array}{l}\text { Momordica } \\
\text { cochinchinensis } \\
\text { L. }\end{array}$ & Emulgade & 200 & I & 90 & $\begin{array}{l}\text { Antioxidant; Anti-aging } \\
\text { Skin tanning, skin care and } \\
\text { skin protection }\end{array}$ & Cosmetics & (Mai et al., 2018) \\
\hline $\begin{array}{l}\text { Frankincense + } \\
\text { Myhrr oil }\end{array}$ & $\begin{array}{l}\text { Commiphora } \\
\text { myrrha L. }\end{array}$ & $\begin{array}{l}\text { Compritol } 888 \\
\text { ATO }\end{array}$ & 113.3 & -16.8 & $80-60$ & Antitumor & Medicine & (Wang, 2012) \\
\hline Copaiba oil & $\begin{array}{l}\text { Copaifera } \\
\text { officinalis } \mathrm{L} \text {. }\end{array}$ & Cetyl palmitate & 126.06 & l & 1 & Antifungal & Cosmetics & (Svetlichny et al., 2015) \\
\hline
\end{tabular}




\begin{tabular}{|c|c|c|c|c|c|c|c|c|}
\hline $\begin{array}{l}\text { Copaiba oil+ } \\
\text { Allantoin }\end{array}$ & $\begin{array}{l}\text { Copaifera } \\
\text { officinalis L. }\end{array}$ & Cetyl palmitate & 118.63 & / & / & Antifungal & Cosmetics & (Svetlichny et al., 2015) \\
\hline \multicolumn{9}{|c|}{ Ultrasonication method } \\
\hline \multirow[t]{2}{*}{ Zataria multiflora } & $\begin{array}{l}\text { Zataria } \\
\text { multiflora Boiss. }\end{array}$ & $\begin{array}{l}\text { Precirol ATO } 5 \\
\text { Stearic acid } \\
\text { Glyceryl } \\
\text { monostearate }\end{array}$ & $220-486$ & -37.8 to -27.2 & $85.3-95.2$ & $\begin{array}{l}\text { Fungicide } \\
\text { Pesticide }\end{array}$ & $\begin{array}{l}\text { Food } \\
\text { Medicine } \\
\text { Agriculture }\end{array}$ & (Nasseri et al., 2020) \\
\hline & & $\begin{array}{l}\text { Glyceryl } \\
\text { monostearate } \\
\text { Precirol }{ }^{\circledR} \text { ATO } 5\end{array}$ & 255.5 & -37.8 & 84 & Antifungal & Medicine & (Nasseri et al., 2016) \\
\hline$\beta$-elemene & / & $\begin{array}{l}\text { Glyceryl } \\
\text { monostearate } \\
\text { Glyceryl } \\
\text { tristearate }\end{array}$ & 128.4 & -3.07 & l & Antitumor & Medicine & (He et al., 2019) \\
\hline Clove & $\begin{array}{l}\text { Syzygium } \\
\text { aromaticum } \mathrm{L} .\end{array}$ & $\begin{array}{l}\text { Precirol }{ }^{\circledR} \text { ATO } 5 \\
\text { Stearic acid } \\
\text { Glyceryl } \\
\text { monostearate }\end{array}$ & 397.2 & -20.9 & / & Antimicrobial & Medicine & (Bazzaz et al., 2018) \\
\hline Linalool & / & $\begin{array}{l}\text { Myristyl } \\
\text { myristate Cetyl } \\
\text { esters } \\
\text { Cetyl palmitate }\end{array}$ & $90-130$ & -4 & $>80$ & Anticancer & Medicine & $\begin{array}{l}\text { (Rodenak-Kladniew et al., } \\
\text { 2017) }\end{array}$ \\
\hline \multirow[t]{2}{*}{ Eugenol } & / & $\begin{array}{l}\text { Stearic } \\
\text { acid/Compritol }\end{array}$ & $363-423$ & l & l & Antifungal & Medicine & (Garg and Singh, 2013) \\
\hline & & $\begin{array}{l}\text { Stearic acid } \\
\text { Caprylic } \\
\text { triglyceride }\end{array}$ & 87.7 & -19.2 & 98.5 & Antifungal & Medicine & (Garg and Singh, 2011) \\
\hline \multirow[t]{2}{*}{ Coconut } & $\begin{array}{l}\text { Cocos nucifera } \\
\text { L. }\end{array}$ & Stearic acid & 608 & -47.5 & 99.9 & Moisturizing lotion & Cosmetics & (Noor et al., 2013) \\
\hline & \multicolumn{8}{|c|}{ Nanostructured lipid carriers } \\
\hline \multicolumn{9}{|c|}{ High pressure homogenization } \\
\hline Cinnamon & $\begin{array}{l}\text { Cinnamomum } \\
\text { cassia persl. }\end{array}$ & $\begin{array}{l}\text { Cocoa butter } \\
\text { Almond oil }\end{array}$ & $100-120$ & -14.9 to -17.5 & $>82.1$ & Antimicrobial, antioxidant & Food & (Bashiri et al., 2020b) \\
\hline Sucupira & $\begin{array}{l}\text { Pterodon } \\
\text { emarginatus L. }\end{array}$ & $\begin{array}{l}\text { Imwitor }{ }^{\circledR} 900 \mathrm{~K} \\
\text { Tripalmitin }\end{array}$ & 148.1 & l & 99.9 & Antidiabetic & Medicine & (Vieira et al., 2020) \\
\hline Squaw mint & $\begin{array}{l}\text { Mentha } \\
\text { pulegium L. }\end{array}$ & $\begin{array}{l}\text { Precirol }{ }^{\mathbb{}} \text { ATO } 5 \\
\text { Miglyol }^{\mathbb{R}} 812\end{array}$ & $40-250$ & -10 to -15 & l & Wound healing & Cosmetics & (Khezri et al., 2020) \\
\hline
\end{tabular}




\begin{tabular}{|c|c|c|c|c|c|c|c|c|}
\hline Rosemary & $\begin{array}{l}\text { Rosmarinus } \\
\text { officinalis } \mathrm{L} .\end{array}$ & $\begin{array}{l}\text { Precirol }{ }^{\circledR} \text { ATO } 5 \\
\text { Miglyol }^{\circledR} 812\end{array}$ & $100-250$ & -15.7 & 92.1 & Wound healing & Cosmetics & (Khezri et al., 2019) \\
\hline Peppermint & $\begin{array}{l}\text { Mentha piperita } \\
\text { L. }\end{array}$ & $\begin{array}{l}\text { Precirol }{ }^{\circledR} \text { ATO } 5 \\
\text { Miglyol }^{\circledR} 812\end{array}$ & $40-250$ & -10 to -15 & 1 & Wound healing & Cosmetics & (Ghodrati et al., 2019) \\
\hline Clove & $\begin{array}{l}\text { Syzygium } \\
\text { aromaticum L. }\end{array}$ & $\begin{array}{l}\text { Beeswax } \\
\text { Coconut oil }\end{array}$ & $121-367$ & / & $\approx 60$ & $\begin{array}{l}\text { Cholinesterase enzyme } \\
\text { inhibition }\end{array}$ & Medicine & (de Meneses et al., 2019) \\
\hline Ridolfia segetum & $\begin{array}{l}\text { Ridolfia } \\
\text { segetum } \mathrm{L} .\end{array}$ & Precirol ${ }^{\circledR}$ ATO 5 & 143 & 16.3 & 100 & $\begin{array}{l}\text { Antioxidant; anti- } \\
\text { inflammatory }\end{array}$ & Medicine & (Miranda et al., 2019) \\
\hline B-elemene & 1 & $\begin{array}{l}\text { Glycerol } \\
\text { monostearate } \\
\text { Glyceryl } \\
\text { monolinoleate } \\
\text { Oleoyl } \\
\text { macrogolglycerides }\end{array}$ & 138.9 & -20.2 & 82.11 & Antitumor & Medicine & (Shi et al., 2013) \\
\hline Thymoquinone & / & $\begin{array}{l}\text { Hydrogenated } \\
\text { palm oil } \\
\text { Olive oil } \\
\text { Lipoid }^{\circledR} \text { S100 }\end{array}$ & 75 & -31 & l & Antiulcer & Medicine & (Sidding et al., 2013) \\
\hline $\begin{array}{l}\text { Sunflower } \\
\text { Crambe } \\
\text { Canola }\end{array}$ & $\begin{array}{l}\text { Helianthus } \\
\text { annuus } \mathrm{L} . \\
\text { Crambe } \\
\text { maritima } \mathrm{L} . \\
\text { Brassica napus } \\
\text { L. }\end{array}$ & $\begin{array}{l}\text { Sunflower oil } \\
\text { Crambe oil } \\
\text { Canola oil }\end{array}$ & $\begin{array}{l}48.23- \\
342.10\end{array}$ & -22.3 to -29.7 & / & Source of phytosterols & Food & (Santos et al., 2019) \\
\hline Pomegranate seed & $\begin{array}{l}\text { Punica } \\
\text { granatum L. }\end{array}$ & $\begin{array}{l}\text { Glycerol } \\
\text { monostearate }\end{array}$ & $108-145$ & 34.4 to -44.3 & $51-70$ & $\begin{array}{l}\text { Antioxidant } \\
\text { UVA protector }\end{array}$ & Cosmetics & (Badea et al., 2015) \\
\hline Wheat germ & $\begin{array}{l}\text { Triticum } \\
\text { aestivum } \mathrm{L} \text {. }\end{array}$ & Emulgade & & & & & & \\
\hline Blackcurrant seed & Ribes nigrum L. & & & & & & & \\
\hline Sesame & $\begin{array}{l}\text { Sesamum } \\
\text { indicum } \mathrm{L} .\end{array}$ & & & & & & & \\
\hline Carrot root & $\begin{array}{l}\text { Daucus carota } \\
\text { subsp. Sativus }\end{array}$ & & & & & & & \\
\hline $\begin{array}{l}\text { Raspberry seed } \\
\text { Rice bran }\end{array}$ & $\begin{array}{l}\text { Rubus idaeus } \mathrm{L} . \\
\text { Oryza sativa L. }\end{array}$ & & & & & & & \\
\hline Olive & $\begin{array}{l}\text { Olea europaea } \\
\text { L. }\end{array}$ & $\begin{array}{l}\text { Hydrogenated } \\
\text { palm oil }\end{array}$ & 61.14 & -25.4 & l & Source of PUFA & Medicine & (How et al., 2013) \\
\hline $\begin{array}{l}\text { Grape seed + } \\
\text { Laurel }\end{array}$ & Vitis vinifera $\mathrm{L}$. & $\begin{array}{l}\text { n-Hexadecyl } \\
\text { palmitate }\end{array}$ & $<150$ & / & / & Antitumor; antioxidant & Medicine & (Lacatusu et al., 2015) \\
\hline
\end{tabular}


Glycerol

monostearate

Myritol $^{\circledR} 318$

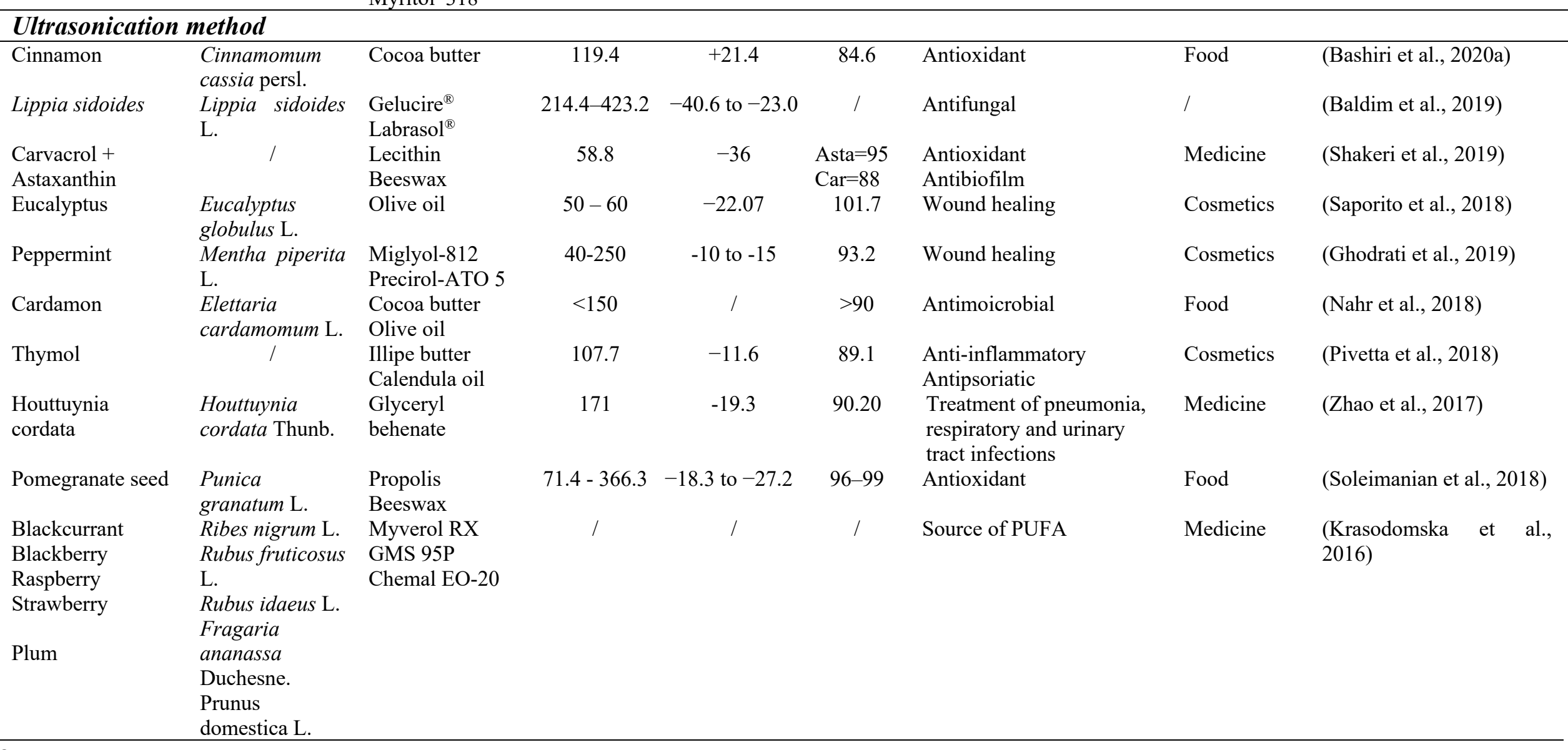

1179 


\section{Application}

\subsection{Agriculture field}

The indiscriminate use of chemicals in field as well as during postharvest poses serious problems for the environment and the human health. The excessive application of synthetic fungicides can also have other negative side effects. The appearance of resistance in the pathogen populations has been notified for many fungi (Saharan et al., 2013). In addition, over the last few years increasing consumers concern regarding contamination of crops with fungicidal residues has been reported (Shukla, 2018). Therefore, low toxicity and more environmentally friendly compounds as an alternative to chemical fungicides was brought to the forefront. Among them, GRAS (generally regarded as safe) antifungal compounds such as EO have been reported (Shukla, 2018; Sotelo-Boyás et al., 2015). Due to their broad spectrum of activity against plant pathogenic fungi and insects-pests, EO have been used as antifungal, insecticidal, repellent, antifeedant and oviposition deterrent (De Souza et al., 2005; Shukla, 2018). However, the replacement of synthetic compounds is not easy due to the poor stability shown by EOs during the processing steps. Therefore, nanoencapsulation has been proposed for this purpose (Maryam et al., 2015). According to the literature, pNPs are widely used for EO encapsulation in agriculture industry.

Recently, Khoobdel et al. (2017) investigated the insecticidal activity of Rosmarinus officinalis EO-loaded pNPs against the red flour beetle, Tribolium castaneum. Fumigant and contact toxicity assays revealed that the developed particles had significant increase in fumigant and contact toxicity as compared to the pure EO. At the $72 \mathrm{~h}$ exposure for fumigant toxicity, the mortality of Tribolium castaneum adults was $83.3 \%$ for free EO at a concentration of 27.76 $\mu \mathrm{L} / \mathrm{L}$ air and $100 \%$ for EO-loaded nanoparticles at concentration of $19.12 \mu \mathrm{L} / \mathrm{L}$ air (Khoobdel et al., 2017). Moreover, Zhaveh et al. (2015) related the superior performance of Cuminum cyminum EO nanogels against Aspergillus flavus as compared to the free oil to the encapsulation 
in chitosan : cafeic acid nanoparticles. Similar results were already reported when investigating insecticidal activity against Bemisia tabaci for Zanthoxylum rhoifolium EO-loaded nanoparticles as compared to the free oil (Christofoli et al., 2015). Therefore, the nanoencapsulation can enhance the insecticidal potential of EO due to the controlled and slow release of EO and increased surface area of the nanoparticles.

Sotelo-Boyas and his coworkers (2015) combined the bacterial efficiency of chitosan with those of lime and thyme EO in pNPs to eradicate Pectobacterium carotovorum, plant phytopathogenic bacteria, involved in the decay of fresh vegetables and fruits like radishes, onions, potatoes, cucumbers, carrots, eggplant, squash, peppers, tomato and cabbage. For instance, chitosan was highly used for its potential effect in the control of phytopathogenic fungi Gram-negative and Gram positive bacteria (Benhabiles et al., 2012; Kaur et al., 2012; Zhu et al., 2016). The antibacterial study demonstrated that thyme based-nanoparticles showed the highest inhibitory effect on the growth of Pectobacterium carotovorum than free chitosan nanoparticles and lime based- nanoparticles. The inhibition halo diameters were found 15, 13 and $24 \mathrm{~mm}$ for chitosan free nanoparticles, lime-chitosan nanoparticles and Thyme-chitosan nanoparticles, respectively. Moreover, the number of colonies forming units (CFU) could not be determined (countless colonies) for chitosan free nanoparticles. While for lime- and thymechitosan nanoparticles, CFU were found 450 and 240, respectively (Sotelo-Boyás et al., 2015). Furthermore, the results of antifungal assay carried out on chitosan:pepper tree EO nanoparticles revealed that higher activity was assessed for the nanoparticles on the viability of Aspergillus parasiticus spores as compared to that of chitosan and pepper tree oil present individually. One may conclude that the antifungal effect of chitosan nanoparticles was attributed to two reasons: 1) the small size of nanoparticles will increase the contact area with fungus; 2) The cationic nature of chitosan allows electrostatic interaction with proteins and 
phospholipids of the plasmatic membrane of the microorganism which in turn cause membrane destabilization and death.

With respect to the use of lipid based-nanocarriers in agriculture industry, few reports have been investigated in the last decade. Liposomes were used for the first time for rosemary EO encapsulation to inhibit the seed germination of invasive alien species (Acacia saligna) (Maccioni et al., 2019). The incorporation of rosemary EO in liposomes limited the loss of EO volatile components and delivering them into the seed resulting in enhancing EO efficacy. Similarly, Adel et al. (2015) pointed out that Pelargonium graveolens EO loaded-SLN were stable under field conditions and exhibit higher larvicidal activity against Phthorimaea operaculella as compared to the free oil.

\subsection{Food field}

In recent years, consumer demands in eating healthy and less processed foods have boosted remarkably. Functional foods play a pivotal role in promoting health and preventing degenerative diseases such as heart disease, cancer and diabetes, which account for almost two thirds of deaths in the world (Conto et al., 2012; Rubilar et al., 2012). Foods enriched with long chain omega-3 polyunsaturated fatty acids are classified as functional foods by acting on human health. The ingestion of omega-3 fatty acids is accompanied with a prevention of cardiovascular diseases, a decreased risk of cancer, autoimmune and inflammatory diseases (Azizi et al., 2019; Conto et al., 2012; Gallardo et al., 2013). However, polyunsaturated fatty acids are very susceptible to oxidation during processing and storage resulting in decreased nutritional value and sensory quality. Thus, micro and nanoencapsulation of lipids have been used in this concern (Gökmen et al., 2011).

Currently, several nanocarriers have been designed in the literature to encapsulate several healthful oils like chia seed oil (Campo et al., 2017), walnut oil (Shamaei et al., 2017), 
flaxseed oil (Carneiro et al., 2013; Gallardo et al., 2013; Pu et al., 2010), pomegranate oil (Soleimanian et al., 2018), roasted coffee oil (Freiberger et al., 2015) and fruit seed oil

1255

1256

1257

1258

1259

1260

1261

1262

1263

1264

1265

1266

1267

1268

1269

1270

1271

1272

1273

1274

1275

1276

1277 (blackcurrant, blackberry, raspberry, strawberry and plum) (Krasodomska et al., 2016). In 2012, Rubilar et al. developed a soup fortified with linseed oil microcapsules and depicted that microencapsulation protected linseed oil from oxidation with respect to free oil (Rubilar et al., 2012). Similarly, Gökmen et al. (2011) demonstrated the feasibility to include flaxseed oil nanoparticles in bread without affecting the sensorial properties.

At the same time, foods are paramount carriers of many damaging agents like virus, bacteria, parasites, and toxins which can cause food-borne diseases (Dussault et al., 2014). Every year, around $30 \%$ of people suffer from foodborne diseases in developed countries (Lee et al., 2014). Meanwhile, due to the increased consumer awareness to the use of synthetic food preservatives or aromatic agents, the tendency toward natural ones is gaining more and more attention (Alikhani-Koupaei, 2015). In light of that, using EO with antioxidant, antibacterial and antifungal properties and applying nanoparticulate systems are effective approaches in this regard (Bazzaz et al., 2018; Khatibi et al., 2017). In 2017, Cui and his coworkers developed thyme EO-loaded liposomes to treat salmonellosis, an important food-borne disease, usually associated with direct consumption or cross contamination of animal origin foods, especially poultry, and poultry related products (Cui et al., 2017b). They investigated in their study the time-kill analysis of liposome-encapsulated thyme oil on fresh chicken contaminated with Salmonella enteritidis. Results demonstrated that Salmonella enteritidis colonies reduced by $71.16,90.45,83.02,89.53$ and $97.71 \%$ after exposure to $300 \mathrm{mg} / \mathrm{mL}$ liposomes for $3,4,5,6$, and 7 days, respectively (Cui et al., 2017b). In another work study, the antimicrobial activity of curry plant EO loaded-liposomes against Bacillus cereus in rice flour was investigated (Cui et al., 2017a). Results showed that the antibacterial activity and active time of curry plant EO loaded-liposomes were significantly boosted when compared to the free EO. For instance, the 
population of Bacillus cereus in rice flour was almost unchanged or even increased after EO treatment. However, it reduced significantly after 4 days liposomes treatment (Cui et al., 2017a). Gomes et al. (2011b) related the boosting in trans cinnamaldehyde or -eugenol against both Salmonella and Listeria Spp activity to three reasons: the improved hydrophilicity, the sustained release, and the small size of pNPs. In 2018, Lin et al. investigated the antimicrobial activity of thyme EO-loaded liposomes against Escherichia coli O157:H7 in four vegetable juices: tomato, carrot, cucumber and lettuce juices (Lin et al., 2018). Indeed, Enterohaemorrhagic Escherichia coli serotype O157:H7 as a main human pathogen may cause food borne outbreaks, bloody diarrhea, hemorrhagic colitis and hemolytic uremic syndrome and even death (Khatibi et al., 2017). Results showed that solid liposomes exhibited significant reduction in Escherichia coli $\mathrm{O} 157: \mathrm{H} 7$ when compared to group control. For instance, no bacterial growth was observed on nutrient agar plate in the case of cucumber juice and lettuce juice treated with $5 \mathrm{mg} / \mathrm{mL}$ liposomes. While, treating tomato juice and carrot juice with the same concentration of liposomes lead to 99.99 and $99.80 \%$ reduction of Escherichia coli O157:H7 (Lin et al., 2018). Moreover, Khatibi et al. (2017) found that the relative transcriptional level of Stx2A gene of Escherichia coli $\mathrm{O} 157: \mathrm{H} 7$ was decreased from 0.721 to 0.646 when using $75 \%$ minimum inhibitory concentration (MIC) of Zataria multiflora EO loaded-nanoliposomes.

The antibacterial mechanism of EOs loaded-nanocarriers has been investigated. In 2015, Cui et al. investigated the antibacterial mechanism of liposomes containing clove EO against Staphylococcus aureus in Tofu (Cui et al., 2015). A selective antimicrobial activity for Staphylococcus aureus by means of pore-forming toxins to activate clove oil release from liposomes was noticed. In fact, the liposomes did not fuse with biological membranes but release clove oil after toxins secretion by the bacteria. About $99.87 \%$ reduction in population was observed in Staphylococcus aureus after $24 \mathrm{~h}$ of liposome treatment. However, no 
reduction was observed in Escherichia coli population after liposome treatment due to the fact that these bacteria did not secrete toxins and therefore clove oil could not reach them (Cui et al., 2015).

The antioxidant and antimicrobial activities of EO-loaded nanocarriers were found to be conserved for long period. In this context, the physicochemical qualities of fresh-cut bananas in contact with free rosemary EO, rosemary oil plus mucilage and rosemary oil liposomes were evaluated during 9 days storage at $5^{\circ} \mathrm{C}$ (Alikhani-Koupaei, 2015). Sensory analysis revealed that liposomal formulations was more efficient in enhancing the quality of fresh-cut bananas and extending their shelf life (Alikhani-Koupaei, 2015). Likewise, the conversion of cardamom EO to NLC (Nahr et al., 2018) and nanoliposomes (Nahr et al., 2019) greatly conserves its antioxidant and antimicrobial activities for long period. The NLC showed MIC values around $1100 \mu \mathrm{g} / \mathrm{ml}$ for both bacteria after 30 days compared to that of cardamom oil emulsion. The MIC values were around 4400 and $2200 \mu \mathrm{g} / \mathrm{ml}$ for Staphylococcus aureus and Escherichia coli, respectively (Nahr et al., 2018).

The biological activity of nanocarriers encapsulated plant oils was affected by operating parameters and particles ingredients. In 2017, Mohammed and his coworkers depicted that a high antioxidant efficiency of Nigella sativa EO-loaded microparticles prepared by spray drying process was associated with high ratio of wall material $(30 \%)$, medium of oil concentration $(10 \%)$ and low inlet temperature $\left(160^{\circ} \mathrm{C}\right)$ (Mohammed et al., 2017). Furthermore, Bazzaz et al. (2018) investigated the antimicrobial activity of SLN encapsulated Eugenia caryophyllata EO against Salmonella typhi, Pseudomonas aeruginosa, Staphylococcus aureus and Candida albicans using time-kill methods. Results demonstrated that the SLN formulations were effective in Gram negative bacteria and fungi killing, especially those containing stearic acid compared to glycerol monostearate (Bazzaz et al., 2018). 

by several work studies (Cui et al., 2016a, 2016b; Engel et al., 2017; Liu et al., 2017). Cinnamon

1329

1330

1331

1332

1333

1334

1335

1336

1337

1338

1339

1340

1341

1342

1343

1344

1345

EO, known for its antimicrobial properties, has been formulated in chitosan/poly lactic acid fibers for food packaging application as an alternative for synthetic chemicals due to consumer concerns over food safety (Liu et al., 2017). Results showed high long-term inactivation rates against Escherichia coli and Staphylococcus aureus (Liu et al., 2017). Cinnamon EO was further formulated in liposomes and tested for its Methicillin-resistant Staphylococcus aureus antibiofilm properties on the surfaces of different materials like stainless steel, gauze, nylon membrane, and non-woven fabrics (Cui et al., 2016a). Results revealed a significant enhancement of the anti-biofilm activities and active time for liposome-encapsulated cinnamon EO when compared to the free oil. For instance, the counts of viable Staphylococcus aureus in biofilms formed were reduced by 2.08 and $2.82 \operatorname{logs}$ on gauze and 4.55 and 5.42 logs on nonwoven fabrics after five days treatment with free cinnamon oil and liposome containing cinnamon oil, respectively (Cui et al., 2016a). Additionally, the antibacterial effect of salvia EO nanoliposomes against Staphylococcus aureus biofilms attached on milk container was explored by scanning electron microscopy and confocal laser scanning microscopy and results revealed that salvia EO nanoliposomes have high anti-biofilm activity against Staphylococcus aureus biofilms on milk container (Cui et al., 2016b). Furthermore, Engel et al. (2017) noticed the antimicrobial potential of liposome-encapsulated thymol and carvacrol against pools of Staphylococcus aureus and Salmonella adhered to stainless steel.

\subsection{Medicinal field}

\subsubsection{Antimicrobial activity}

The management of bacterial infection is raising serious concern across the globe. The emergence of multi-drug-resistant bacterial pathogens and the ability of microorganisms to form biofilms result high tolerance to high amounts of antibiotics and to all host defense 
mechanisms (Mandal et al., 2014). Faced with this challenge, the scientists throughout the world search for new antimicrobial agents, such as plant oils based formulations which are economic and ecologic antimicrobial agents; and combine them with nanotechnology (Liakos et al., 2018). In this context, Ianniteli et al. (2011) investigated the effects of carvacrol-loaded poly (lactide-co-glycolide)-nanocapsules on the viscoelastic features of Staphylococcus epidermidis biofilms by rheological measurements. Results revealed the ability of carvacrol loaded nanoparticles to reduce the elasticity and mechanical stability of preformed biofilms which in turn enable the penetration of antimicrobial agents into the deep core of biofilms (Iannitelli et al., 2011). Liakos et al. (2016) tested the antibiofilm activity of poly lactide nanoparticles encapsulating lemongrass EO against Candida albicans, Escherichia coli, Staphylococcus aureus and Pseudomonas aeruginosa. Results showed higher anti-biofilm effect for Candida albicans and Escherichia coli tested strains. The cytotoxicity of the prepared nanoparticles was further analyzed and results revealed a high cell viability and good growth of human cells (Liakos et al., 2016). Subsequently, in 2018, the same research team tested the antibiofilm activity of cellulose acetate pNPs containing either lemongrass, peppermint or cinnamon EO and the results showed high antibiofilm activity against Candida albicans and Staphylococcus aureus (Liakos et al., 2018). Manconi et al. (2018)proposed the use of liposomes containing Thymus capitatus EO as antibacterial-antioxidant mouthwash for the treatment of oral cavity diseases. The liposomes were biocompatible, able to prevent oxidative stress and favor wound repair in keratinocytes. Their antibacterial activity was evidenced against commensal Streptococcus sanguinis and cariogenic Streptococcus mutans and Lactobacillus acidophilus (Manconi et al., 2018). Similarly, Priyadarshini et al. (2018) proposed the use of poly (lactide-co-glycolide)-nanoparticles containing clove EO as antibacterial systems for dental purposes by removing bacterial plaque and reducing dental diseases. Confocal microscopy demonstrated successful delivery and position of clove oil 
loaded-nanoparticles inside dentinal tubules. In another work study, the antiviral activity of Santolina insularis EO loaded-liposomes against Herpes simplex virus-type 1 was investigated (Valenti et al., 2001). Although the in vitro activity of free oil was higher than liposomal oil, the high stability of liposomes make them an interesting delivery system for antiviral treatment; they could be administered in drops for ocular herpetic infection, parenterally for diffused systemic infections or topically on lips and mucosae from gel or cream formulations (Valenti et al., 2001). Furthermore, Zhao et al. (2017) highlighted the use of SLN as a carrier for the encapsulation and sustained inhalation delivery of yuxingcago EO for the treatment of respiratory infectious diseases. Besides prolonging pulmonary retention up to $24 \mathrm{~h}$ after intratracheal administration to rats, yuxingcago EO loaded-SLN enhance the area under the curve (AUC) values by 4.5-7.7 folds compared to the intratracheally dosed EO solution and by 257-438 folds to the intravenously dosed EO solution (Zhao et al., 2017).

\subsubsection{Antifungal activity}

Considering the antifungal properties of Zataria multiflora EO, Nasseri et al. developed Zataria multiflora EO loaded-SLN to enhance its activity against Aspergillus ochraceus, Aspergillus niger, Aspergillus flavus, Alternaria solani, Rhizoctonia solani, and Rhizopus stolonifera (Nasseri et al., 2016). Results showed that the encapsulated oil was more efficient than the free one. For instance, the MIC for the encapsulated oil on the fungal pathogens of Aspergillus ochraceus, Aspergillus niger, Aspergillus flavus, Alternaria solani, Rhizoctonia solani, and Rhizopus stolonifer was 200, 200, 200, 100, 50 and 50 ppm, respectively; while for un-encapsulated oil, it was 300, 200, 300, 200, 200 and 200 ppm (Nasseri et al., 2016). Furthermore, the nanoencapsulation enhanced the antifungal properties of copaiba oil against Candida krusei, Microsporum canis, Candida parapsilosis and Trichophyton rubrum with $\mathrm{MIC}_{90}$ values of $250,1.95,7.8$ and $1.95 \mu \mathrm{g} / \mathrm{mL}$, respectively. In another work study, microparticles encapsulating Lippia sidoides EO were found more efficient than ketaconazole, 
used as positive control, in eradicating Candida albicans, Candida glabrata, Candida krusei and Candida parapsilosis (Fernandes et al., 2008).

Recently, many studies related the occurrence of some diseases like teratogenesis, mutation and hepatocellular carcinoma to the high exposure to aflatoxin which is secondary metabolites synthesized by toxigenic fungi: Aspergillus flavus, Aspergillus parasiticus and Aspergillus nomius. López-meneses et al. (2018) investigated the antifungal and antiaflatoxigenic activities against Aspergillus parasiticus of Shinus molle EO-loaded chitosan nanoparticles. Results showed that the prepared nanoparticles affected the spore's germination and viability, delayed mycelial growth and reduced aflatoxin production.

\subsubsection{Larvicidal activity}

Currently, several reports has demonstrated the larvicidal activity of Lippia sidoides EO against larvae of Aedes (Stegomyia aegypti), the dengue vector which is responsible for many diseases, and even deaths, in tropical countries like Brazil (Carvalho et al., 2003). In order to boost its larvicidal effect, Paula et al. (2010) developed angico gum : chitosan nanoparticles containing Lippia Sidoides EO and investigated the in vivo activity on 20 third instar Stegomyia aegypti larvae. Results demonstrated that the larval mortality was proportional to the oil loading. For instance, the sample oil: angico gum-chitosan 1:20 showed the lowest loading (3.3\%) and consequently the lowest mortality, with $52 \%$ after $24 \mathrm{~h}$ and $60 \%$ after $48 \mathrm{~h}$. Sample oil: angico gum-chitosan 1:10 showed 85 and $92 \%$ mortality after 24 and 48 h, respectively (Paula et al., 2010). Similar results were found by Abreu et al. when studying the larvicidal activity of Lippia Sidoides EO loaded-cashew gum : chitosan nanoparticles (Abreu et al., 2012).

\subsubsection{Antitumor activity}

The antitumor activity of frankincense and myrrh oil loaded-SLN was assessed on H22 tumor-bearing mice and results revealed an enhancement in antitumor efficiency of SLN when compared to that of suspension and cyclodextrine inclusion (Wang, 2012). The inhibition rates 
were $31.23,34.81$ and $43.66 \%$ for oil suspension, oil- $\beta$-cyclodextrin and oil-SLN, respectively.

1428

1429

Similarly, Celia et al. (2013) found that liposomal formulations encapsulating bergamot EO showed a greater reduction in human SH-SY5Y neuroblastoma cells viability and a greater increase in cell mortality at various concentrations and time points as compared to their free drug counterparts. Same results were also reported by Detoni et al. (2012) where MLVs and SUVs containing Zanthoxylum tingoassuiba $E O$ were more efficient in reducing the viability of glioma cells than free EO. In another work study, docosahexaenoic acid was encapsulated in liposomes and investigated for its anticancer activity and results showed a strong inhibition of FaDu head, neck squamous carcinoma and 4T1 breast cancer cells in in vitro cultures (Alaarg et al., 2016). In 2013, Shi and his coworkers developed NLC containing $\beta$-elemene and investigated their pharmacokinetics, anti-tumor effects, and venous irritation (Shi et al., 2013). In this study, $\beta$-elemene-NLC suspensions were injected in an ear vein test, and compared with elemene injection and saline solution used as positive and negative controls, respectively. Results demonstrated no obvious discoloration or damage at the injection site in either $\beta$ elemene-NLC groups or saline solution group, two days after the injection. However, unencapsulated $\beta$-elemene caused macroscopic edema and erythema at the injection site. Additionally, the pharmacokinetic study revealed that the availability of the $\beta$-elemene was increased by formulation into NLC since they showed higher AUC and slower clearance as compared to elemene injection. Furthermore, the anti-tumor efficacy of $\beta$-elemene-NLC was significantly higher than that of elemene injections with inhibition rates of 34.36 and $24.11 \%$, respectively (Shi et al., 2013).

\subsection{Cosmetic field}

Wound healing is one of the most complicated physiological processes. Indeed, tissue regeneration enhancement and infection prevention are key factors to reduce pain, discomfort, and scar formation (Jahromi et al., 2018). Several chemical products have been proposed for 
wound repair; however, their uses are limited due to the complications and side effects (Purohit et al., 2012). Recently, researchers have paid great attention to the effectiveness of plant oils thanks to their antioxidant, antimicrobial, and anti-inflammatory properties (Raut and Karuppayil, 2014). In this context, Ghodrati et al. (2019) investigated the therapeutic effect of NLC containing peppermint EO on infected wound. For in vivo study, two full-thickness wounds with the size of $5 \mathrm{~mm}$ were created in each mouse and inoculated with Pseudomonas aeruginosa and Staphylococcus aureus. Results showed that peppermint EO-NLC could accelerate wound healing in the infected wound model by reducing the total bacterial count, and increasing neovascularization, fibroblast infiltration, collagen deposition, re-epithelization, and levels of FGF-2 and EGF mRNA expressions when compared to control group. Similarly, Zhang et al. reported a decrease in TGF- $b 1$, MMP-1, collagen I and collagen III levels and an increase in apoptosis cells, caspase -3 and -9 levels after application of Ligusticum chuanxiong EO-loaded liposomes on formed hypertrophic scars in the rabbit ear model (H. Zhang et al., 2012). Furthermore, NLC based on olive oil and loaded with eucalyptus oil promote wound healing in rat burn model by cell proliferation enhancement, good bioadhesion, cell biocompatibility and antimicrobial properties (Saporito et al., 2018). In 2018, Pivetta et al. prepared carbopol-gels containing thymol loaded-NLC as promising approach for treating skin inflammatory disorders (Pivetta et al., 2018). In their study, they investigated the antiinflammatory effects of thymol-NLC gel on two mouse models: the cutaneous acute inflammation model induced by croton oil and ear edema model induced by anthralin. Results showed that thymol encapsulated in NLC provided better anti-inflammatory effect than free thymol (Pivetta et al., 2018).

Chronic skin infections in immunocompromised patients has become an important public health issue because they can become serious, resulting in invasive infections (Svetlichny et al., 2015). In this context, Ortan et al. (2013) developed hydrogels containing 
Anethum graveolens oil entrapped in liposomes to treat fungal infections in skin. The in vitro release kinetics study using Franz diffusion cell showed that the designed hydrogels follow a zero order kinetic model after a period of three hours from the beginning of the experiment (Ortan et al., 2013). Moreover, hydrogel containing eugenol entrapped in either stearic acid- or compritol-SLN were designed for epidermal targeting to treat fungal infections in skin (Garg and Singh, 2013). Ex vivo permeation and retention studies for almond oil solution of eugenol and three types of hydrogels containing: eugenol-stearic acid-SLN, eugenol-compritol-SLN or eugenol-hydroxypropyl- $\beta$-cyclodextrin complex; were established with full thickness human cadaver skin using Franz diffusion cell. Results revealed higher accumulation of eugenol in the epidermis (62.65 and $52.86 \mu \mathrm{g} / \mathrm{cm}^{2}$ for eugenol-stearic acid-SLN and eugenol-compritol-SLN, respectively) when compared to that of almond oil solution of eugenol $\left(3.45 \mu \mathrm{g} / \mathrm{cm}^{2}\right)$ and eugenol-hydroxypropyl- $\beta$-cyclodextrine complex $\left(9.77 \mu \mathrm{g} / \mathrm{cm}^{2}\right)($ Garg and Singh, 2013).

Currently, VO exhibit a great concern as raw materials in the development of natural and eco-friendly cosmetics due to their benefits including antioxidant, moisturizers and emollients properties. In addition, they provide skin protection against reactive oxygen species and prevent oxidative stress (Dhavamani et al., 2014; Saraf et al., 2010). In order to obtain efficient formulations with UV protection performance and antioxidant activity, Badea et al. (2015) formulated creams containing NLC entrapping various VO and their combinations (pomegranate seed oil, wheat germ oil, blackcurrant seed oil, sesame seed oil, carrot root oil, raspberry seed oil and rice bran oil) with a synthetic UVA filter (diethylamino hydroxy benzoyl hexyl benzoate). The UV protection factors were evaluated on the individual VO and on cream formulations based on NLC and results showed that the best UV protection was assured by pomegranate seed oil combined with wheat germ-loaded NLC based cream resulting in a SPF of 5.1 and an UVAPF of 9.5 (Badea et al., 2015).

\subsection{Textiles}



as they enhance the native properties and promote new functions in the textile products like flame retardency, UV resistance, photo-catalytic, antimicrobial, antibiotic and wrinkle recovery to the fabrics (Javid et al., 2014). In medical field, textile consumers are becoming more aware and conscious of the deleterious effect that microorganisms may have upon textile materials like drapes, bed sheets, pillow cases, gowns and masks which are frequently used in hospitals (Thelagavath and Kannaian, 2008). In this context, Li et al. (2013) grafted moxa oil microcapsules made with gelatin and arabic gum on cotton fabric and investigated their antibacterial activity against Staphylococcus aureus and the results showed strong antibacterial effect. Similarly, ozonated red pepper seed oil antimicrobial microcapsules were applied on $100 \%$ polypropylene non-woven fabric and showed good antimicrobial activity against Staphylococcus aureus, Escherichia coli and Candida albicans (Ozyıldız et al., 2012). Furthermore, Rajendran et al. (2013) reported that Ocimum sanctum oil loaded alginatenanoparticles possessed remarkable antibacterial activities with excellent wash durability. After 20 washes, the inhibition percentage was $100 \%$ for Bacillus cereus, Pseudomonas aeruginosa and Staphylococcus aureus except for Escherichia coli (90\%). After 30 washes, the bacterial inhibition was reduced to 95, 87, 98 and 98\% for Bacillus cereus, Escherichia coli, Pseudomonas aeruginosa and Staphylococcus aureus, respectively (Rajendran et al., 2013). In 2013, Javid et al. reported that antibacterial activity of cotton fabric grafted with chitosan Recent developments in textile industry were conducted to perfumed textiles in jackets, sweaters, T-shirts and undershirts to meet consumers' needs for comfort and wellbeing. During wearing, the mechanical forces on the capsules result in opening of the capsules and releasing of the designed aroma and deodorant (Ghayempour and Montazer, 2016). In this context, Liu 
et al. (2015) treated methyl methacrylate-styrene nanoparticles containing cologne EO on the cotton fabric through immersion and the release study revealed that $6.8 \%$ cologne EO remained in fabrics after being washed 15 times. In another work, Wang et al. reported that ethyl cellulose microcapsule can retain $50 \%$ of the lavender oil after 2 months, while almost no EO persisted on the direct sprayed fabric after 7 days (Wang et al., 2009). Additionally, Li et al. (2013) found that orange oil retention of microcapsules on the cotton and polyester fabrics was 8 days longer than free oil.

\section{Conclusion and perspectives}

In the last two decades, the growing demand for natural bioactive products especially essential and vegetable oils with the same efficiency or even more than chemical synthesized drugs has urged researchers to focalize most of their efforts on developing new approaches of extending the shelf life of these bioactive agents. In fact, plant oils are very sensitive to external factors when used as such. The encapsulation of these bioactive agents represents a relevant alternative to extend their physical stabilities, protecting them from oxidation and other deleterious environmental factors like light, heat, oxygen and humidity, besides improving their efficacy mainly owning to their nanometer size range. In this bibliographic paper, we emphasize recent advances of both polymer and lipid based-nanocarriers including polymeric nanoparticles, liposomes and solid lipid nanoparticles in the emergence of new concepts for the effective use of plant oils. A number of benefits and drawbacks are linked to each carrier. For instance, both solid lipid nanoparticles and polymeric nanoparticles have more oil stability and prolonged release than liposomes; while liposomes offer wide application spectrum especially to the skin delivery thanks to their chemical nature which is very close to that of the skin layers. Although solid lipid nanoparticles are safer than polymeric nanoparticles since the avoidance of organic solvents, they were less used to encapsulate both essential and vegetable oils, according to the investigations discussed above. This was may be related to the high 
temperature requirements which in turn cause oil loss and thus decrease the encapsulation efficiency. Several preparation methods have been reported for each nanocarrier; they are differentiated by the complexity of their execution and the characteristic of their final product; nonetheless, the right selection of the suitable carrier with the appropriate preparation method is the crucial key to determine the carrier features responsible for the best attainment of the final goal. The discussed nanostructured systems provide pertinent perspectives for applications in several fields like medicinal, cosmetic, culinary, agriculture and textiles. Nowadays, the association of plants oils and active molecules is attracting special attention. Lipid core nanocapsules and nanostructured lipid carriers represent promising carriers to entrap both plant oil and synthetic drugs. The appropriate selection of plant oil is very important for achieving the high loading capacity and physical stability of the hydrophobic drugs. In addition, the oil may complement or even enhance the biological activities of these drugs. Hence, the research in the field of plants oils encapsulation can make an important contribution to the development of new methodologies in the treatment and diagnosis of major chronic diseases.

Experimental advances are necessary in engineering plant oils loaded nanocarriers with broader applications and functionalities. Some techniques discussed in this review provide poor control over the final structure and stability of the obtained colloidal systems. Others lack from scalability and reproducibility; therefore, new techniques with improved control and reproducibility are crucial to design nanocarriers with predictable properties.

Even if several advances have been already reported in the literature regarding the application of plants oils nanocarriers for pharmaceutical and cosmetics purposes, more in vivo studies are required to provide reliable results. Additionally, plant oils mechanism of action, toxic effects, pharmacokinetic parameters, biodistribution in biological systems and removal mechanisms must be investigated. Moreover, with the aim of improving the biodistribution of colloidal systems, scientists throughout the world are currently focalizing their efforts on the 
functionalization of the particle surface with special ligands to target specific organs and tissues.

However, to our knowledge, there are no reports in the literature that deal with targeting delivery of plant oils loaded nanocarriers. Such demonstrations would provide a blueprint for the development of new concepts and products in large-scale for broader application.

\section{CRediT authorship contribution statement}

Narimane Lammari: Conceptualization, Writing - original draft, Investigation, Visualization.

Ouahida Louaer: Supervision, Writing - review \& editing. Abdeslam Hassen Meniai: Writing - review \& editing. Hatem Fessi: Conceptualization. Abdelhamid Elaissari: Supervision, Writing - review \& editing, Conceptualization.

\section{Declaration of Competing Interest}

The authors declare that they have no known competing financial interests or personal relationships that could have appeared to influence the work reported in this paper.

\section{Funding}

This research did not receive any specific grant from funding agencies in the public, commercial, or not-for-profit sectors.

\section{References}

Abdullah, S.W., Ahmed, K.S.D., Khidher, K.Q., 2018. Plant essential oils as grain protectants against Rhizopertha dominica (Coleoptera:Bostrichidae) during storage. Tikrit J. Pure Sci. $23,41-44$.

Abreu, F.O.M.S., Oliveira, E.F., Paula, H.C.B., Paula, R.C.M., 2012. Chitosan/cashew gum nanogels for essential oil encapsulation. Carbohydr. Polym. 89, 1277-1282. https://doi.org/10.1016/j.carbpol.2012.04.048

Adel, M.., Atwa, W.., Hassan, M.., Salem, N.., Farghaly, D.S., Ibrahim, S.., 2015. Biological activity and field persistence of Pelargonium graveolens (Geraniales: Geraniaceae) loaded solid lipid nanoparticles (SLNs) on Phthorimaea operculella (Zeller) (PTM) 
(Lepidoptera : Gelechiidae). Int. J. Sci. Res. 4, 514-520.

Ahsaei, S.M., Talebi-Jahromi, K., Amoabediny, G., 2020. Insecticidal activity of polycaprolactone nanoparticles decorated with chitosan containing two essential oils against Tribolium confusum. Int. $\mathrm{J}$. Pest Manag. https://doi.org/10.1080/09670874.2020.1825875

Alaarg, A., Jordan, N.Y., Verhoef, J.J.F., Metselaar, J.M., Storm, G., Kok, R.J., 2016. Docosahexaenoic acid liposomes for targeting chronic inflammatory diseases and cancer : an in vitro assessment. Int. J. Nanomedicine 11, 5027-5040.

Ali, B., Al-Wabel, N.A., Shams, S., Ahamad, A., Khan, S.A., Anwar, F., 2015. Essential oils used in aromatherapy: A systemic review. Asian Pac. J. Trop. Biomed. 5, 601-611.

Ali, F.R., El-Anany, A.M., 2017. Hypolipidemic and hypocholesterolemic effect of roselle (Hibiscus sabdariffa L.) seeds oil in experimental male rats. J. Oleo Sci. 66, 41-49.

Alikhani-Koupaei, M., 2015. Liposomal and edible coating as control release delivery systems for essential oils : comparison of application on storage life of fresh-cut banana. Qual. Assur. Saf. Crop. Foods 7, 175-185. https://doi.org/10.3920/QAS2013.0297

Allen, T.M., Cullis, P.R., 2013. Liposomal drug delivery systems: from concept to clinical applications. Adv. Drug Deliv. Rev. 65, 36-48.

Almeida, J.S., Jezur, L., Fontana, M.C., Paese, K., Silva, C.B., Pohlmann, A.R., Guterres, S.S., Beck, R.C.R., 2009. Oil-based nanoparticles containing alternative vegetable oils (grape seed oil and almond kernel oil): Preparation and characterization. Lat. Am. J. Pharm. 28, $165-172$.

Almoustafa, H.A., Alshawsh, M.A., Chik, Z., 2017. Technical aspects of preparing PEG-PLGA nanoparticles as carrier for chemotherapeutic agents by nanoprecipitation method. Int. J. Pharm. 533, 275-284.

Antonioli, G., Fontanella, G., Echeverrigaray, S., Delamare, A.P.L., Pauletti, G.F., Barcellos, 

T., 2020. Poly(lactic acid) nanocapsules containing lemongrass essential oil for postharvest decay control: In vitro and in vivo evaluation against phytopathogenic fungi. Food Chem. 326, 126997.

Auezova, L., Najjar, A., Kfoury, M., Fourmentin, S., Greige-Gerges, H., 2020. Antibacterial activity of free or encapsulated selected phenylpropanoids against Escherichia coli and Staphylococcus epidermidis. J. Appl. Microbiol. 128, 710-720.

Averina, E., Allémann, E., 2013. Encapsulation of alimentary bioactive oils of the Baikal Lake area into pH-sensitive micro- and nanoparticles. LWT - Food Sci. Technol. 53, 271-277. https://doi.org/10.1016/j.lwt.2013.01.020

Azizi, M., Li, Y., Kaul, N., Abbaspourrad, A., 2019. Study of the physicochemical properties of fish oil solid lipid nanoparticle in the presence of palmitic acid and quercetin. J. Agric. Food Chem. 67, 671-679. https://doi.org/10.1021/acs.jafc.8b02246

Azzi, J., Auezova, L., Danjou, P., Fourmentin, S., Greige-Gerges, H., 2018. First evaluation of drug-in-cyclodextrin-in-liposomes as an encapsulating system for nerolidol. Food Chem. 255, 399-404. https://doi.org/10.1016/j.foodchem.2018.02.055

Badea, G., Ioana, L., Badea, N., Ott, C., Meghea, A., 2015. Use of various vegetable oils in designing photoprotective nanostructured formulations for UV protection and antioxidant activity. Ind. Crop. Prod. 67, 18-24. https://doi.org/10.1016/j.indcrop.2014.12.049

Badri, W., Asbahani, A. El, Miladi, K., Baraket, A., Agusti, G., Agha, Q., Errachid, A., Fessi, H., Elaissari, A., 2018. Poly ( $\varepsilon$-caprolactone ) nanoparticles loaded with indomethacin and Nigella Sativa L. essential oil for the topical treatment of inflammation. J. Drug Deliv. Sci. Technol. 46, 234-242. https://doi.org/10.1016/j.jddst.2018.05.022

Badri, W., Miladi, K., Eddabra, R., Fessi, H., Elaissari, A., 2015. Elaboration of nanoparticles containing indomethacin: Argan oil for transdermal local and cosmetic application. J. Nanomater. 2015, 1-9. https://doi.org/10.1155/2015/935439 
Bae, E.K., Lee, S.J., 2008. Microencapsulation of avocado oil by spray drying using whey protein and maltodextrin. J. Microencapsul. 25, 549-560. https://doi.org/10.1080/02652040802075682

Bagheri, R., Ariaii, P., Motamedzadegan, A., 2020. Characterization, antioxidant and antibacterial activities of chitosan nanoparticles loaded with nettle essential oil. Food Meas. https://doi.org/10.1007/s11694-020-00738-0

Bai, C., Zheng, J., Zhao, L., Chen, L., Xiong, H., Mcclements, D.J., 2019. Development of oral delivery Systems with enhanced antioxidant and anticancer activity : coix seed oil and $\beta$ carotene coloaded liposomes. J. Agric. Food Chem. 67, 406-414. https://doi.org/10.1021/acs.jafc.8b04879

Bai, X., Li, C., Yu, L., Jiang, Y., Wang, M., Lang, S., Liu, D., 2019. Development and characterization of soybean oil microcapsules employing kafirin and sodium caseinate as wall materials. LWT 111, 235-241. https://doi.org/10.1016/j.lwt.2019.05.032

Baldim, I., Tonani, L., von Zeska Kress, M.R., Pereira Oliveira, W., 2019. Lippia sidoides essential oil encapsulated in lipid nanosystem as an anti-candida agent. Ind. Crops Prod. 127, 73-81. https://doi.org/10.1016/j.indcrop.2018.10.064

Bangham, A.D., Standish, M.M., Watkins, J.C., 1965. Diffusion of univalent ions across the lamellae of swollen phospholipids. J. Mol. Biol. 13, 238-252.

Bashiri, S., Ghanbarzadeh, B., Ayaseh, A., Dehghannya, J., Ehsani, A., 2020a. Preparation and characterization of chitosan-coated nanostructured lipid carriers $(\mathrm{CH}-\mathrm{NLC})$ containing cinnamon essential oil for enriching milk and anti-oxidant activity. LWT - Food Sci. Technol. 119, 108836.

Bashiri, S., Ghanbarzadeh, B., Ayaseh, A., Dehghannya, J., Ehsani, A., Adun, P., 2020b. Essential oil-loaded nanostructured lipid carriers: The effects of liquid lipid type on the physicochemical properties in beverage models. Food Biosci. 35, 100526. 
https://doi.org/10.1016/j.fbio.2020.100526

1678

1679

1680

1681

1682

1683

1684

1685

1686

1687

1688

1689

1690

1691

1692

1693

1694

1695

1696

1697

1698

1699

1700

1701

Batzri, S., Korn, E.D., 1973. Single bilayer liposomes prepared without sonication. Biochim. Biophys. Acta - Biomembr. 298, 1015-1019.

Bayón-Cordero, L., Alkorta, I., Arana, L., 2019. Application of solid lipid nanoparticles to improve the efficiency of anticancer drugs. Nanomaterials 9, 474.

Bazzaz, B.S.F., Khameneh, B., Namazi, N., Iranshahi, M., Davoodi, D., Golmohammadzadeh, S., 2018. Solid lipid nanoparticles carrying Eugenia caryophyllata essential oil : the novel nanoparticulate systems with broad-spectrum antimicrobial activity. Lett. Appl. Microbiol. 66, 506-513. https://doi.org/10.1111/lam.12886

Beirão da costa, S., Duarte, C., Bourbon, A.I., Pinheiro, A.C., Januário, M.I.N., Vicente, A.A., Beirão-da-costa, M.L., Delgadillo, I., 2013. Inulin potential for encapsulation and controlled delivery of oregano essential oil. Food hydrocolloids. 33, 199-206. https://doi.org/10.1016/j.foodhyd.2013.03.009

Beirão da costa, S., Duarte, Claudia, Bourbon, A.I., Pinheiro, A.C., Teresa, A., Moldão, M., Isabel, M., Januário, N., Vicente, A.A., Delgadillo, I., Duarte, Catarina, Luísa, M., 2012. Effect of the matrix system in the delivery and in vitro bioactivity of microencapsulated oregano essential oil. J. Food Eng. 110, 190-199. https://doi.org/10.1016/j.jfoodeng.2011.05.043

Benhabiles, M.S., Salah, R., Lounici, H., Drouiche, N., Goosen, M.F.A., Mameri, N., 2012. Antibacterial activity of chitin, chitosan and its oligomers prepared from shrimp shell waste. Food Hydrocoll. 29, 48-56.

Bilia, A.R., Guccione, C., Isacchi, B., Righeschi, C., Firenzuoli, F., Bergonzi, M.C., 2014. Essential oils loaded in nanosystems : A developing strategy for a successful therapeutic approach. Evidence-Based Complement. Altern. Med. 2014, 1-14.

Boukroufa, M., Boutekedjiret, C., Petigny, L., Rakotomanomana, N., Chemat, F., 2015. Bio- 
refinery of orange peels waste: A new concept based on integrated green and solvent free extraction processes using ultrasound and microwave techniques to obtain essential oil, polyphenols and pectin. Ultrason. Sonochem. 24, 72-79.

Calo, J.R., Crandall, P.G., O’Bryan, C.A., Ricke, S.C., 2015. Essential oils as antimicrobials in food systems - A review. Food Control 54, 111-119.

Calvo, P., Remunan Lopez, J.L., Vila-Jato, Alonso, M.J., 1997. Novel hydrophilic chitosan polyethylene oxide nanoparticles as protein carriers. J. Appl. Polym. Sci. 63, 125-132.

Campo, C. De, Pereira, P., Maria, T., Costa, H., Guterres, S.S., Rios, A.D.O., Flôres, H., 2017. Nanoencapsulation of chia seed oil with chia mucilage (Salvia hispanica L.) as wall material: characterization and stability evaluation. Food Chem. 234, 1-9. https://doi.org/10.1016/j.foodchem.2017.04.153

Cao, Y., Zhou, W., Li, J., Huang, X., Yuan, Y., Lin, L., 2016. Preparation and stability evaluation of pectin coated galanga essential oil liposomes, in: 2nd International Conference on Architectural, Civil and Hydraulics Engineering (ICACHE 2016) Preparation. pp. 285-290.

Carneiro, H.C.F., Tonon, R. V, Grosso, C.R.F., Hubinger, M.D., 2013. Encapsulation efficiency and oxidative stability of flaxseed oil microencapsulated by spray drying using different combinations of wall materials. J. Food Eng. 115, 443-451. https://doi.org/10.1016/j.jfoodeng.2012.03.033

Carneiro, N.S., Alves, C.C.., Alves, J.M., Egea, M.B., Martins, C.H.., Silva, T.S., Bretanha, L.C., Balleste, M.P., Mlicke, G.A., Silveira, E. V, Miranda, M.L.., 2017. Chemical composition, antioxidant and antibacterial activities of essential oils from leaves and flowers of Eugenia klotzschiana Berg (Myrtaceae). An. Acad. Bras. Cienc. 89.

Carvalho, A., Melo, V., Craveiro, A., Machado, M., Bantim, M., Rabelo, E., 2003. Larvicidal activity of the essential oil from Lippia sidoides Cham. against Aedes aegypti Linn. Mem. 
1728

Carvalho, F.O., Silva, É.R., Nunes, P.S., Felipe, F.A., Ramos, K.P.P., Ferreira, L.A.S., Lima, V.N.B., Shanmugam, S., Oliveira, A.S., Guterres, S.S., Camargo, E.A., Cravalho Olivera, T.V., de Albuquerque Júnior, R.L.C., de Lucca Junior, W., Quintans-Júnior, L.J., Araújo, A.A.S., 2020. Effects of the solid lipid nanoparticle of carvacrol on rodents with lung injury from smoke inhalation. Naunyn. Schmiedebergs. Arch. Pharmacol. 393, 445-455. https://doi.org/10.1007/s00210-019-01731-1

Celia, C., Trapasso, E., Locatelli, M., Navarra, M., Anna, C., Wolfram, J., Carafa, M., Maria, V., Britti, D., Di, L., Paolino, D., 2013. Anticancer activity of liposomal bergamot essential oil (BEO) on human neuroblastoma cells. Colloids Surfaces B Biointerfaces 112, 548553. https://doi.org/10.1016/j.colsurfb.2013.09.017

Ceole, L.F., Cardoso, M.D.G., Soares, M.J., 2017. Nerolidol, the main constituent of Piper aduncum essential oil, has anti-Leishmania braziliensis activity. Parasitology 144, 11791190.

Cerri, G.C., Lima, L.C.F., Lelis, D. de F., Barcelos, L. da S., Feltenberger, J.D., Mussi, S.V., Monteiro-Junior, R.S., Santos, R.A.S. dos, Ferreira, L.A.M., Santos, S.H.S., 2019. Sclareol-loaded lipid nanoparticles improved metabolic profile in obese mice. Life Sci. 218, 292-299. https://doi.org/10.1016/j.1fs.2018.12.063

Chansang, A., Champakaew, D., Junkum, A., Amornlerdpison, D., Chaithong, U., Jitpakdi, A., Riyong, D., Wannasan, A., Intirach, J., Muangmoon, R., Pitasawat, B., 2018. Potential of natural essential oils and cinnamaldehyde as insecticides against the dengue vector Aedes Aegypti (Diptera: Culicidae). Southeast Asian J. Trop. Med. Public Health 49, 6-22.

Chattopadhyay, S., Prez, F. Du, 2016. Simple design of chemically crosslinked plant oil nanoparticles by triazolinedione- ene chemistry. Eur. Polym. J. 81, 77-85. https://doi.org/10.1016/j.eurpolymj.2016.05.022 
Chen, B., Mcclements, D.J., Decker, E.A., 2011. Minor components in food oils : A critical review of their roles on lipid oxidation chemistry in bulk oils and emulsions. Crit. Rev. Food Sci. Nutr. 51, 901-916. https://doi.org/10.1080/10408398.2011.606379

Chen, Y.-F., Wang, Y.-W., Huang, W.-S., Lee, M.-M., Wood, W.G., Leung, Y.-M., Tsai, H.Y., 2016. Trans-cinnamaldehyde, an essential oil in cinnamon powder, ameliorates cerebral ischemia-induced brain injury via inhibition of neuroinflammation through attenuation of iNOS, COX-2 expression and NFא-B signaling pathway. NeuroMolecular Med. 18, 322-333.

Cheng, Y.-T., Lu, C.-C., Yen, G. chin, 2015. Beneficial effects of camellia oil (Camellia oleifera Abel.) on hepatoprotective and gastroprotective activities. J. Nutr. Sci. Vitaminol. $61, \mathrm{~S} 100-\mathrm{S} 102$.

Cherkaoui-Tangi, K., Israili, Z.H., Lyoussi, B., 2016. Vasorelaxant effect of essential oil isolated from Nigella sativa L. seeds in rat aorta: Proposed mechanism. Pak. J. Pharm. Sci. $29,1-8$.

Chew, S.-C., Tan, C.-P., Tan, C.-H., Nyam, K.-L., 2020. In vitro bioaccessibility of spray dried refined kenaf(Hibiscus cannabinus) seed oil applied in coffee drink. J. Food Sci. Technol. 57, 2507-2515. https://doi.org/10.1007/s13197-020-04286-9

Chew, S.C., PingTan, C., Nyam, K.L., 2018. Microencapsulation of refined kenaf (Hibiscus cannabinus L.) seed oil by spray drying using $\beta$-cyclodextrin / gum arabic / sodium caseinate. J. Food Eng. J. 237, 78-85. https://doi.org/10.1016/j.jfoodeng.2018.05.016

Chikezie, P.C., Ibegbulem, C.O., Mbagwu, F.N., 2015. Bioactive principles from medicinal plants. Res. J. Phytochem. 9, 88-115. https://doi.org/10.3923/rjphyto.2015.88.115

Chin, S., Ping, C., Lin, K., 2018. Microencapsulation of refined kenaf (Hibiscus cannabinus L.) seed oil by spray drying using $\beta$-cyclodextrin / gum arabic / sodium caseinate. J. Food Eng. 237, 78-85. https://doi.org/10.1016/j.jfoodeng.2018.05.016 
Chizzola, R., 2013. Regular monoterpenes and sesquiterpenes (essential oils), in: K. G. Ramawat \& J. M. Mérillon (Eds.), Natural products. Springer-Verlag Berlin Heidelberg, pp. 2973-3008. https://doi.org/10.1007/978-3-642-22144-6

Christofoli, M., Cristina, E., Costa, C., Bicalho, K.U., Cássia, V. De, Fernandes, M., Cristina, C., Alves, F., Araújo, W.L., Melo, C. De, 2015. Insecticidal effect of nanoencapsulated essential oils from Zanthoxylum rhoifolium (Rutaceae) in Bemisia tabaci populations. Ind. Crop. Prod. 70, 301-308. https://doi.org/10.1016/j.indcrop.2015.03.025

Conto, L.C. de, Oliveira, R.S.P., Martin, L.G.P., Chang, Y.K., Steel, C.J., 2012. Effects of the addition of microencapsulated omega-3 and rosemary extract on the technological and sensory quality of white pan bread. LWT - Food Sci. Technol. 45, 103-109.

Contri, R. V, Kulkamp-guerreiro, I.C., Janine, S., Frank, L.A., Pohlmann, A.R., Guterres, S.S., 2016. Nanoencapsulation of Rose-Hip oil prevents oil oxidation and allows obtainment of gel and film topical formulations. AAPS PharmSciTech 17, 863-871. https://doi.org/10.1208/s12249-015-0379-9

Corrêa-Filho, L.C., Moldao-Martins, M., Alves, V.D., 2019. Advances in the application of microcapsules as carriers of functional compounds for food products. Appl. Sci. 9, 571. https://doi.org/10.3390/app9030571

Cortesi, R., Esposito, E., Gambarin, S., Telloli, P., Menegatti, E., Nastruzzi, C., 1999. Preparation of liposomes by reverse-phase evaporation using alternative organic solvents. J. Microencapsul. 16, 251-256.

Crucho, C.I.C., Barros, M.T., 2017. Polymeric nanoparticles: A study on the preparation variables and characterization methods. Mater. Sci. Eng. C 80, 771-784.

Cui, H., Li, W., Li, C., Vittayapadung, S., Lin, L., 2016a. Liposome containing cinnamon oil with antibacterial activity against methicillin-resistant Staphylococcus aureus biofilm. Biofouling. 32, 215-225. https://doi.org/10.1080/08927014.2015.1134516 
Cui, H., Li, W., Lin, L., 2017a. Antibacterial activity of liposome containing curry plant essential oil against Bacillus cereus in rice. J. food Saf. 37, 3-7. https://doi.org/10.1111/jfs. 12302

Cui, H., Yuan, L., Ma, C., Li, C., Lin, L., 2017b. Effect of nianoliposome-encapsulated thyme oil on growth of Salmonella enteritidis in chicken. J. food Process. Preserv. 41, 1-9. https://doi.org/10.1111/jfpp.13299

Cui, H., Zhao, C., Lin, L., 2015. The specific antibacterial activity of liposome-encapsulated clove oil and its application in tofu. Food Control 56, 128-134. https://doi.org/10.1016/j.foodcont.2015.03.026

Cui, H., Zhou, H., Lin, L., 2016b. The specific antibacterial effect of the salvia oil nanoliposomes against Staphylococcus aureus bio films on milk container. Food Control 61, 92-98. https://doi.org/10.1016/j.foodcont.2015.09.034

Cui, Y., Wu, Z., Liu, X., Ni, R., Zhu, X., Ma, L., Liu, J., 2010. Preparation , safety , pharmacokinetics, and pharmacodynamics of liposomes containing Brucea javanica oil. AAPS PharmSciTech 11, 878-884. https://doi.org/10.1208/s12249-010-9454-4

De-Oliveira, E.F., Paula, H.C.B., De Paula, R.C.M., 2014. Alginate / cashew gum nanoparticles for essential oil encapsulation. Colloids Surfaces B Biointerfaces. 113, 146-151. https://doi.org/10.1016/j.colsurfb.2013.08.038

De Billerbeck, V., 2007. Huiles essentielles et bactéries résistantes aux antibiotiques. Phytothérapie 5, 249-253.

De Meneses, A.C., Marques, E.B.P., Leimann, F.V., Gonçalves, O.H., Ineu, R.P., de Araújo, P.H.H., de Oliveira, D., Sayer, C., 2019. Encapsulation of clove oil in nanostructured lipid carriers from natural waxes: Preparation, characterization and in vitro evaluation of the cholinesterase enzymes. Colloids Surfaces A Physicochem. Eng. Asp. 583, 123879. https://doi.org/10.1016/j.colsurfa.2019.123879 
De Souza, E., De Lima, K.L., Freire, K., De Sousa, C., 2005. Inhibitory action of some essential oils and phytochemicals on the growth of various moulds isolated from foods. Brazilian Arch. Biol. Technol. 48, 245-250.

Detoni, C.B., Oliveira, D.M. De, Santo, I.E., São Pedro, A., El-bacha, R., Velozo, E. da S., Ferreira, D., Elaine, C., Cabral-albuquerque, D.M., 2012. Evaluation of thermal-oxidative stability and antiglioma activity of Zanthoxylum tingoassuiba essential oil entrapped into multi- and unilamellar liposomes. J. Liposome Res. 22, 1-7. https://doi.org/10.3109/08982104.2011.573793

Devi, N., Deka, C., Hazarika, D., Kakati, D., 2012. Study of complex coacervation of gelatin A and sodium alginate for microencapsulation of olive oil. J. Macromol. Sci. Part A 49, 936-945. https://doi.org/10.1080/10601325.2012.722854

Dhavamani, S., Rao, Y.P.C., Lokesh, B.R., 2014. Total antioxidant activity of selected vegetable oils and their influence on total antioxidant values in vivo. Food Chem. 164, $551-555$.

Dhifi, W., Bellili, S., Jazi, S., Bahloul, N., Mnif, W., 2016. Essential oils' chemical characterization and investigation of some biological activities: A critical review. Med. 3, 25.

Diba, V.C., Statham, B.N., 2003. Contact urticaria from cinnamal leading to anaphylaxis. Contact Dermatitis 48, 119.

Dilika, F., Bremner, P., Meyer, J., 2000. Antibacterial activity of linoleic and oleic acids isolated from Helichrysum pedunculatum: a plant used during circumcision rites. Fitoterapia 71, 450-2.

Dima, C., Assadpour, E., Dima, S., Jafari, S.M., 2020. Bioavailability and bioaccessibility of food bioactive compounds; overview and assessment by in vitro methods. Compr. Rev. Food Sci. Food Saf. 19, 2862-2884. https://doi.org/10.1111/1541-4337.12623 
Dima, C., Cotârlet, M., Alexe, P., Dima, S., 2014. Reprint of “ Microencapsulation of essential oil of pimento [ Pimenta dioica ( L ) Merr .] by chitosan / k-carrageenan complex coacervation method”. Innov. Food Sci. Emerg. Technol. 25, 97-105. https://doi.org/10.1016/j.ifset.2014.07.008

Dong, Z., Ma, Y., Hayat, K., Jia, C., Xia, S., Zhang, X., 2011. Morphology and release profile of microcapsules encapsulating peppermint oil by complex coacervation. J. Food Eng. 104, 455-460. https://doi.org/10.1016/j.jfoodeng.2011.01.011

Drozdek, S., Bazyli, U., 2016. Biocompatible oil core nanocapsules as potential co-carriers of paclitaxel and fluorescent markers : preparation, characterization and bioimaging. Colloid Polym. Sci. 294, 225-237. https://doi.org/10.1007/s00396-015-3767-5

Dussault, D., Vu, K.D., Lacroix, M., 2014. In vitro evaluation of antimicrobial activities of various commercial essential oils, oleoresin and pure compounds against food pathogens and application in ham. Meat Sci. 96, 514-520.

Duthie, G.G., Gardner, P.T., Morrice, P.C., McPhail, D.B., 2016. The Contribution of d $\alpha$ tocopherol and $\mathrm{d} \gamma$-tocopherol to the antioxidant capacity of several edible plant oil. Nat. Sci. 8, 41-48.

Ekor, M., 2013. The growing use of herbal medicines: issues relating to adverse reactions and challenges in monitoring safety. Front. Pharmacol. 4. 177.

El-Asbahani, Abdelhafed, Miladi, K., Addi, H., Bitar, A., Casabianca, H., Abdelhamid, E.M., Hartmann, D., Jilale, A., Renaud, F., Elaissari, A., 2015. Antimicrobial activity of nanoencapsulated essential oils: comparison to non-encapsulated essential oils. J. Colloid Sci. Biotechnol. 4, 39-48.

El-Asbahani, A, Miladi, K., Badri, W., Sala, M., Addi, E.H.A., Casabianca, H., Mousadik, A. El, Hartmann, D., Jilale, A., Renaud, F.N.R., Elaissari, A., 2015. Essential oils: From extraction to encapsulation. Int. J. Pharm. 483, 220-243. 
El-say, K.M., El-sawy, H.S., 2017. Polymeric nanoparticles : Promising platform for drug delivery. Int. J. Pharm. 528, 675-691. https://doi.org/10.1016/j.ijpharm.2017.06.052

Elshafie, H.S., Ippolito, C., 2017. An overview of the biological effects of some mediterranean essential oils on human health. Biomed Res. Int. 2017, e9268468.

Encina, C., Vergara, C., Gimenez, B., Oyarzún-ampuero, F., Robert, P., 2016. Conventional spray-drying and future trends for the microencapsulation of fish oil. Trends Food Sci. Technol. 56, 46-60. https://doi.org/10.1016/j.tifs.2016.07.014

Engel, J.B., Heckler, C., Tondo, E.C., Daroit, D.J., Malheiros, P. ia da S., 2017. Antimicrobial activity of free and liposome-encapsulated thymol and carvacrol against Salmonella and Staphylococcus aureus adhered to stainless steel. Int. J. Food Microbiol. 252, 18-23. https://doi.org/10.1016/j.ijfoodmicro.2017.04.003

Ephrem, E., Greige-Gerges, H., Fessi, H., Charcosset, C., 2014. Optimisation of rosemary oil encapsulation in polycaprolactone and scale-up of the process. J. Microencapsul. 31, 746753. https://doi.org/10.3109/02652048.2014.918669

Esfandyari-Manesh, M., Ghaedi, Z., Asemi, M., Khanavi, M., Manayi, A., Jamalifar, H., Atyabi, F., Dinarvand, R., 2013. Study of antimicrobial activity of anethole and carvone loaded PLGA nanoparticles. J. Pharm. Res. 7, 290-295. https://doi.org/10.1016/j.jopr.2013.04.019

Esmaeili, A., Asgari, A., 2015. In vitro release and biological activities of Carum copticum essential oil (CEO) loaded chitosan nanoparticles. Int. J. Biol. Macromol. 81, 283-290. https://doi.org/10.1016/j.ijbiomac.2015.08.010

Falcao, D.Q., Mourao, S.C., Araujo, J.L. de, Pereira, P.A.K., Cardoso, A.C.A., Almeida, K.B. de, Zibetti, F.M., Lima, B.G., 2015. Chapter 23: Challenges in development of essential oil nanodelivery systems and future prospects, in Naik, J. (Ed.), Nano Based Drug 
Fang, Z., Bhandari, B., 2012. Spray drying , freeze drying and related processes for food ingredient and nutraceutical encapsulation, in: Garti, N., McClements, D.J., (Eds.), Encapsulation technologies and delivery systems for food ingredients and nutraceuticals.

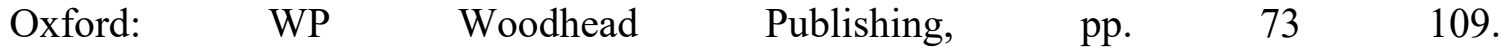
https://doi.org/10.1533/9780857095909.2.73

Fernandes, L.P., Turatti, I.C.C., Lopes, N.P., Ferreira, J.C., Candido, R.C., Oliveira, W.P., Fernandes, L.P., Turatti, I.C.C., Lopes, N.P., Ferreira, J.C., 2008. Volatile retention and antifungal properties of spray- dried microparticles of Lippia sidoides essential oil. Dry. Technol. 26, 1534-42. https://doi.org/10.1080/07373930802464034

Fessi, H., Puisieux, F., Devissaguet, J.P., Ammoury, N., Benita, S., 1989. Nanocapsule formation by interfacial polymer deposition following solvent displacement. Int. J. Pharm. $55, \mathrm{R} 1-\mathrm{R} 4$.

Feyzioglu, G.C., Tornuk, F., 2016. Development of chitosan nanoparticles loaded with summer savory (Satureja hortensis L.) essential oil for antimicrobial and antioxidant delivery $\begin{array}{llllll}\text { applications. } & \text { LWT } & - & \text { Food } & \text { Sci. } & \text { Technol. 70, }\end{array}$ https://doi.org/10.1016/j.lwt.2016.02.037

Fioramonti, S.A., Stepanic, E.M., Tibaldo, A.M., Pavón, Y.L., Santiago, L.G., 2019. Spray dried flaxseed oil powdered microcapsules obtained using milk whey proteins-alginate double layer emulsions. Food Res. Int. 119, 931-940. https://doi.org/10.1016/j.foodres.2018.10.079

Frank, L.A., Contri, R. V, Beck, R.C.R., Pohlmann, A.R., Guterres, S.S., 2015. Improving drug biological effects by encapsulation into polymeric nanocapsules. Adv. Rev. 7, 623-639. https://doi.org/10.1002/wnan.1334

Frascareli, E.C., Silva, V.M., Tonon, R. V, Hubinger, M.D., 2011. Effect of process conditions 
on the microencapsulation of coffee oil by spray drying. Food Bioprod. Process. 90, 413424. https://doi.org/10.1016/j.fbp.2011.12.002

Freiberger, E.B., Kaufmann, K.C., Bona, E., Araújo, P.H.H. de, Sayer, C., Leimann, F.V., Gonçalves, O.H., 2015. Encapsulation of roasted coffee oil in biocompatible nanoparticles. LWT - Food Sci. Technol. 64, 381-359. https://doi.org/10.1016/j.lwt.2015.05.039

Friedrich, R.B., Fontana, M.C., Beck, R.C.R., 2008. Development and physicochemical characterization of dexamethasone-loaded polymeric nanocapsule suspensions. Quim. Nova 31, 1131-1136.

Froiio, F., Ginot, L., Paolino, D., Lebaz, N., Bentaher, A., Fessi, H., Elaissari, A., 2019. Essential oils-loaded polymer particles: Preparation, characterization and antimicrobial property. Polymers (Basel). 11, 1017. https://doi.org/10.3390/polym11061017

Froiio, F., Lammari, N., Tarhini, M., Alomari, M., Louaer, W., Meniai, A.H., Paolino, D., Fessi, H., Elaissari, A., 2020. Chapter 16 - Polymer-based nanocontainers for drug delivery, in: Tri, P.N., Do. T.O., Nguyen, T.A. (Eds.), Smart Nanocontainers Micro and Nano Technologies. Elsevier Science Publishing Co Inc.: New York, USA. pp. 271-285.

Gad, H.A., Abd El-Rahman, F.A.A., Hamdy, G.M., 2019. Chamomile oil loaded solid lipid nanoparticles: A naturally formulated remedy to enhance the wound healing. J. Drug Deliv. Sci. Technol. 50, 329-338. https://doi.org/10.1016/j.jddst.2019.01.008

Gallardo, G., Guida, L., Martinez, V., López, M.C., Bernhardt, D., Blasco, R., Pedroza-islas, R., Hermida, L.G., 2013. Microencapsulation of linseed oil by spray drying for functional food application. Food reseach Int. 52, 473-482. https://doi.org/10.1016/j.foodres.2013.01.020

Gammone, M.A., Riccioni, G., Parrinello, G., D’Orazio, N., 2019. Omega-3 polyunsaturated fatty scids: Benefits and endpoints in Sport. Nutrients 11, 1-16. 
Ganesan, K., Sukalingam, K., Xu, B., 2018. Impact of consumption and cooking manners of vegetable oils on cardiovascular diseases-A critical review. Trends Food Sci. Technol. 71, $132-154$.

Garcia-Rellán, D., Verdeguer, M., Salamone, A., Blázquez, M.A., Boira, H., 2016. Chemical composition, herbicidal and antifungal activity of Satureja cuneifolia essential oils from Spain. Nat. Prod. Commun. 2, 11-19.

Garg, A., Singh, S., 2013. Targeting of eugenol-loaded solid lipid nanoparticles to the epidermal layer of human skin. Nanomedicine 9, 1223-1238.

Garg, A., Singh, S., 2011. Enhancement in antifungal activity of eugenol in immunosuppressed rats through lipid nanocarriers. Colloids Surfaces B Biointerfaces 87, 280-288. https://doi.org/10.1016/j.colsurfb.2011.05.030

Garud, A., Singh, D., Garud, N., 2012. Solid lipid nanoparticles (SLN): Method , characterization and applications. Int. Curr. Pharm. J. 1, 384-393.

Gavahian, M., Farahnaky, A., Farhoosh, R., Javidnia, K., Shahidi, F., 2015. Extraction of essential oils from Mentha piperita using advanced techniques: Microwave versus ohmic assisted hydrodistillation. Food Bioprod. Process. 94, 50-58.

Ge, Y., Ge, M., 2016. Distribution of Melaleuca alternifolia essential oil in liposomes with Tween 80 addition and enhancement of in vitro antimicrobial effect. J. Exp. Nanosci. 11, 345-358. https://doi.org/10.1080/17458080.2015.1065013

Ge, Y. of tea tree oil-loaded liposomal formulation using response surface methodology D. of tea tree oil-loaded liposomal formulation using response surface methodology, Ge, M., 2015. Development of tea tree oil-loaded liposomal formulation using response surface methodology. J. Liposome Res. 25 , $222-231$ https://doi.org/10.3109/08982104.2014.987786

Ge, Y., Tang, J., Fu, H., Fu, Y., Wu, Y., 2019. Characteristics , controlled-release and 
antimicrobial properties of Tea tree oil liposomes-incorporated chitosan-based electrospun nanofiber mats. Fibers Polym. 20, 698-708. https://doi.org/10.1007/s12221-019-1092-1

George, K.W., Alonso-gutierrez, J., Keasling, J.D., Lee, T.S., 2015. Isoprenoid drugs , biofuels , and chemicals - Artemisinin, Farnesene and Beyond. Adv. Biochem. Eng. Biotechnol. 148, 355-89. https://doi.org/10.1007/10

Geszke-Moritz, M., Moritz, M., 2016. Solid lipid nanoparticles as attractive drug vehicles: Composition, properties and therapeutic strategies. Mater. Sci. Eng. C 68, 982-944.

Ghanbarzadeh, B., Babazadeh, A., Hamishehkar, H., 2016. Nano-phytosome as a potential food-grade delivery system. Food Biosci. 15, 126-135.

Ghayempour, S., Montazer, M., 2016. Micro/nanoencapsulation of essential oils and fragrances: Focus on perfumed, antimicrobial, mosquito-repellent and medical textiles. J. Microencapsul. 33, 497-510. https://doi.org/10.1080/02652048.2016.1216187

Ghodrati, M., Reza, M., Hamishehkar, H., 2019. Encapsulation of Peppermint essential oil in nanostructured lipid carriers: In vitro antibacterial activity and accelerative effect on infected wound healing. Colloids Surfaces A 564, 161-169. https://doi.org/10.1016/j.colsurfa.2018.12.043

Gökmen, V., Ataç, B., Barone, R., Fogliano, V., Kaplun, Z., Shimoni, E., 2011. Development of functional bread containing nanoencapsulated omega-3 fatty acids. J. Food Eng. 105, 585-591. https://doi.org/10.1016/j.jfoodeng.2011.03.021

Gomes, C., Moreira, R.G., Castell-perez, E., 2011a. Nanoparticles with entrapped trans cinnamaldehyde and eugenol for antimicrobial delivery applications. J. Food Sci. 76, 16 24. https://doi.org/10.1111/j.1750-3841.2010.01985.x

Gomes, C., Moreira, R.G., Castell-perez, E., 2011b. Poly (DL-lactide-co-glycolide) (PLGA) nanoparticles with entrapped trans-cinnamaldehyde and eugenol for antimicrobial delivery applications. J. Food Sci. 76, 16-24. 
González, A., Martínez, M.L., Paredes, A.J., León, A.E., Ribotta, P.D., 2016. Study of the preparation process and variation of wall components in chia (Salvia hispanica L.) oil microencapsulation. $\quad$ Powder $\quad$ Technol. $\quad 301, \quad 868-875$. https://doi.org/10.1016/j.powtec.2016.07.026

Guner, S.F., Yagci, Y., Erciyes, T.A., 2006. Polymers from triglyceride oils 31, 633-670. https://doi.org/10.1016/j.progpolymsci.2006.07.001

Hadian, Z., 2016. A review of nanoliposomal delivery system for stabilization of bioactive omega-3 fatty acids. Electron. Physician 8, 1776-1785.

Hadian, Z., Ali, M., Moghimi, H.R., Barzegar, M., 2014. Formulation , characterization and optimization of liposomes containing eicosapentaenoic and docosahexaenoic acids; A methodology approach. Iran. J. Pharm. Res. 13, 393-404.

Hammoud, Z., Gharib, R., Fourmentin, S., Elaissari, A., Greige-Gerges, H., 2019. New findings on the incorporation of essential oil components into liposomes composed of lipoid S100 and cholesterol. Int. J. Pharm. 561, 161-170. https://doi.org/10.1016/j.ijpharm.2019.02.022

Hardman, D., Fakas, S., 2016. Polyunsaturated fatty acids as dietary supplements: Biological activities and sources. Int. J. Clin. Nutr. Diet. 2, 2.

Hasheminejad, N., Khodaiyan, F., Safari, M., 2019. Improving the antifungal activity of clove essential oil encapsulated by chitosan nanoparticles. Food Chem. 275, 113-122. https://doi.org/10.1016/j.foodchem.2018.09.085

Hassanen, N.H.M., Eissa, A.M.F., Sa'eb A. M Hafez, Mosa, E.A.M., 2015. Antioxidant and antimicrobial activity of celery (Apium graveolens) and coriander (Coriandrum sativum) herb and seed essential oils. Int. J. Curr. Microbiol. Appl. Sci. 4, 284-296.

Hassanshahian, M., Saadatfar, A., Masoumipour, F., 2020. Formulation and characterization of nanoemulsion from Alhagi maurorum essential oil and study of its antimicrobial, 
antibiofilm, and plasmid curing activity against antibiotic-resistant pathogenic bacteria. J. Environ. Heal. Sci. Eng. 18, 1015-1027.

He, H., Yao, J., Zhang, Y., Chen, Y., Wang, K., Lee, R.J., Yu, B., Zhang, X., 2019. Solid lipid nanoparticles as a drug delivery system to across the blood-brain barrier. Biochem. Biophys. Res. Commun. 519, 385-390. https://doi.org/10.1016/j.bbrc.2019.09.017

Herculano, E.D., Paula, H.C.B. De, Dias, F.G.B., Pereira, V.D.A., 2015. Physicochemical and antimicrobial properties of nanoencapsulated Eucalyptus staigeriana essential oil. LWT Food Sci. Technol. 61, 484-491. https://doi.org/10.1016/j.lwt.2014.12.001

Hosseini, S.F., Zandi, M., Rezaei, M., Farahmandghavi, F., 2013. Two-step method for encapsulation of oregano essential oil in chitosan nanoparticles: Preparation, characterization and in vitro release study. Carbohydr. Polym. 95, 50-56. https://doi.org/10.1016/j.carbpol.2013.02.031

How, C.W., Rasedee, A., Abbasalipourkabir, R., 2013. Characterization and cytotoxicity of nanostructured lipid carriers formulated with olive oil, hydrogenated palm oil, and polysorbate 80 . IEEE Trans. Nanobioscience $12,72-78$.

Hoyos-leyva, J.D., Bello-perez, L.A., Agama-acevedo, J.E., Alvarez-ramirez, J., JaramilloEcheverry, L.M., 2019. Characterization of spray drying microencapsulation of almond oil into taro starch spherical aggregates. LWT - Food Sci. Technol. 101, 526-533. https://doi.org/10.1016/j.lwt.2018.11.079

Hsu, E., Parthasarathy, S., 2017. Anti-inflammatory and antioxidant effects of sesame oil on atherosclerosis: A descriptive literature review. Cureus 9, 1438.

Hu, J., Wang, X., Xiao, Z., Bi, W., 2015. Effect of chitosan nanoparticles loaded with cinnamon essential oil on the quality of chilled pork. LWT - Food Sci. Technol. 63, 519-526. https://doi.org/10.1016/j.lwt.2015.03.049

Huang, J., Wang, Q., Chu, L., Xia, Q., 2020. Liposome-chitosan hydrogel bead delivery system 
for the encapsulation of linseed oil and quercetin: Preparation and in vitro characterization studies. LWT - Food Sci. Technol. 117, 108615.

Iannitelli, A., Grande, R., di Stefano, A., di Giulio, M., Sozio, P., Bessa, L.J., Laserra, S., Paolini, C., Protasi, F., Cellini, L., 2011. Potential antibacterial activity of carvacrol-loaded poly(DL-lactide-co-glycolide) (PLGA) nanoparticles against microbial biofilm. Int. J. Mol. Sci. 12, 5039-5051. https://doi.org/10.3390/ijms12085039

Immordino, M.L., Dosio, F., Cattel, L., 2006. Stealth liposomes: Review of the basic science, rationale, and clinical applications, existing and potential. Int. J. Nanomedicine 1, 297315.

Intahphuak, S., Khonsung, P., Panthong, A., 2010. Anti-inflammatory, analgesic, and antipyretic activities of virgin coconut oil. Pharm. Biol. 48, 151-157.

Jahromi, M.M., Zangabad, P.S., Basri, S.M., Zangabad, M.S., Ghamarypour, A., Aref, A., Karimi, M., Hamblin, M., 2018. Nanomedicine and advanced technologies for burns: preventing infection and facilitating wound healing. Adv. Drug Deliv. Rev. 123, 33-64.

Jajarm, F.H., Moravvej, G., Awal, M.M., Golmohammadzadeh, S., 2020. Insecticidal activity of solid lipid nanoparticle loaded by Ziziphora clinopodioides Lam. against Tribolium castaneum (Herbst, 1797) (Coleoptera: Tenebrionidae). Int. J. Pest Manag. https://doi.org/10.1080/09670874.2020.1713420.

Jamil, B., Abbasi, R., Abbasi, S., Imran, M., Khan, S.U., Ihsan, A., Javed, S., Bokhari, H., Imran, M., 2016. Encapsulation of cardamom essential oil in chitosan nano-composites : In-vitro efficacy on antibiotic-resistant bacterial pathogens and cytotoxicity studies. Front. Microbiol. 7, 1-10. https://doi.org/10.3389/fmicb.2016.01580

Jassbi, A.R., Zare, M., Jamebozorgi, F.H., 2017. Chemical composition and biological activity of the essential oil and solvent extracts of Scaligeria nodosa. Open Bioact. Compd. J. 5, $16-22$. 
Javid, A., Raza, Z.A., Hussain, T., Rehman, A., Javid, A., Raza, Z.A., Hussain, T., Rehman, A., 2014. Chitosan microencapsulation of various essential oils to enhance the functional properties of cotton fabric chitosan microencapsulation of various essential oils to enhance the functional properties of cotton fabric. J. Microencapsul. 31, 461-468. https://doi.org/10.3109/02652048.2013.879927

Jummes, B., Sganzerla, W.G., da Rosa, C.G., Noronha, C.M., Nunes, M.R., Bertoldi, F.C.,

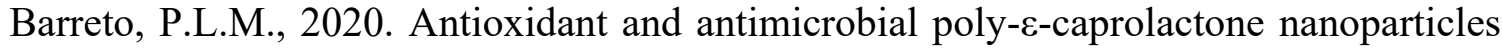
loaded with Cymbopogon martinii essential oil. Biocatal. Agric. Biotechnol. 23, 101499. https://doi.org/10.1016/j.bcab.2020.101499

Kaliamurthi, S., Selvaraj, G., 2016. Insight on solid lipid nanoparticles: characterization and application in diabetes mellitus. J. Crit. Rev. 3, 11-16.

Kanner, J., Lapidot, T., 2001. The stomach as a bioreactor: dietary lipid peroxidation in the gastric fluid and the effects of plant-derived antioxidants. Free Radic. Biol. Med. 31, 13881395. https://doi.org/10.1016/S0891-5849(01)00718-3

Kaur, P., Thakur, R., Choudhary, A., 2012. An in vitro study of the antifungal activity of silver/chitosan nanoformulations against important seed borne pathogens. Int. J. Sci. Technol. Res. 1, 83-86.

Khatibi, S.A., Misaghi, A., Moosavy, M.H., Basti, A.A., Mohamadian, S., Khanjari, A., 2017. Effect of nanoliposomes containing Zataria multiflora Boiss . essential oil on gene expression of Shiga toxin 2 in Escherichia coli O157 : H7. J. Appl. Microbiol. 124, 389397. https://doi.org/10.1111/jam.13641

Khezri, K., Farahpour, M.R., Mounesi Rad, S., 2020. Efficacy of Mentha pulegium essential oil encapsulated into nanostructured lipid carriers as an in vitro antibacterial and infected wound healing agent. Colloids Surfaces A Physicochem. Eng. Asp. 589, 124414. https://doi.org/10.1016/j.colsurfa.2020.124414 
Khezri, K., Farahpour, M.R., Rad, S.M., 2019. Accelerated infected wound healing by topical application of encapsulated rosemary essential oil into nanostructured lipid carriers. Artif. Cells, Nanomedicine, Biotechnol. 47, 980-988.

Khoobdel, M., Ahsaei, S.M., Farzaneh, M., 2017. Insecticidal activity of polycaprolactone nanocapsules loaded with Rosmarinus officinalis essential oil in Tribolium castaneum (Herbst). Entomol. Res. 47, 175-184.

Khosravi, K., 2013. Essential oils as natural food preservatives: Antimicrobial and antioxidant applications, in: Doughari, J.H. (Ed.), Antimicrobials from nature: effective control agents for drug resistant pathogens. Transworld research network, India. pp. 15-37.

Kochikuzhyil, B.M., Devi, K., Fattepur, S.R., 2010. Effect of saturated fatty acid-rich dietary vegetable oils on lipid profile, antioxidant enzymes and glucose tolerance in diabetic rats. Indian J. Pharmacol. 42, 142-145.

Krasodomska, O., Paolicelli, P., Cesa, S., Antonietta, M., Jungnickel, C., 2016. Protection and viability of fruit seeds oils by nanostructured lipid carrier (NLC) nanosuspensions. J. Colloid Interface Sci. 479, 25-33. https://doi.org/10.1016/j.jcis.2016.06.041

Kris-Etherton, P.M., Harris, W.S., Appel, L.J., 2003. Omega-3 fatty acids and cardiovascular disease: New recommendations from the american heart association. J. Am. Heal. Assoc. $23,151-152$.

Kumar, A., Sharma, A., Upadhyaya, K.C., 2016. Vegetable oil: Nutritional and industrial perspective. Curr. Genomics 17, 230-240.

Kumari, A., Yadav, S.K., Yadav, S.C., 2010. Biodegradable polymeric nanoparticles based drug delivery systems. Colloids Surfaces B Biointerfaces 75, 1-18.

Lacatusu, I., Badea, N., Badea, G., Oprea, O., Mihaila, M.A., Kaya, D.A., Stan, R., Meghea, A., 2015. Lipid nanocarriers based on natural oils with high activity against oxygen free radicals and tumor cell proliferation. Mater. Sci. Eng. C. 56, 88-94. 
2128

2129

2130

Lacatusu, I., Mitrea, E., Badea, N., Stan, R., Oprea, O., Meghea, A., 2013. Lipid nanoparticles based on omega-3 fatty acids as effective carriers for lutein delivery . Preparation and in vitro characterization studies. J. Funct. Foods 5, 1260-1269. https://doi.org/10.1016/j.jff.2013.04.010

Lammari, N., Demautis, T., Louaer, O., Hassen, A., Bentaher, A., Elaissari, A., 2021. Nanocapsules containing Saussurea lappa essential oil: Formulation, characterization, antidiabetic, anti-cholinesterase and anti-inflammatory potentials. Int. J. Pharm. 593, 120138. https://doi.org/10.1016/j.ijpharm.2020.120138

Lammari, N., Froiio, F., Louaer, M., Cristiano, M.C., Bensouici, C., Paolino, D., Louaer, W., Meniai, A.H., Elaissari, A., 2020. Poly (ethyl acrylate-co-methyl methacrylate-cotrimethylammoniethyl methacrylate chloride) (Eudragit RS 100) nanocapsules as nanovector carriers for Phoenix dactylifera L. seeds oil: a versatile antidiabetic agent. Biomacromolecules $\quad$ DOI: $\quad$ https://dx.doi.org/10.1021/acs.biomac.0c00255. https://doi.org/10.1021/acs.biomac.0c00255

Langenheim, J.H., 2003. Plant resins: chemistry, evolution, ecology and ethnobotany. Timber Press, Portland, OR.

Laohasongkram, K., Mahamaktudsanee, T., Chaiwanichsiri, S., 2011. Microencapsulation of macadamia oil by spray drying. Ital. Oral Surg. 1, 1660-1665. https://doi.org/10.1016/j.profoo.2011.09.245

Laouini, A., Jaafer-Maalej, C., Limayem-Blouza, I., Sfar, S., Charcosset, C., Fessi, H., 2012. Preparation , characterization and applications of liposomes : State of the art. J. Colloid Sci. Biotechnol. 1, 147-168. https://doi.org/10.1166/jcsb.2012.1020

Lee, S.Y., Kim, K.B.W.R., Lim, S.I., Ahn, D.H., 2014. Antibacterial mechanism of Myagropsis myagroides extract on Listeria monocytogenes. Food Control 42, 23-28. 
Li, L., Au, W., Hua, T., Zhao, D., Wong, K., 2013. Improvement in antibacterial activity of moxa oil containing gelatin-arabic gum microcapsules. Text. Res. J. 83, 1236-1241.

Li, Y., Ai, L., Yokoyama, W., Shoemaker, C., Wei, D., Ma, J., Zhong, F., 2013. Properties of chitosan-microencapsulated orange oil prepared by spray-drying and its stability to detergents. J. Agric. Food Chem. 61, 3311-3319.

Liakos, I.L., Grumezescu, A.M., Holban, A.M., Florin, I., D’Autilia, F., Carzino, R., Bianchini, P., Athanassiou, A., 2016. Polylactic acid-lemongrass essential oil nanocapsules with antimicrobial properties. Pharmaceuticals 9, 42. https://doi.org/10.3390/ph9030042

Liakos, I.L., Iordache, F., Carzino, R., Scarpellini, A., Oneto, M., Bianchini, P., Grumezescu, A.M., Holban, A.M., Mihai, A., Maria, A., 2018. Cellulose acetate - essential oil nanocapsules with antimicrobial activity for biomedical applications. Colloids Surfaces B Biointerfaces 172, 471-479. https://doi.org/10.1016/j.colsurfb.2018.08.069

Limaverde, P.W., Campina, F.F., Cunha, F.A.. da, Crispim, F.D., Figueredo, F.G., Lima, L.F., Oliveira-Tintino, C.D. de M., Matos, Y.M.L.S. de, Morais-Braga, M.F.B., Menezes, I.R.., Balbino, V.Q., Coutinho, H.D.., Siqueira-Júnior, J.P., Almeida, J.R.G.., Tintino, S.R., 2017. Inhibition of the TetK efflux-pump by the essential oil of Chenopodium ambrosioides L. and $\alpha$-terpinene against Staphylococcus aureus IS-58. Food Chem. Toxicol. 109, 957-961.

Lin, L., Chen, W., Li, C., Cui, H., 2019a. Enhancing stability of Eucalyptus citriodora essential oil by solid nanoliposomes encapsulation. Ind. Crops Prod. 140, 111615. https://doi.org/10.1016/j.indcrop.2019.111615

Lin, L., Gu, Y., Sun, Y., Cui, H., 2019b. Characterization of chrysanthemum essential oil triplelayer liposomes and its application against Campylobacter jejuni on chicken. LWT - Food Sci. Technol. 107, 16-24. https://doi.org/10.1016/j.lwt.2019.02.079

Lin, L., Zhu, Y., Thangaraj, B., Abdel-samie, M.A.S., Cui, H., 2018. Improving the stability of 
thyme essential oil solid liposome by using $\beta$ - cyclodextrin as a cryoprotectant. Carbohydr. Polym. 188, 243-251. https://doi.org/10.1016/j.carbpol.2018.02.010

Liolios, C.C., Gortzi, O., Lalas, S., Tsaknis, J., Chinou, I., 2009. Liposomal incorporation of carvacrol and thymol isolated from the essential oil of Origanum dictamnus L . and in vitro antimicrobial activity. Food Chem. 112, 77-83. https://doi.org/10.1016/j.foodchem.2008.05.060

Liu, C., Liang, B., Shi, G., Li, Z., Zheng, X., 2015. Preparation and characteristics of nanocapsules containing essential oil for textile application. Flavour Fragr. J. 30, 295-301. https://doi.org/10.1002/ffj.3245

Liu, N., Guan, T., Zhou, W., Li, J., Cao, Y., Lin, L., 2016. Preparation and characterization of Galanga essential oil liposomes. In: The 2016 International Conference on Advances in Energy, Environment and Chemical Science (AEECS 2016). pp. 99-105.

Liu, Y., Wang, S., Zhang, R., Lan, W., Qin, W., 2017. Development of poly (lactic acid)/ chitosan fibers loaded with essential oil for antimicrobial applications. Nanomaterials. 7, 194. https://doi.org/10.3390/nano7070194

Lligadas, G., Ronda, J.C., Galia, M., Cadiz, V., 2010. Plant oils as platform chemicals for polyurethane synthesis : current state-of-the-art. Biomacromolecules. 11, 2825-2835.

López-meneses, A.K., Plascencia-jatomea, M., Lizardi-mendoza, J., Fernández-quiroz, D., 2018. Schinus molle L . essential oil-loaded chitosan nanoparticles: Preparation, characterization, antifungal and anti-aflatoxigenic properties. LWT - Food Sci. Technol. 96, 597-603. https://doi.org/10.1016/j.lwt.2018.06.013

Lozano, M., Gonza, D., Calvo, P., Herna, T., 2012. Microencapsulation of extra-virgin olive oil by spray-drying : Influence of wall material and olive quality. Eur. J. lipid Sci. Technol. 112, 852-858. https://doi.org/10.1002/ejlt.201000059

Luque-Alcaraz, A.G., Cortez-Rocha, M.O., Velázquez-Contreras, C.A., Acosta-Silva, A.L., 

Jatomea, M., 2016. Enhanced antifungal effect of chitosan/Pepper tree (Schinus molle) essential oil bionanocomposites on the viability of Aspergillus parasiticus spores. J. Nanomater. 2016, 6060137. https://doi.org/10.1155/2016/6060137

Lv, Y., Yang, F., Li, X., Zhang, X., Abbas, S., 2014. Formation of heat-resistant nanocapsules of jasmine essential oil via gelatin / gum arabic based complex coacervation. Food

Maccioni, A., Santo, A., Falconieri, D., Piras, A., Manconi, M., Maxia, A., Bacchetta, G., 2019.

Mai, C.H., LE, T.T.T., Diep, T.T., Le, T.H.N., Nguyen, D.T., Bach, L.G., 2018. Development of solid lipid nanoparticles of Gac (Momordica cocochinensis Spreng) oil by nanoemulsion technique. Asian J. Chem. 30, 293-297. https://doi.org/10.14233/ajchem.2018.20902

Mainardi, T., Kapoor, S., Bielory, L., 2009. Complementary and alternative medicine: herbs, phytochemicals and vitamins and their immunologic effects. J. allergu cinical Immunol. 123, 283-94.

Manconi, M., Petretto, G., Guy, D., Escribano, E., Milia, E., Pinna, R., Palmieri, A., Firoznezhad, M., Peris, J.E., Usach, I., Fadda, A.M., Caddeo, C., Manca, M.L., 2018. Thymus essential oil extraction, characterization and incorporation in phospholipid vesicles for the antioxidant / antibacterial treatment of oral cavity diseases. Colloids Surfaces B Biointerfaces 171, 115-122. https://doi.org/10.1016/j.colsurfb.2018.07.021

Mandal, S.M., Roy, A., Ghosh, A.K., Hazra, T.K., Basak, A., Franco, O.L., 2014. Challenges and future prospects of antibiotic therapy: from peptides to phages utilization. Front. 
Pharmacol. 5, 105.

2228

2229

2230

2231

2232

2233

2234

2235

2236

2237

2238

2239

2240

2241

2242

2243

2244

2245

2246

2247

2248

2249

2250

2251

Marchiori, M.C.L., Rigon, C., Camponogara, C., Oliveira, S.M., Cruz, L., 2017. Hydrogel containing silibinin-loaded pomegranate oil based nanocapsules exhibits antiinflammatory effects on skin damage UVB radiation-induced in mice. J. Photochem. Photobiol. ,B Biol. 170, 25-32. https://doi.org/10.1016/j.jphotobiol.2017.03.015

Márquez-Ruiz, G., García-Martínez, M.C., Holgado, F., 2008. Changes and effects of dietary oxidized lipids in the gastrointestinal tract. Lipids insights 11-19.

Maryam, I., Huzaifa, U., Hindatu, H., Zubaida, S., 2015. Nanoencapsulation of essential oils with enhanced antimicrobial activity: A new way of combating antimicrobial Resistance. J. Pharmacogn. Phytochem. 4, 165-170.

Matos, S.P. De, Lucca, L.G., Koester, L.S., 2019. Essential oils in nanostructured systems : Challenges in preparation and analytical methods. Talanta 195, 204-214. https://doi.org/10.1016/j.talanta.2018.11.029

Matthäus, B., 2010. Oxidation of edible oils, in: Decker, E.A., Elias, R.J., McClements, D.J. (Eds.), Oxidation in foods and beverages and antioxidant applications. Woodhead Publishing Limited, pp. 183-283.

Mattheolabakis, G., Rigas, B., Constantinides, P, A., 2012. Nanodelivery strategies in cancer chemotherapy: biological rationale and pharmaceutical perspectives. Nanomedicine 10 , $1577-1590$.

McDaniel, A., Tonyali, B., Yucel, U., Trinetta, V., 2019. Formulation and development of lipid nanoparticle antifungal packaging films to control postharvest disease. J. Agric. Food Res. 1, 100013. https://doi.org/10.1016/j.jafr.2019.100013

Mehnert, W., Mäder, K., 2012. Solid lipid nanoparticles: Production, characterization and applications. Adv. Drug Deliv. Rev. 64, 83-101.

Meier, M.A.R., Jurgen, M.O., Schubert, U.S., 2007. Plant oil renewable resources as green 
alternatives in polymer science. Chem. Soc. Rev. 36, 1788-1802. https://doi.org/10.1039/b703294c

2254

2255

2256

2257

2258

2259

2260

2261

2262

2263

2264

2265

2266

2267

2268

2269

2270

Miao, S., Wang, P., Su, Z., Zhang, S., 2014. Vegetable-oil-based polymers as future polymeric biomaterials. Acta Biomater. 10, 1692-1704. https://doi.org/10.1016/j.actbio.2013.08.040

Miladi, K., Sfar, S., Fessi, H., Elaissari, A., 2016. Nanoprecipitation process : From particle preparation to in vivo applications, in: Vauthier, C., Ponchel, G. (Eds.), Polymer Nanoparticles for Nanomedicines. Springer: Cham, Switzerland, pp. 17-53. https://doi.org/10.1007/978-3-319-41421-8

Miranda, M., Cruz, M.T., Vitorino, C., Cabral, C., 2019. Nanostructuring lipid carriers using Ridolfia segetum (L.) Moris essential oil. Mater. Sci. Eng. C 103, 109804. https://doi.org/10.1016/j.msec.2019.109804

Mishra, H., Mishra, P.K., Iqbal, Z., Jaggi, M., Madaan, A., Bhuyan, K., Gupta, Namita, Gupta, Neha, Vats, K., Verma, R., Talegaonkar, S., 2019. Co-delivery of eugenol and dacarbazine by hyaluronic acid-coated liposomes for targeted inhibition of survivin in treatment of resistant metastatic melanoma. Pharmaceutics 11, 163.

Moghaddam, M., Mehdizadeh, L., 2017. Chemistry of essential oils and factors influencing their constituents, in: Grumezescu, A.M., Holban, A.M. (Eds.), Soft Chemistry and Food Fermentation. Elsevier Science Publishing Co Inc., New York., pp. 379-419. https://doi.org/10.1016/B978-0-12-811412-4.00013-8

Mohammed, N.K., Tan, C., Manap, Y.A., Alhelli, A.M., Hussin, A.S.M., 2017. Process conditions of spray drying microencapsulation of Nigella sativa oil. Powder Technol. 315, 1-14. https://doi.org/10.1016/j.powtec.2017.03.045

Morsy, N.F.S., 2017. Chemical structure, quality indices and bioactivity of essential oil constituents, in: El-Shemy, H. (Ed.), Active Ingredients from Aromatic and Medicinal Plants. IntechOpen, Spain, pp. 175-206. 
Mozafari, M.R., Khosravi-Darani, K., Borazan, G.G., Cui, J., Pardakhty, A., Yurdugul, S., 2008. Encapsulation of food ingredients using nanoliposome technology. Int. J. Food Prop. 11, 833-844.

Mozafari, M.R., Mortazavi, S.M., 2005. A new technique for the preparation of non-toxic liposomes and nanoliposomes: The heating method, in: Nanoliposomes: From Fundamentals to Recent Developments.. Trafford Publishing Ltd., Oxford, UK. . pp. 9198.

Nagavarma, B.V.N., Yadav, H.K.S., Ayaz, A., Vasudha, L.S., Shivakumar, H.G., 2012. Different techniques for preparation of polymeric nanoparticles-A review. Asian J. Pharm. Clin. Res. 5, e33413145.

Nahr, F.K., Ghanbarzadeh, B., Hamishehkar, H., Kafil, H.S., 2018. Food grade nanostructured lipid carrier for cardamom essential oil : Preparation, characterization and antimicrobial activity. J. Funct. Foods 40, 1-8. https://doi.org/10.1016/j.jff.2017.09.028

Nahr, F.K., Ghanbarzadeh, B., Hamishehkar, H., Samadi, H., Hoseini, M., Esmaeilnejad, B., 2019. Investigation of physicochemical properties of essential oil loaded nanoliposome for enrichment purposes. LWT - Food Sci. Technol. 105, 282-289. https://doi.org/10.1016/j.lwt.2019.02.010

Najafi, M.N., Arianmehr, A., Sani, A.M., 2020. Preparation of Barije (Ferula gummosa) essential oil-loaded liposomes and evaluation of physical and antibacterial effect on Escherichia coli O157:H7. J. Food Prot. 83, 511-517.

Nasseri, M., Golmohammadzadeh, S., Arouiee, H., Jaafari, M.R., Neamati, H., 2020. Preparation and comparison of various formulations of solid lipid nanoparticles (SLNs) containing the essential oil of Zataria multiflora. J. Hortic. postharvest Res. 3, 73-84.

Nasseri, M., Golmohammadzadeh, S., Arouiee, H., Reza, M., Neamati, H., 2016. Antifungal activity of Zataria multiflora essential oil-loaded solid lipid nanoparticles in-vitro 
2303

2304

2305

2306

2307

2308

2309

2310

Natrajan, D., Srinivasan, S., Sundar, K., Ravindran, A., 2015. Formulation of essential oilloaded chitosan alginate nanocapsules. J. Food Drug Anal. 23, 560-568. https://doi.org/10.1016/j.jfda.2015.01.001

Nazari, M., Ghanbarzadeh, B., Kafil, H.S., Zeinali, M., 2019. Garlic essential oil nanophytosomes as a natural food preservative : Its application in yogurt as food model. Colloid interface Sci. Commun. 30, 1-7. https://doi.org/10.1016/j.colcom.2019.100176

Niza, E., Božik, M., Bravo, I., Clemente-Casares, P., Lara-Sanchez, A., Juan, A., Klouček, P., Alonso-Moreno, C., 2020. PEI-coated PLA nanoparticles to enhance the antimicrobial activity of carvacrol. Food Chem. 328, 127131.

Nkanga, C.I., Bapolisi, A.M., Okafor, N.I., Krause, R.W.M., 2019. General perception of liposomes : Formation, manufacturing and applications, in: Catala, A. (Ed.), Liposomes Advances and Perspectives. IntechOpen, Spain., pp. 1-24.

Nonato, F.R., Santana, D.G., Melo, F.M. de, Santos, G.G.L. dos, Brustolim, D., Camargo, E.A., Sousa, D.P. de, Soares, M.B.P., Villarreal, C.F., 2012. Anti-inflammatory properties of rose oxide. Int. Immunopharmacol. 14, 4(4):779-84.

Noor, N.M., Aziz, A.A., Sarmidi, M.R., Aziz, R., 2013. The effect of virgin coconut oil loaded solid lipid particles (VCO-SLPs ) on skin hydration and skin elasticity. J. Teknol. 62, 3943.

Nosari, A.B.F.L., Lima, J.F., Serra, O.A., Alexandre, L., Freitas, P., 2015. Improved green coffee oil antioxidant activity for cosmetical purpose by spray drying microencapsulation. Rev. Bras. Farmacogn. 25, 307-311. https://doi.org/10.1016/j.bjp.2015.04.006

Orhan, I.E., Mesaik, M.A., Jabeen, A., Kan, Y., 2016. Immunomodulatory properties of various natural compounds and essential oils through modulation of human cellular immune response. Ind. Crops Prod. 81, 117-122. 
Orhan, I.R., Özçelik, B., Şener, B., 2011. Evaluation of antibacterial, antifungal, antiviral, and antioxidant potentials of some edible oils and their fatty acid profiles. Turkish J. Biol. 35, $251-258$.

Ortan, A., Câmpeanu, G., Dinu-Pîrvu, C., Popescu, L., 2009. Studies concerning the entrapment of Anethum graveolens essential oil in liposomes. Roum. Biotechnol. Lett. 14, 4411-4417.

Ortan, A., Ferdes, M., Rodino, S., Pirvu, C.D., Draganescu, D., 2013. Topical delivery system of liposomally encapsulated volatile oil of Anethum Graveolens. Farmacia 61, 361-370.

Ourique, A., Azoubel, S., Ferreira, C., Silva, C., Marchiori, M., Pohlmann, A., Guterres, S., Beck, R., 2010. Lipid-core nanocapsules as a nanomedicine for parenteral administration of tretinoin: development and in vitro antitumor activity on human myeloid leukaemia cells. J. Biomed. Nanotechnol. 6, 214-23.

Özçelik, B., Aslan, M., Orhan, I., Karaoglu, T., 2005. Antibacterial, antifungal, and antiviral activities of the lipophylic extracts of Pistacia vera L. Microbiol. Res. 160, 159-64.

Ozek, G., Schepetkin, I.A., Utegenova, G.A., Kirpotina, L.N., Andrei, S.R., Ozek, T., Baser, K.H.C., Abidkulova, K.T., Kushnarenko, S. V, Khlebnikov, A.I., Damron, D.S., Quinn, M.T., 2017. Chemical composition and phagocyteimmunomodulatory activity of Ferula iliensis essential oils. J. Leukoc. Biol. 101, 1361-1371.

Ozy1ldı, F., Karagonlu, S., Basal, G., Uzel, A., Bayraktar, O., 2012. Micro-encapsulation of ozonated red pepper seed oil with antimicrobial activity and application to nonwoven fabric. Lett. Appl. Microbiol. 56, 168-179. https://doi.org/10.1111/lam.12028

Pandey, A.K., Kumar, P., Singh, P., Tripathi, N.N., Bajpai, V.K., 2016. Essential oils: Sources of antimicrobials and food preservatives. Front. Microbiol. 7, 1-14.

Patel, D., 2013. Development \& screening approach for lipid nanoparticle: A review. Int. J. Innov. Pharm. Sci. 2, 27-32.

Patil, Y., Jadhav, S., 2014. Novel methods for liposome preparation. Chem. Phys. Lipids 177, 
Paula, H.C.B., Sombra, F.M., Abreu, F.O.M.S., Paula, R.C.M., 2010. Lippia sidoides essential oil encapsulation by angico gum/chitosan nanoparticles. J. Braz. Chem. Soc. 21, 23592366.

Pedro, A.S., Santo, I.E., Silva, C. V, Detoni, C., Albuquerque, E., 2013. The use of nanotechnology as an approach for essential oil-based formulations with antimicrobial activity. In: Méndez-vilas, A. (Ed.), Microbial pathogens and strategies for combating them: science, technology and education. Badajoz : Formatex Research Center, pp. 13641374.

Peng, S., Zhou, L., Liu, Wei, Gan, L., Liu, Weilin, Liang, R., Liu, C., Niu, J., Cao, Y., Liu, Z., Chen, X., 2015. Strage stability and actibacterial activity of eugenol nanoliposomes prepared by an ethanol injection-dynamic high pressure microfluidization method. J. o f Food Prot. 78, 22-30. https://doi.org/10.4315/0362-028X

Pina-Barrera, A.M., Alvarez-Roman, R., Baez-Gonzalez, J.G., Amaya-Guerra, C.A., RivasMorales, C., Gallardo-Rivera, C.T., Galindo-Rodriguez, S.A., 2019. Application of a multisystem coating based on polymeric nanocapsules containing essential oil of Thymus vulgaris L. to increase the shelf life of table grapes (Vitis vinifera L.). IEEE Trans. Nanobioscience 18, 549-557. https://doi.org/10.1109/TNB.2019.2941931

Pivetta, T.P., Simões, S., Araújo, M.M., Carvalho, T., Arruda, C., Marcato, P.D., 2018. Development of nanoparticles from natural lipids for topical delivery of thymol: Investigation of its anti-inflammatory properties. Colloids Surfaces B Biointerfaces 164, 281-290. https://doi.org/10.1016/j.colsurfb.2018.01.053

Popiolski, T.M., Otsuka, I., Halila, S., Muniz, E.C., Soldi, V., Borsali, R., Catarina, F.D.S., 2016. Preparation of polymeric micelles of poly (Ethylene oxide- b-lactic acid) and their encapsulation with lavender oil. Mater. Res. 19, 1356-1365. 
Poudel, A., Gachumi, G., Wasan, K.M., Bashi, Z.D., El Aneed, A., Badea, I., 2019. Development and characterization of liposomal formulations containing phytosterols extracted from canola oil deodorizer distillate along with tocopherols as food additives. Pharmaceutics 11, 185. https://doi.org/10.3390/pharmaceutics11040185

Priyadarshini, B.M., Antipina, M.N., Fawzy, A.S., 2018. Formulation and characterisation of poly ( lactic-co-glycolic acid ) encapsulated clove oil nanoparticles for dental applications. Inst. Eng. Technol. 12, 311-317. https://doi.org/10.1049/iet-nbt.2017.0141

Pu, J., Bankston, J.D., Sathivel, S., 2010. Developing microencapsulated flaxseed oil containing shrimp (Litopenaeus setiferus) astaxanthin using a pilot scale spray. Biosyst. Eng. 108, 121-132. https://doi.org/10.1016/j.biosystemseng.2010.11.005

Purohit, S.., Solanki, R., Soni, M.., 2012. Experimental evaluation of Aloe vera leaves pulp as topical medicament on wound healing. Int. J. Pharmacol. Res. 2, 110-112.

Rahman, H.S., Rasedee, A., How, C.W., Abdul, A.B., Zeenathul, A.N., Othman, H.H., Saeed, M.I., Yeap, S.K., 2013. Zerumbone-loaded nanostructured lipid carriers : preparation, characterization, and antileukemic effect. Int. J. Nanomedicine 8, 2769-2781.

Rahman, H.S., Rasedee, A., Othman, H.H., Chartrand, M.S., Namvar, F., Yeap, S.K., Samad, N.A., Andas, R.J., Nadzri, N.M., Anasamy, T., Ng, K., How, C.W., 2014. Acute toxicity study of zerumbone-loaded nanostructured lipid carrier on BALB/c mice model. Biomed Res. Int. 2014, 1-15.

Rajendran, R., Radhai, R., Kotresh, T.M., Csiszar, E., 2013. Development of antimicrobial cotton fabrics using herb loaded nanoparticles. Carbohydr. Polym. 91, 613-617. https://doi.org/10.1016/j.carbpol.2012.08.064

Rajivgandhi, G., Saravanan, K., Ramachandran, G., Li, J., Yin, L., Quero, F., Alharbi, N.S., Kadaikunnan, S., Khaled, J.M., Manoharan, N., Li, W., 2020. Enhanced anti-cancer activity of chitosan loaded Morinda citrifolia essential oil against A549 human lung cancer 

cells. Int. J. Biol. Macromol. 164, 4010-4021.

2403

2404

2405

2406

2407

2408

2409

2410

2411

2412

2413

2414

2415

2416

2417

2418

2419

2420

2421

2422

2423

2424

2425

2426

Rajkumar, V., Gunasekaran, C., Dharmaraj, J., Chinnaraj, P., Paul, C.A., Kanithachristy, I., 2020. Structural characterization of chitosan nanoparticle loaded with Piper nigrum essential oil for biological efficacy against the stored grain pest control. Pestic. Biochem. Physiol. 166, 104566.

Ramteke, K.H., Joshi, S.A., Dhole, S.N., 2012. Solid lipid nanoparticle : A review. IOSR J. Pharm. 2, 34-44.

Rani, S., Sharma, A.K., Khan, I., Gothwal, A., 2017. Polymeric nanoparticles in targeting and delivery of drugs, in Nanotechnology-Based Approaches for Targeting and delivery of Drugs and Genes. Elsevier Science Publishing Co Inc.: New York, USA. https://doi.org/10.1016/B978-0-12-809717-5.00008-7

Rao, J.P., Geckeler, K.E., 2011. Polymer nanoparticles: Preparation techniques and sizecontrol parameters. Prog. Polym. Sci. 36, 887-913. https://doi.org/10.1016/j.progpolymsci.2011.01.001

Rasti, B., Jinap, S., Mozafari, M.R., 2013. Optimization on preparation condition of polyunsaturated fatty acids nanoliposome prepared by Mozafari method. J. Liposome Res. 2104, 1-7. https://doi.org/10.3109/08982104.2013.839702

Rasti, B., Jinap, S., Mozafari, M.R., Yazid, A.M., 2012. Comparative study of the oxidative and physical stability of liposomal and nanoliposomal polyunsaturated fatty acids prepared with conventional and Mozafari methods. Food Chem. 135, 2761-2770. https://doi.org/10.1016/j.foodchem.2012.07.016

Rates, S.M.K., 2001. Plants as source of drugs. Toxicon 39, 603-613.

Raut, J.S., Karuppayil, S.M., 2014. Experimental evaluation of Aloe vera leaves pulp as topical medicament on wound healing. Ind. Crop. Prod. 62, 250-264.

Rein, M.J., Renouf, M., Cruz-Hernandez, C., Actis-Goretta, L., Thakkar, S.K., da Silva Pinto, 
M., 2013. Bioavailability of bioactive food compounds: a challenging journey to bioefficacy. Br. J. Clin. Pharmacol. 75, 588-602. https://doi.org/10.1111/j.13652125.2012.04425.x

2430

2431

2432

2433

2434

2435

2436

2437

2438

2439

2440

2441

2442

2443

2444

2445

2446

2447

2448

2449

2450

2451

Ribeiro-Santos, R., Andrade, M., Melo, N.R. de, Sanches-Silva, A., 2017. Use of essential oils in active food packaging: Recent advances and future trends. Trends Food Sci. Technol. $61,132-140$

Rigo, L.A., Frescura, V., Fiel, L., Coradini, K., Ourique, A.F., Emanuelli, T., Tedesco, S., Silva, C.B., Stanic, S., Pohlmann, A.R., Carlos, R., Beck, R., 2013. Influence of the type of vegetable oil on the drug release profile from lipid-core nanocapsules and in vivo genotoxicity study. Pharm. Technol. Dev. 1-10. https://doi.org/10.3109/10837450.2013.829097

Rigo, L.A., Silva, C.R., Oliveira, S.M., Cabreira, T.N., Silva, C.B., Ferreira, J., Beck, R.C.R., 2015. Nanoencapsulation of rice bran oil increases its protective effects against UVB radiation-induced skin injury in mice. Eur. J. Pharm. Biopharm. 93, 11-17. https://doi.org/10.1016/j.ejpb.2015.03.020

Risaliti, L., Kehagia, A., Daoultzi, E., Lazari, D., Bergonzi, M.C., Vergkizi-nikolakaki, S., Hadjipavlou-litina, D., Bilia, A.R., 2019. Liposomes loaded with Salvia triloba and Rosmarinus officinalis essential oils : In vitro assessment of antioxidant, antiinflammatory and antibacterial activities. J. Drug Deliv. Sci. Technol. 51, 493-498. https://doi.org/10.1016/j.jddst.2019.03.034

Roccia, P., Martínez, M.L., Llabot, J.M., Ribotta, P.D., 2014. Influence of spray-drying operating conditions on sunflower oil powder qualities. Powd 254, 307-313. https://doi.org/10.1016/j.powtec.2014.01.044

Rodea-gonzález, D.A., Cruz-olivares, J., Román-guerrero, A., Rodríguez-huezo, M.E., Vernoncarter, E.J., Pérez-alonso, C., 2012. Spray-dried encapsulation of chia essential oil (Salvia 
hispanica L.) in whey protein concentrate-polysaccharide matrices. J. Food Eng. 111, 102-109. https://doi.org/10.1016/j.jfoodeng.2012.01.020

Rodenak-Kladniew, B., Islan, G.A., de Bravo, M.G., Durán, N., Castro, G.R., 2017. Design, characterization and in vitro evaluation of linalool-loaded solid lipid nanoparticles as potent tool in cancer therapy. Colloids Surfaces B Biointerfaces 154, 123-132. https://doi.org/10.1016/j.colsurfb.2017.03.021

Rodríguez, J., Martín, M.J., Ruiz, M.A., Clares, B., 2016. Current encapsulation strategies for bioactive oils : From alimentary to pharmaceutical perspectives. Food Reseach Int. 83, 4159. https://doi.org/10.1016/j.foodres.2016.01.032

Rozman, N.A.S., Tong, W.Y., Leong, C.R., Anuar, M.R., Karim, S., Ong, S.K., Yusof, F.A.M., Tan, W.-N., Sulaiman, B., Ooi, M.L., Lee, K.C., 2020. Homalomena pineodora essential oil nanoparticle inhibits diabetic wound pathogens. Sci. Rep. 10, 3307.

Rubilar, M., Morales, E., Contreras, K., Ceballos, C., Acevedo, F., Villarroel, M., Shene, C., 2012. Development of a soup powder enriched with microencapsulated linseed oil as a source of omega-3 fatty acids. Eur. J. Lipid Sci. Technol. 114, 423-433. https://doi.org/10.1002/ejlt.201100378

Rushmi, Z.T., Akter, N., Mow, R.J., Afroz, M., Kazi, M., Matas, M. De, Rahman, M., Shariare, M.H., 2017. The impact of formulation attributes and process parameters on black seed oil loaded liposomes and their performance in animal models of analgesia. Saudi Pharm. J. 25, 404-412. https://doi.org/10.1016/j.jsps.2016.09.011

Saffari, M., Shirazi, F.H., Moghimi, H.R., 2016. Terpene-loaded liposomes and isopropyl myristate as chemical permeation enhancers toward liposomal gene delivery in lung cancer cells ; A comparative study. Iran. J. Pharm. Res. 15, 261-267.

Sagiri, S.S., Anis, A., Pal, K., 2016. A Review on encapsulation of vegetable oils : Strategies, preparation methods and application. Polym. Plast. Technol. Eng. 55, 37-41. 
2478

2479

2480

2481

2482

2483

2484

2485

2486

2487

2488

2489

2490

2491

2492

2493

2494

2495

2496

2497

2498

2499

2500

2501

Saha, S., Ghosh, M., 2011. Antioxidant effect of vegetable oils containing conjugated linolenic acid isomers against induced tissue lipid peroxidation and inflammation in rat model. Chem. Biol. Interact. 190, 109-120.

Saharan, V., Mehrotra, A., Khatik, R., Rawal, P., Sharma, S.S., Pal, A., 2013. Synthesis of chitosan based nanoparticles and their in vitro evaluation against phytopathogenic fungi. Int. J. Biol. Macromol. 62, 677-683.

Sailaja, A.K., Amareshwar, P., Chakravarty, P., 2011. Formulation of solid lipid nanoparticles and their applications. Curr. pharma Res. 1, 197-203.

Salari, S., Salari, R., 2019. Nanoliposomal system of rosemary essential oil made by specific human cell phospholipids and evaluation of its anti-cancer properties. Appl. Nanosci. 9, 2085-2089. https://doi.org/10.1007/s13204-019-01009-1

Salminen, H., Helgason, T., Kristinsson, B., Kristbergsson, K., Weiss, J., 2017. Tuning of shell thickness of solid lipid particles impacts the chemical stability of encapsulated x-3 fish oil. J. Colloid Interface Sci. 490, 207-216. https://doi.org/10.1016/j.jcis.2016.11.063

Sameen, D.E., Ahmed, S., Qin, W., Zhang, Q., Chen, H., Dai, J., He, L., Liu, Y., 2020. Preparation and characterization of grass carp collagen-chitosan-lemon essential oil composite films for application as food packaging. Int. J. Biol. Macromol. 160, 340-351.

Santos, V. da S., Braz, B.B., Silva, A.Á., Cardoso, L.P., Ribeiro, A.P.B., Santana, M.H.A., 2019. Nanostructured lipid carriers loaded with free phytosterols for food applications. Food Chem. 298, 125053. https://doi.org/10.1016/j.foodchem.2019.125053

Saporito, F., Sandri, G., Bonferoni, M.C., Rossi, S., Boselli, C., Cornaglia, A.I., Mannucci, B., Grisoli, P., Vigani, B., Ferrari, F., 2018. Essential oil-loaded lipid nanoparticles for wound healing. Int. J. Nanomedicine 13, 175-186.

Saraf, S., Sahu, S., Kaur, C., Saraf, S., 2010. Comparative measurement of hydration effects of 
Sarangi, M.K., Padhi, S., 2016. Solid lipid nanoparticles- A review. J. criticla Rev. 3, 5-12. https://doi.org/10.5958/0975-4377.2016.00030.6

2505

Sebaaly, C., Charcosset, C., Stainmesse, S., Fessi, H., Greige-gerges, H., 2016a. Clove essential oil-in-cyclodextrin-in-liposomes in the aqueous and lyophilized states : From laboratory to large scale using a membrane contactor. Carbohydr. Polym. 138, 75-85.

Sebaaly, C., Greige-Gerges, H., Agusti, G., Fessi, H., Charcosset, C., 2015a. Large-scale preparation of clove essential oil and eugenol-loaded liposomes using a membrane contactor and a pilot plant. J. Liposome Res. 26, 126-38. https://doi.org/10.3109/08982104.2015.1057849

Sebaaly, C., Greige-gerges, H., Stainmesse, S., Fessi, H., Charcosset, C., 2016b. Effect of composition, hydrogenation of phospholipids and lyophilization on the characteristics of eugenol-loaded liposomes prepared by ethanol injection method. Food Biosci. 15, 1-10. https://doi.org/10.1016/j.fbio.2016.04.005

Sebaaly, C., Jraij, A., Fessi, H., Charcosset, C., Greige-gerges, H., 2015b. Preparation and characterization of clove essential oil-loaded liposomes. Food Chem. 178, 52-62. https://doi.org/10.1016/j.foodchem.2015.01.067

Shakeri, F., Shakeri, S., Hojjatoleslami, M., 2014. Preparation and characterization of carvacrol loaded polyhydroxybutyrate nanoparticles by nanoprecipitation and dialysis methods. J. Food Sci. 79, 697-705. https://doi.org/10.1111/1750-3841.12406

Shakeri, M., Hadi, S., Shakeri, S., 2019. Carvacrol and astaxanthin co-entrapment in beeswax solid lipid nanoparticles as an efficient nano-system with dual antioxidant and anti-biofilm activities. LWT - Food Sci. Technol. 107, 280-290. https://doi.org/10.1016/j.lwt.2019.03.031

Shamaei, S., Sadegh, S., Aghbashlo, M., Tsotsas, E., Kharaghani, A., 2017. Microencapsulation 

of walnut oil by spray drying: Effects of wall material and drying conditions on physicochemical properties of microcapsules. Innov. Food Sci. Emerg. Technol. 39, 101112. https://doi.org/10.1016/j.ifset.2016.11.011

Shi, F., Yang, G., Ren, J., Guo, T., Du, Y., Feng, N., 2013. Formulation design, preparation, and in vitro and in vivo characterizations of $\beta$-elemene- loaded nanostructured lipid carriers. Int. J. Nanomedicine 8, 2533-2541.

Shukla, A.C., 2018. Essential oils as green pesticides for postharvest disease management. Acta Hortic. 1210, 199-206.

Sidding, Abdelwahab, I., Sheikh, B.Y., Taha, M.M.E., How, C.W., Abdullah, R., Yagoub, U., El-sunousi, R., Eid, E.E., 2013. Thymoquinone-loaded nanostructured lipid carriers : preparation, gastroprotection, in vitro toxicity, and pharmacokinetic properties after extravascular administration. Int. J. Nanomedicine 8, 2163-2172.

Silva-Flores, P.G., Opez, L.A.P.-L., Rivas-Galindo, V.M., Paniagua-Vega, D., GalindoRodriguez, S.A., Alvarez-Roman, R., 2019. Simultaneous GC-FID quantification of main components of Rosmarinus officinalis L . and Lavandula dentata essential oils in polymeric nanocapsules for antioxidant application. J. Anal. Methods Chem. 2019, 1-9.

Sodeifian, G. hossein, Nedasadat, S., Seyed, Sajadian, A.A., Ghorbandoost, S., 2016. Application of supercritical carbon dioxide to extract essential oil from Cleome coluteoides Boiss: Experimental, response surface and grey wolf optimization methodology. J. Supercrit. Fluids 114, 55-63.

Soleimanian, Y., Amir, S., Goli, H., Varshosaz, J., Sahafi, S.M., 2018. Formulation and characterization of novel nanostructured lipid carriers made from beeswax , propolis wax and pomegranate seed oil. Food Chem. 244, 83-92. https://doi.org/10.1016/j.foodchem.2017.10.010

Sotelo-Boyás, M.., Valverde-Aguilar, G., Plascencia-Jatomea, M., Correa Pacheco, Z., 
Jiménez-Aparicio, A., Solorza-Feria, J., Barrera-Necha, L., Bautista-Baños, S., 2015. Characterization of chitosan nanoparticles added with essential oils. In vitro effect on Pectobacterium carotovorum. Rev. Mex. Ing. química 14, 589-599.

Sotelo-Boyás, M.E., Correa-Pacheco, Z., Bautista-Banos, S., Gómez, Y.G. y, 2017a. Release study and inhibitory activity of thyme essential oil-loaded chitosan nanoparticles and nanocapsules against foodborne bacteria. Int. J. Biol. Macromol. 103, 409-414. https://doi.org/10.1016/j.ijbiomac.2017.05.063

Sotelo-Boyás, M.E., Correa-Pacheco, Z.N., Bautista-Baños, S., Corona-Rangel, M.L., $2017 b$. Physicochemical characterization of chitosan nanoparticles and nanocapsules incorporated with lime essential oil and their antibacterial activity against food-borne pathogens. LWT - Food Sci. Technol. 77, 15-20. https://doi.org/10.1016/j.lwt.2016.11.022

Sousa, V.P. de, Crean, J., Borges, V.R. de A., Rodrigues, C.R., Tajber, L., Boylan, F., Cabral, L.M., 2013. Nanostructured systems containing babassu (Orbignya speciosa) oil as a potential alternative therapy for benign prostatic hyperplasia. Int. J. Nanomedicine 8, 3129-3139.

Souza, J.R., Bonfim, K.S., Lorevice, M.V., Correa, D.S., Mattoso, L.H.C., Moura, M.R. de, 2020. Antibacterial properties of oregano essential oil encapsulated in $\operatorname{poly}(\varepsilon-$ Caprolactone) nanoparticles. Adv. Sci. Eng. Med. 12, 7.

Stano, P., Bufali, S., Pisano, C., Bucci, F., Barbarino, M., Santaniello, M., Carminati, P., Luisi, P.L., 2004. Novel camptothecin analogue (gimatecan)-containing liposomes prepared by the ethanol injection method. J. Liposome Res. 14, 87-109.

Sun, X., Cameron, R.G., Bai, J., 2020. Effect of spray-drying temperature on physicochemical, antioxidant and antimicrobial properties of pectin/sodium alginate microencapsulated carvacrol. Food Hydrocoll. 100, 105420. https://doi.org/10.1016/j.foodhyd.2019.105420

Suomela, J.-P., Ahotupa, M., Sjövall, O., Kurvinen, J.-P., Kallio, H., 2004. Diet and lipoprotein 
oxidation: Analysis of oxidized triacylglycerols in pig lipoproteins. Lipids 39, 639-647. https://doi.org/10.1007/s11745-004-1277-4

Sutaphanit, P., Chitprasert, P., 2014. Optimisation of microencapsulation of holy basil essential oil in gelatin by response surface methodology. Food Chem. 150, 313-320. https://doi.org/10.1016/j.foodchem.2013.10.159

Svetlichny, G., Kulkamp-Guerreiro, I.C., Cunha, S.L., Silva, F.E.K., Bueno, K., Pohlmann, A.R., Fuentefria, A.M., Guterres, S.S., 2015. Solid lipid nanoparticles containing copaiba oil and allantoin : development and role of nanoencapsulation on the antifungal activity. Pharmazie 70, 155-164. https://doi.org/10.1691/ph.2015.4116

Tabassum, N., Vidyasagar, G.., 2014. In vitro antimicrobial activity of edible oils against human pathogens causing skin infections. Int. J. Pharm. Sci. Res. 5, 4493-4498. https://doi.org/10.13040/IJPSR.0975-8232.5(10).4493-98

Tabatabai, M.B., Mirjalili, M., Yazdiyan, F., Hekmatimoghaddam, S., 2018. Antibacterial activity and cytotoxicity of nanoliposomic and nanoniosomic essential oil of Trachyspermum copticum. Proc. Natl. Acad. Sci. India Sect. B - Biol. Sci. 89, 1109-1116. https://doi.org/10.1007/s40011-018-1025-6

Tahir, H.U., Sarfraz, R.A., Ashraf, A., Adil, S., 2016. Chemical composition and antidiabetic activity of essential oils obtained from two spices (Syzygium aromaticum and Cuminum cyminum). Int. J. Food Prop. 19, 2156-2164.

Tang, J., Ge, Y., 2017. Development and evaluation of novel eucalyptus essential oil liposomes /chitosan composite sponges for medical use. Fibers Polym. 18, 424-433. https://doi.org/10.1007/s12221-017-6983-4

Thakre, A.D., Mulange, S. V, Kodgire, S.S., Zore, G.B., Karuppayil, S.M., 2016. Effects of cinnamaldehyde, ocimene, camphene, curcumin and farnesene on Candida albicans. Adv. Microbiol. 6, 627-643. 
Thelagavath, G., Kannaian, T., 2008. Dual antimicrobial and blood repellent finishes for cotton hospital fabrics. Ind J. Fibre Text. Res. 33, 23-9.

Tian, H., Lu, Z., Li, D., Hu, J., 2018. Preparation and characterization of citral-loaded solid lipid nanoparticles. Food Chem. 248, $78-85$. https://doi.org/10.1016/j.foodchem.2017.11.091

Timbe, P.P.R., Motta, A. de S., Isaía, H.A., Brandelli, A., 2020. Polymeric nanoparticles loaded with Baccharis dracunculifolia DC essential oil: Preparation, characterization, and antibacterial activity in milk. J. Food Process. Preserv. 44, e14712. https://doi.org/10.1111/jfpp.14712

Tonon, R. V, Grosso, C.R.F., Hubinger, M.D., 2011. Influence of emulsion composition and inlet air temperature on the microencapsulation of flaxseed oil by spray drying. Food Res. Int. 44, 282-289. https://doi.org/10.1016/j.foodres.2010.10.018

Tonon, R. V, Pedro, R.B., Grosso, C.R.F., Hubinger, M.D., 2012. Microencapsulation of flaxseed oil by spray drying : Effect of oil load and type of wall material. Dry. Technol. 30, 1491-1501. https://doi.org/10.1080/07373937.2012.696227

Turek, C., Stintzing, F.C., 2013. Stability of essential oils: A review. Compr. Rev. Food Sci. Food Saf. 12, 40-53.

Us-medina, U., Julio, L.M., Segura-campos, M.R., Ixtaina, V.Y., Tomás, M.C., 2018. Development and characterization of spray-dried chia oil microcapsules using by-products from chia as wall material. Powder Technol. 334, 1-8. https://doi.org/10.1016/j.powtec.2018.04.060

Valenti, D., Logu, A. De, Loy, G., Sinico, C., Bonsignore, L., Cottiglia, F., Grarau, D., Fadda, A.M., 2001. Liposome-incorporated Santolina insularis essential oil: Preparation, characterization and in vitro antiviral activity. J. Liposome Res. 11, 73-90.

Vanderhoff, J.W., Asser, M.S. El, 1979. Polymer emulsification process. 
Vélez, M.A., Perotti, M.C., Hynes, E.R., Gennaro, A.M., 2019. Effect of lyophilization on food grade liposomes loaded with conjugated linoleic acid. J. Food Eng. 240, 199-206. https://doi.org/10.1016/j.jfoodeng.2018.07.033

Vemuri, S., Rhodes, C.T., 1995. Preparation and characterization of liposomes as therapeutic delivery systems: a review. Pharm. Acta Helv. 70, 95-111.

Vieira, R., Severino, P., Nalone, L.A., Souto, S.B., Silva, A.M., Lucarini, M., Durazzo, A., Santini, A., Souto, E.B., 2020. Sucupira oil-loaded nanostructured lipid carriers (NLC): Lipid screening, factorial design, release profile, and cytotoxicity. Molecules 25, 1-22. https://doi.org/10.3390/molecules25030685

Vrouvaki, I., Koutra, E., Kornaros, M., Avgoustakis, K., Lamari, F.N., Hatziantoniou, S., 2020. Polymeric nanoparticles of Pistacia lentiscus var. chia essential oil for cutaneous applications. Pharmaceutics 12, 353.

Wachtel-Galor, S., Benzie, I.F.F., 2011. Herbal medicine: An introduction to its history, usage, regulation, current trends, and research needs, in: Benzie, I.F.F., Wachtel-Galor, S. (Eds.), Herbal Medicine: Biomolecular and Clinical Aspects. CRC Press, pp. 1-10.

Wang, J.M., Zheng, W., Song, Q.W., Zhu, H., Zhou, Y., 2009. Preparation and characterization of natural fragrant microcapsules. J. Fiber Bioeng. Informatics 1, 293-300.

Wang, Q., Lv, S., Lu, J., Jiang, S., Lin, L., 2015. Evaluation of carboxymethyl chitosan coated liposomes containing fish oil. J. Food Sci. 80, 1460-1467. https://doi.org/10.1111/17503841.12929

Wang, S., Shi, Y., Han, L., 2018. Development and evaluation of microencapsulated peony seed oil prepared by spray drying: Oxidative stability and its release behavior during invitro digestion. J. Food Eng. 231, 1-9. https://doi.org/10.1016/j.jfoodeng.2018.03.007

Wang, X., Liu, L., Xia, S., Muhoza, B., Cai, J., Zhang, X., Duhoranimana, E., Su, J., 2019. Sodium carboxymethyl cellulose modulates the stability of cinnamaldehyde-loaded 

liposomes at high ionic strength. Food Hydrocoll. 93, 10-18.

Wang, Z., 2012. Preparation and characterization of solid lipid nanoparticles loaded with frankincense and myrrh oil. Int. J. Nanomedicine 7, 2033-2043. https://doi.org/10.2147/IJN.S30085

Warnke, P., Becker, S., Podschun, R., Sivananthan, S., Springer, I., Russo, P., Wiltfang, J., Fickenscher, H., Sherry, E., 2009. The battle against multi-resistant strains: Renaissance of antimicrobial essential oils as a promising force to fight hospital-acquired infections. J. Craniomaxillofac. Surg. 37, 392-7.

Warshaw, E.M., Maibach, H.I., Taylor, J.S., Sasseville, D., DeKoven, F., Zirwas, M., Fransway, A., Mathias, C., Zug, K., DeLeo, V., Fowler, J., Marks, J., Pratt, M., Storrs, F., Belsito, D., 2015. North American contact dermatitis group patch test results: 2011-2012. Dermatitis 26, 49-59.

Weber, J., Funk, N.L., Motta, M.H., Guedes, A.M., Visintainer, A.P.C., Tedesco, S.B., Silva, C.D.B., Chalmers, H., 2016. Association of borage oil and betamethasone dipropionate in lipid-core nanocapsules: characterization, photostability and in vitro irritation test. J. Nanosci. Nanotechnol. 16, 1354-1362. https://doi.org/10.1166/jnn.2016.11674

Woranuch, S., Yoksan, R., 2013. Eugenol-loaded chitosan nanoparticles : I . Thermal stability improvement of eugenol through encapsulation. Carbohydr. Polym. 96, 578-585. https://doi.org/10.1016/j.carbpol.2012.08.117

Wu, Z., Zhou, W., Pang, C., Deng, W., Xu, C., Wang, X., 2020. Multifunctional chitosan-based coating with liposomes containing laurel essential oils and nanosilver for pork preservation. Food Chem. 295, 16-25.

Xenakis, A., Papadimitriou, V., Sotiroudis, T.G., 2010. Colloidal structures in natural oils. Curr. Opin. Colloid Interface Sci. 15, 55-60. https://doi.org/10.1016/j.cocis.2009.11.007

Yadav, N., Khatak, S., Sara, U.V.S., 2013. Solid lipid nanoparticles- A review. Int. J. Appl. 
Yaep, S., Beh, B., Ali, N., Yusof, H., 2015. Antistress and antioxidant effects of virgin coconut oil in vivo. Exp. Ther. Med. 9, 39-42.

Yang, J., Han, S., Zheng, H., Dong, H., Liu, J., 2015. Preparation and application of micro/nanoparticles based on natural polysaccharides. Carbohydr. Polym. 123, 53-66.

Yang, X., Gao, N., Hu, L., Li, J., Sun, Y., 2015. Development and evaluation of novel microcapsules containing poppy-seed oil using complex coacervation. J. Food Eng. 161, 87-93. https://doi.org/10.1016/j.jfoodeng.2015.03.027

Yang, Z., Peng, Z., Li, J., Li, S., Kong, L., Li, P., Wang, Q., 2014. Development and evaluation approach. Food Chem. 145, 272-277. https://doi.org/10.1016/j.foodchem.2013.08.074

Yara-Varón, E., Li, Y., Balcells, M., Canela-Garayoa, R., Fabiano-Tixier, A.-S., Chemat, F., 2017. Vegetable oils as alternative solvents for green oleo-extraction, purification and formulation of food and natural products. Molecules 22, 1474. https://doi.org/10.3390/molecules22091474

Yoshida, P.A., Yokota, D., Foglio, M.A., Rodrigues, R.A.F., Pinho, S.C., 2010. Liposomes incorporating essential oil of Brazilian cherry (Eugenia uniflora L.): Characterization of aqueous dispersions and lyophilized formulations. J. Microencapsul. 27, 416-425. https://doi.org/10.3109/02652040903367327

Yu, F.L., Greenlaw, R., Fang, Q., Bender, W., Yamaguchi, K., Xue, B.H., Yu, C.C., 2004. Studies on the chemopreventive potentials of vegetable oils and unsaturated fatty acids against breast cancer carcinogenesis at initiation. Eur. J. Cancer Prev. 13, 239-248.

Zabihi, A., Basti, A.A., Amoabediny, G., Khanjari, A., Bazzaz, J.T., Mohammadkhan, F., Bargh, A.H., Vanaki, E., 2017. Physicochemical characteristics of nanoliposome garlic ( Allium sativum L .) essential oil and its antibacterial effect on Escherichia coli O157 : H7. 
2703

2704

2705

2706

2707

2708

2709

2710

2711

2712

2713

2714

2715

2716

2717

2718

2719

2720

2721

2722

2723

2724

2725

2726

Zammit, M.L., 2010. Photosensitivity : Light, sun and pharmacy. J. Malta Coll. Pharm. Pract. $16,12-17$.

Zeghib, A., Kabouche, A., Laggoune, S., Calliste, C.-A., Simon, A., Bressolier, P., Aouni, M., Duroux, J.-L., Kabouche, Z., 2017. Antibacterial, antiviral, Antioxidant and antiproliferative activities of Thymus guyonii essential oil. Nat. Prod. Commun. 12, 16511654.

Zermane, A., Larkeche, O., Meniai, A.-H., Crampon, C., Badens, E., 2016. Optimization of Algerian rosemary essential oil extraction yield by supercritical $\mathrm{CO} 2$ using response surface methodology. Comptes Rendus Chim. 19, 538-543.

Zhang, H., Li, X., Liang, Y., Kang, H., 2020. Effect of chitosan-gelatin coating containing nano-encapsulated tarragon essential oil on the preservation of pork slices. Meat Sci. 166, 108137.

Zhang, H., Ran, X., Hu, C., Qin, L., Lu, Y., Peng, C., 2012. Therapeutic effects of liposomeenveloped Ligusticum chuanxiong essential oil on hypertrophic scars in the rabbit ear model. PLoS One 7, 1-8. https://doi.org/10.1371/journal.pone.0031157

Zhang, K., Zhang, H., Hu, X., Bao, S., Huang, H., 2012. Synthesis and release studies of microalgal oil-containing microcapsules prepared by complex coacervation. Colloids Surfaces B Biointerfaces 89, 61-66. https://doi.org/10.1016/j.colsurfb.2011.08.023

Zhao, Y., Chang, Y.-X., Hu, X., Liu, C.-Y., Quan, L.-H., Liao, Y.-H., 2017. Solid lipid nanoparticles for sustained pulmonary delivery of Yuxingcao essential oil: Preparation, characterization and in vivo evaluation. Int. J. Pharm. 516, 364-371.

Zhaveh, S., Mohsenifar, A., Beiki, M., Tahereh, S., Abdollahi, A., Rahmani-cherati, T., Tabatabaei, M., 2015. Encapsulation of Cuminum cyminum essential oils in chitosancaffeic acid nanogel with enhanced antimicrobial activity against Aspergillus flavus. Ind. 
2728

2729

2730

2731

2732

2733

2734

2735

2736

2737

2738

2739

2740

Zhu, D., Chenga, H., Li, J., Zhang, W., Shen, Y., Chen, Shaojun, Ge, Z., Chen, Shiguo, 2016. Enhanced water-solubility and antibacterial activity of novel chitosan derivatives modified with quaternary phosphonium salt. Mater. Sci. Eng. C 61, 79-84.

Zhu, J., Zhuang, P., Luan, L., Sun, Q., Cao, F., 2015. Preparation and characterization of novel nanocarriers containing krill oil for food application. J. Funct. Foods 19, 902-912. https://doi.org/10.1016/j.jff.2015.06.017

Zhu, Y., Li, C., Cui, H., Lin, L., 2020. Plasma enhanced-nutmeg essential oil solid liposome treatment on the gelling and storage properties of pork meat batters. J. Food Eng. 266, 109696.

Zielińska, A., Ferreira, N.R., Icon, A.F.-G., Nowak, I., Souto, E.B., 2020. Loading, release profile and accelerated stability assessment of monoterpenes-loaded solid lipid nanoparticles (SLN). Pharm. Dev. Technol. 25, 832-844.

Zielinska, A., R.Ferreira, N., Durazzo, A., Lucarini, M., Ciero, N., Mamouni, S. El, Silva, A.M., Nowak, I., Santini, A., Souto, E.B., 2019. Alpha-Pinene-loaded solid lipid nanoparticles dispersion analysis. Molecules 24, 2683. 